Linköping Studies in Science and Technology Licentiate Thesis No. 1861

\title{
The role of biogas in a more sustainable energy system in Sweden \\ Sofia Dahlgren
}

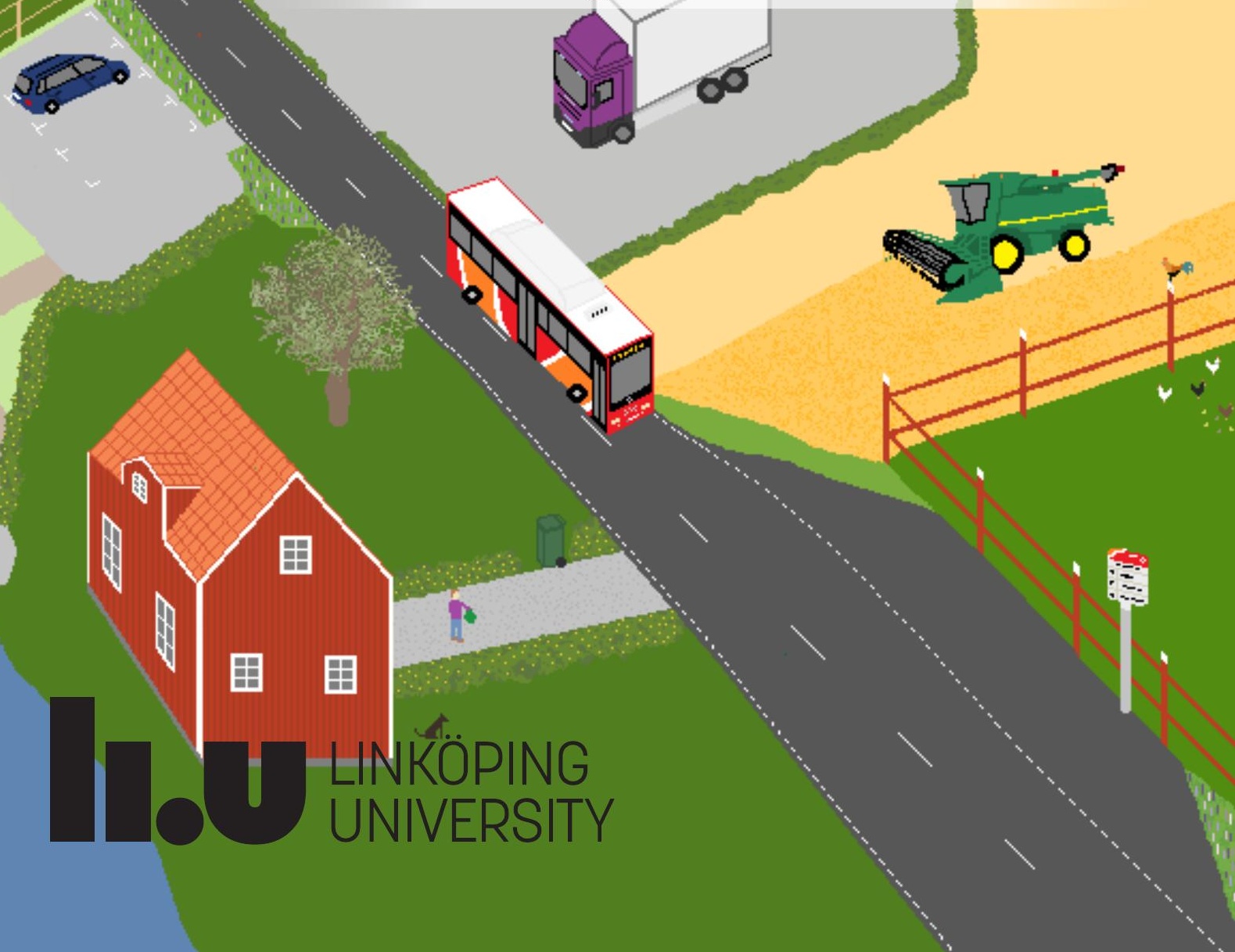


Linköping Studies in Science and Technology

Licentiate Thesis No. 1861

\section{The role of biogas in a more sustainable energy system in Sweden}

\section{Sofia Dahlgren}

Environmental Technology and Management Department of Management and Engineering Linköping University, SE-581 83, Sweden

Linköping 2019 
(C) Sofia Dahlgren, 2019

Institution: IEI/Environmental Technology and Management

ISBN: 978-91-7929-946-0

ISSN: 0280-7971

Printed in Sweden by LiU-Tryck, Linköping, 2019

Cover Design: Sofia Dahlgren

Distributed by:

Linköping University

Department of Management and Engineering

SE-581 83 Linköping, Sweden 


\section{Abstract}

There are numerous problems in the world that need to be dealt with in order to achieve sustainable development. The energy system has significant negative impacts on many of these problems, and there is a need for a transition towards more sustainable energy. Sweden has already started this transition and is using large amounts of renewable energy. However, within the transport sector and the manufacturing sector in particular, large amounts of fossil fuels are still used. Biogas is one alternative that can help solve several sustainability problems and that could be part of a future more sustainable energy system. However, it is not certain what biogas is most suitable to be used for.

The aim of this thesis is to investigate how biogas should be used in a future more sustainable energy system, by answering three research questions: 1) In what ways can biogas be used in a more sustainable energy system? 2) How can we assess whether biogas is suitable in a specific context? and 3) What determines whether it is easy or difficult for a user to start using biogas? These questions are explored in a Swedish context using four appended articles, which are based on two collaborative projects using a combination of workshops, literature reviews and interviews.

Biogas can be used for heat, electricity or fuel in the manufacturing or transport sector. In Sweden, heat and electricity are mainly of interest for smaller production scales, while production on larger scales will likely be dominated by upgrading mostly to CBG but also to LBG. CBG can be used for less energy-intensive purposes, such as cars or buses, while the growing interest in LBG in Sweden may open up new market segments for biogas which are more energy-intensive, such as heavy trucks or shipping, or in geographical locations that are further away from the site of production.

Several sustainability assessment methods exist that can be used to evaluate whether biogas is suitable in a specific context, such as multi-criteria assessments or scenario analyses. These methods can include a number of different aspects that are relevant to biogas use, such as GHG emissions, safety issues, and the vitality of the surrounding region. In order to introduce biogas, six main factors were identified that can make this easier or more difficult: technical maturity, tank volume, distance between the producer and the user, scale of energy use, policies and costs, and strategies of individual organizations.

Overall, the rise in LBG production creates new opportunities for biogas use in both geographical and usage areas that did not previously use biogas. There is no simple answer to what biogas should be used for in the future - rather, this depends on the circumstances. It is also possible that the usage areas that are most suitable now for biogas might not be the most suitable areas in the future, depending on developments within, for example, the electricity system and hydrogen. However, CBG and LBG are likely to dominate biogas production in Sweden until then.

Keywords: biogas, CBG, LBG, energy users, sustainable transitions, sustainability assessments 


\section{Acknowledgments}

My biggest thanks go to my main supervisor, Stefan Anderberg, who always supports me and gives me feedback when I need it, and who gives excellent advice. I also thank my other supervisors, Thomas Magnussson and now also Jonas Ammenberg, who have helped me and my research to develop. A big thanks also to Wisdom Kanda, who co-authored Paper 2 and who in the process helped me to get my first published article.

I would also like to thank Vinnova, the Swedish Energy Agency, Linköping University, and the European Regional Development Fund for funding this research, and a big thanks to all the organizations that have participated in the research that has led to this thesis.

Thank you to all my wonderful colleagues at the Division for Environmental Technology and Management - especially those of you who join our lunch and fika breaks. I also want to give an extra shout-out to Maria Eriksson, our brilliant administrator, and to Carina Sundberg, a friend who is always open to talking and discussing things - no matter whether they are related to difficult research questions that you have no idea about, or whether they are completely nonwork related.

In previous theses, this last part of the acknowledgement seems to be reserved for thanks to family. And I want to say a big thank you to my family - my mother, who I can always count on when I want to talk with someone, my three sisters, who have some strange ideas that pets should preferably be small and fluffy, and all the rest of the family. However, for those of you who know me - or are even just acquainted with me, since this is one of the first things people seem to learn about me - you know that my family also includes a number of non-human members that are very important to me. So to conclude this acknowledgments section, I want to give an extra thank you to the two non-human family members that are most important to me and who keep me company: Samantha and Cinder. Samantha, who has been literally beside me every step of the way - from writing my master's thesis and the application for this position, on all the days that I have worked from home, on both the articles and this thesis. And Cinder, who is a bit too smart for me and who is always giving me lessons in keeping a clean home and putting things away as soon as I am finished with them - especially food. 


\section{List of appended papers}

Paper 1: Dahlgren, S. Biogas-based fuels as renewable energy in the transport sector. Draft.

I carried out the study and wrote the paper, with continuous support and supervision from Stefan Anderberg regarding framing, scope, wording, etc.

Paper 2: Dahlgren, S., Kanda, W., Anderberg, S. Drivers and barriers for increased biogas usage: a demand side perspective focusing on manufacturing, road transport and shipping.

Published in Biofuels in 2019 (DOI: 10.1080/17597269.2019.1657661)

This paper was prepared and written in collaboration between the three authors, from the idea to the submission. However, the authors were responsible for different parts of the paper. My contribution was mainly in connection with sectorial knowledge and the interviews. I wrote the results of the paper and the methods section regarding the interviews alone, and co-wrote the discussion in direct collaboration with Wisdom Kanda. All three authors were equally involved in the restructuring and rewriting process after the first submission.

Paper 3: Ammenberg, J., Dahlgren, S., Sustainability assessment of public transport, part I - a multi-criteria assessment method to compare different bus technologies. Draft.

This paper was prepared and written in collaboration between Jonas Ammenberg and me, from the idea to the final draft. My contribution was mainly in connection with the work that led up to the article - primarily related to the indicators established to compare the alternative bus technologies. The literature review was carried out by both authors and through student projects by the students Éamon Magorrian, Agnes Lundgren, Anders Wilzén, Jacob Dahlstedt and Linnea Orsholm.

Paper 4: Magnusson, T., Anderberg, S., Dahlgren, S., Svensson, N. Socio-technical scenario construction and local practice - Assessing the future use of biogas, biodiesel and electricity in a regional transport system

Draft, to be submitted to Transportation Research Part A: Policy and Practice.

This paper was prepared and written in collaboration between Thomas Magnusson, Stefan Anderberg, Niclas Svensson and me. My contribution related mainly to the quantitative results and writing section 7 ("Comparisons between the scenarios"). 


\section{Contents}

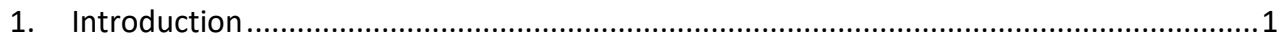

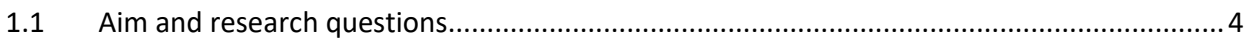

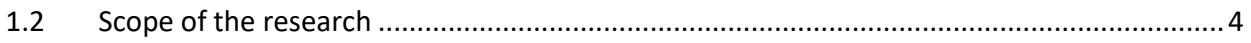

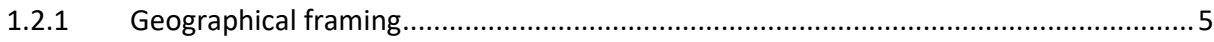

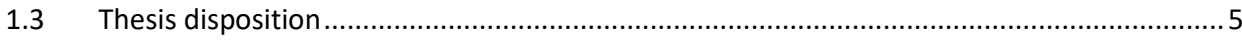

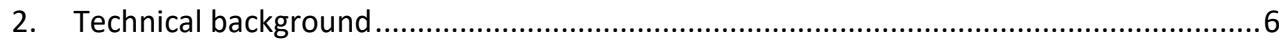

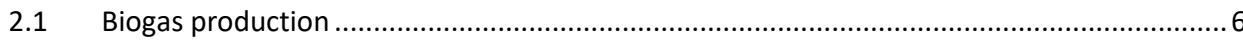

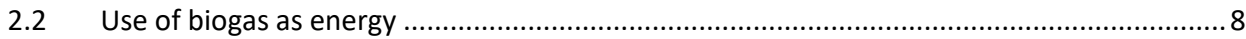

2.3 Biogas as something more than renewable energy ........................................................11

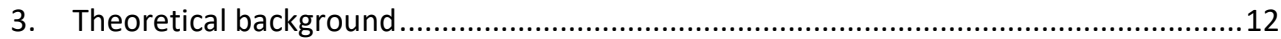

3.1 Sustainable development and sustainability assessments ...............................................13

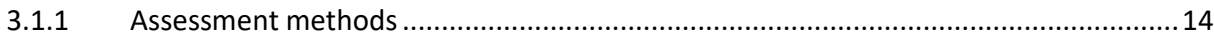

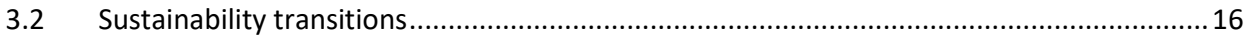

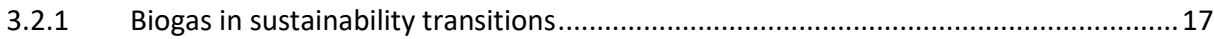

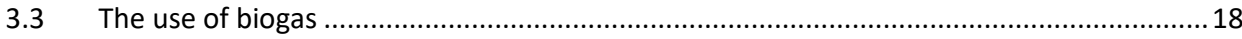

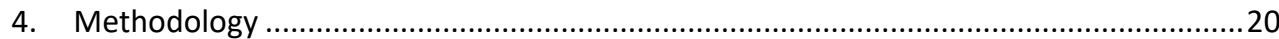

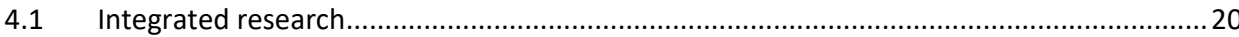

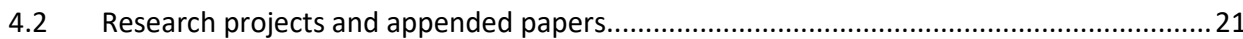

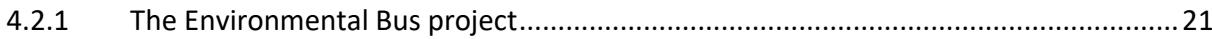

4.2.2 The Biogas Research Center: A sustainability evaluation of bus technologies using

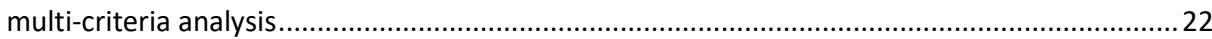

4.2.3 Research projects, appended papers and their relationship to the research questions 22

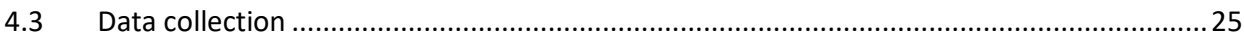

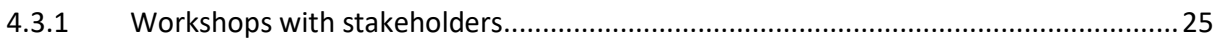

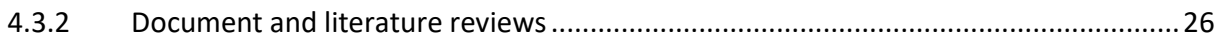

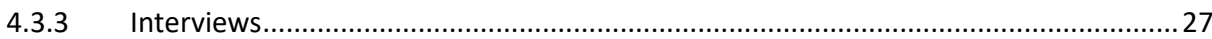

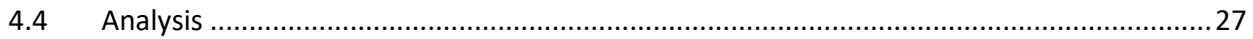

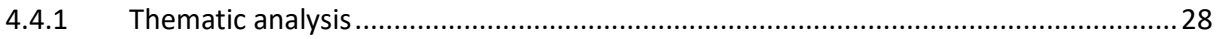

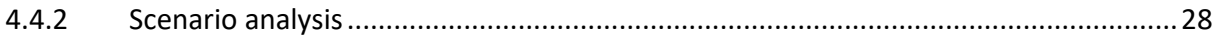

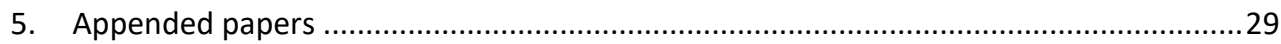

Paper 1: Biogas-based fuels as renewable energy in the transport sector ......................................29

Paper 2: Drivers and barriers for biogas use in manufacturing, road transport and shipping: a demand side perspective. 
Paper 3: Sustainability assessment of public transport, part I - a multi-criteria assessment method to compare different bus technologies

Paper 4: Socio-technical scenario construction and local practice - Assessing the future use of

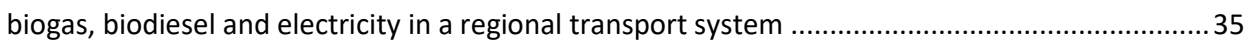

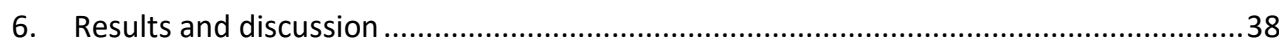

6.1 In what ways can biogas be used in a more sustainable energy system? .............................38

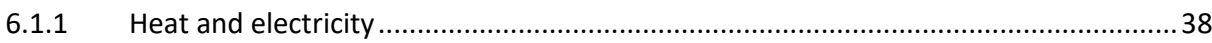

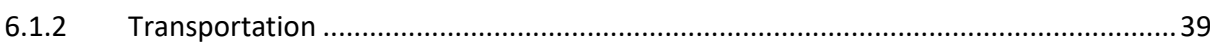

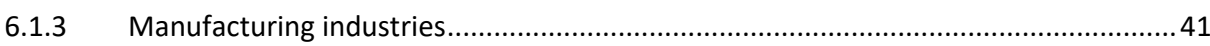

6.2 How can we assess whether biogas is suitable in a specific context? ...................................42

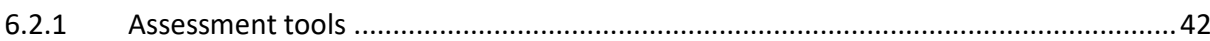

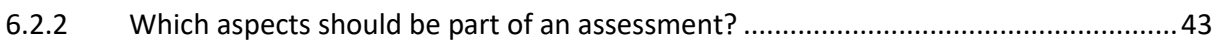

6.3 What determines whether it is easy or difficult for a user to start using biogas? ............... 45

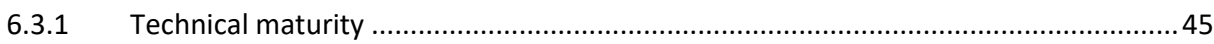

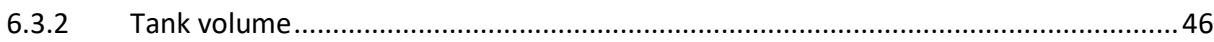

6.3.3 Distance between the producer and the user ........................................................ 46

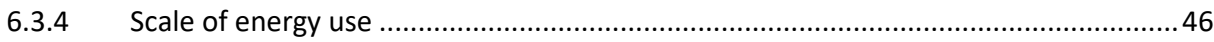

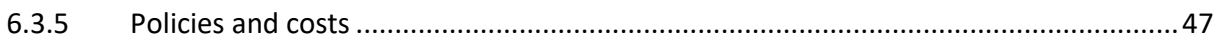

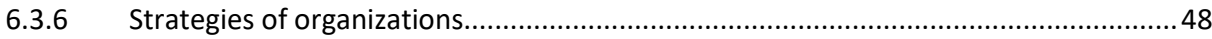

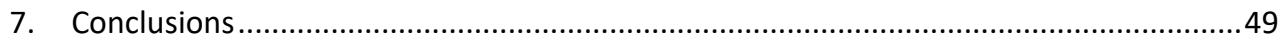

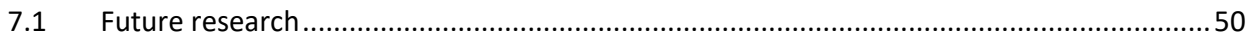

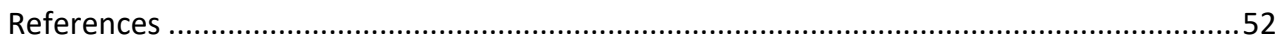




\section{Introduction}

The United Nations (2019a) has drawn up 17 Sustainable Development Goals that need to be reached in order to achieve a sustainable world - everything from peace and justice to clean water and sanitation. Many nations also have national goals, like the environmental goals of Sweden (Sveriges miljömål, 2019) in which issues such as acidification and toxic substances are considered, or the environmental targets of Norway (State of the Environment Norway, 2019) in which there is a focus on issues like the polar regions. These kinds of numerous and diverse goals show that the world is facing a variety of different problems that need to be solved. One difficulty is, however, that only one, or a few, problems are often in focus at the same time when trying to find solutions, and that this can lead to transfers from one problem to another (discussed by e.g. Laurent et al., 2012).

One global problem that is often in focus is global warming. The climate is becoming warmer, which can have huge negative effects on the world - droughts, heavy precipitation events, extreme temperatures, flooding, rising sea levels, loss of habitats, increased ocean acidity and so on (Intergovernmental Panel on Climate Change, 2018). To combat this, 196 UN countries have agreed via the Paris Agreement to work on mitigating this climate change (United Nations, 2019b). A large part of climate change is due to emissions of carbon dioxide from the combustion of fossil fuels (Intergovernmental Panel on Climate Change, 2007). In 2016, 80 \% of the energy used in the world came from fossil sources (International Energy Agency, 2018). To reduce the climate impact and to adhere to the Paris Agreement, we need a transition towards an energy system based on more renewable energy - videlicet, a fundamental transformation in the system towards more sustainable modes of production and consumption (Markard et al., 2012)

Some countries have already started this transition. One example is Sweden, where biofuels, wind and water accounted for 216 TWh of the energy supply in 2017, compared to $154 \mathrm{TWh}$ from fossil fuels (Swedish Energy Agency, 2019a). However, achieving a large-scale transition of the energy system is not easy (Kemp et al., 1998). The energy system is a large sociotechnical system, i.e. a group of interrelated components working together towards a common goal (Hughes, 1987), and which is very closely interlinked with other large technical systems, such as the transport system and industrial systems (Figure 1). Not only do the actual engines or turbines need to be replaced or customized to use renewable fuels, there must also be a change in production, distribution, markets, regulations, etc. to adapt them to the renewable fuels - a systemic change (Kemp et al., 1998). In Sweden, although a large proportion of energy use is already based on renewables, there are still major differences between different parts of the energy system. Electricity and district heating production have come a long way in substituting fossil fuels, with $2 \%$ and $6.5 \%$ of energy use respectively based on fossil fuels in 2017 (Swedish Energy Agency, 2019a). By contrast, 78 \% of the fuels used in the transport sector were fossil fuels in 2017 (excluding electricity, Swedish Energy Agency, 2019a). The transport sector also uses the largest amount of fossil fuels, $66 \mathrm{TWh}$, followed by the manufacturing sector with $28 \mathrm{TWh}$ of fossil fuels (Swedish Energy Agency, 2019a). 
Transportation and manufacturing thus seem to be areas in which it is more difficult to switch to renewable fuels, and where it is particularly important to identify renewable options.

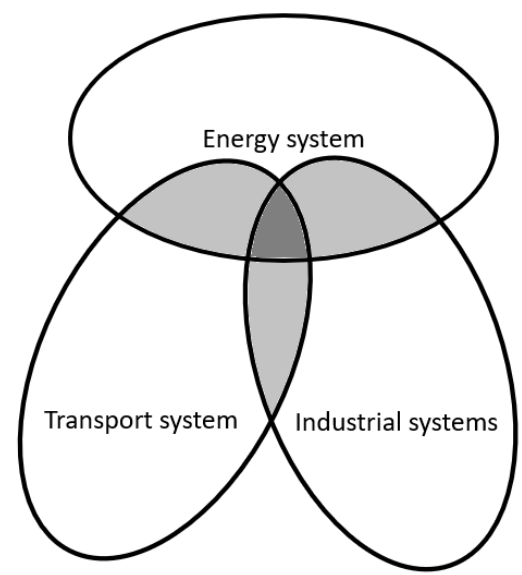

Figure 1. The energy system, where the goal is mainly to produce, distribute and sell energy to users, overlaps with the transport system and the industrial systems, where the main goals are to transport people and goods and to manufacture items. The overlap with the energy system involves the transport and industrial systems needing energy, in the form of fuel and electricity, in order to function. For example, electricity is produced and distributed within the energy system, but it can be used to recharge electric vehicles. Another example is importing crude oil that is refined to produce diesel, and is then transported in a tanker to a refueling station where a truck fills up with diesel in order to transport materials from one factory to another.

The potential amount of renewable energy that could be produced in the world is far greater than the energy needed, if solar power is taken into account (Ladanai and Vinterbäck, 2009). However, most of the renewable energy currently used in Sweden does not come from solar power (Swedish Energy Agency, 2019a), and there are limitations on how much biomass can be produced sustainably, as shown in a number of studies (e.g. Ladanai and Vinterbäck, 2009; Swedish Waste Management Association, 2008). The current production of renewable energy is also low in comparison with the volume of fossil fuels used (International Energy Agency, 2018). The renewable energy alternatives currently available, such as electricity from renewable sources, ethanol, FAME, HVO, and biogas, all have limited production and cannot replace the large volume of fossil fuels used today (Kummamuru, 2017). According to the findings from an investigation commissioned by the Swedish Government, the solution to creating a renewable energy system lies not in choosing which fuel is best, but rather in using several fuel solutions at the same time (Swedish Government Official Reports, 2013). The alternative renewable fuels all have different strengths and weaknesses that make them more or less suitable for specific purposes, such as physical properties that make the fuels hard to store or that are incompatible with the current fuel system (e.g. Paper 1). The global warming potentials of renewable energy also differ depending on which resources are used to produce the fuel and how, and as Gustafsson et al. (2018) show, certain options can have worse global warming potential than some fossil fuels. Apart from global warming, each alternative will also affect other aspects related to sustainability depending on how they are produced. Each 
alternative will also be affected by other issues such as policies, public opinion and invesments. The various alternatives can be used in different ways, depending on where they are best suited.

Biogas, a gaseous mixture consisting mainly of methane and carbon dioxide produced by the anaerobic digestion of biomass, is one such fuel alternative that is not only renewable but can also help solve several sustainability problems - and not just global warming. Biogas can use waste materials such as manure or wastewater sludge to produce energy (Swedish Energy Agency, 2018a), and its production can also have other benefits (Hagman and Eklund, 2016) like producing fertilizers (Alburquerque et al., 2012; Blumenstein et al., 2016; Möller and Müller, 2012), hygienizing waste (Varel et al., 2012) and reducing methane leaks (Cuéllar and Webber, 2008; Fierro et al., 2014). However, waste streams are not infinite, and globally urban waste, agro-industry waste and sewage sludge have been calculated to have the potential to produce enough biogas to replace $5 \%$ of fossil fuel use in 2014 (data from the International Energy Agency, 2018; combined with data from the World Bioenergy Association, 2013). Today, biogas is primarily used for heat and electricity production (Scarlat et al., 2018). In some countries, biogas has also increasingly been upgraded in recent decades to produce biomethane, i.e. the carbon dioxide and other impurities have been removed, in order to be used as vehicle fuel for cars and buses (Paper 1). In Sweden, over half of the biogas is used as fuel for transport, accounting for $70 \%$ of the biogas used for transport in the EU in 2015 (Scarlat et al., 2018). However, biogas can also be used as a renewable energy source in other ways. Liquefied biomethane (LBG) can be used in ships, heavy vehicles and manufacturing (Paper 2), and biogas can be converted into syngas and then further developed into e.g. hydrogen or methanol (Yang et al., 2014).

Many previous studies on biogas use have had a regional or local focus, such as Ammenberg et al. (2018) who studied the regional conditions for biogas solutions in Sweden's Stockholm region and found that public organizations were central actors for biogas, which played a significant role in public transport and taxis. They also found that actors in the region thought that biogas could be suitable for future use in public transport outside cities, as well as in heavyduty vehicles and machinery. Another study with a local focus was carried out by Fallde and Eklund (2015), who studied the development of biogas in Linköping, a city where biogas has been used for buses since the mid-1990s. Further research focuses on specific usage areas to see how biogas would fit there, for example Brynolf (née Bengtsson), Fridell and Andersson (e.g. 2014, 2012; 2014) in their studies of biogas as a potential shipping fuel. There are also studies that have compared biogas use in different areas based on relevant aspects, such as efficiency or cost (e.g. Hakawati et al., 2017; Patrizio et al., 2015). There are thus several different options for where in the energy system biogas could be used. However, it is not certain where biogas is best suited in comparison to other alternatives. 


\subsection{Aim and research questions}

To achieve a large-scale transition to renewable energy, biogas can only be one piece of a larger puzzle. The aim of this research is to investigate how biogas should be used in a future more sustainable energy system. This aim is achieved by answering three research questions:

\section{RQ1. In what ways can biogas be used in a more sustainable energy system?}

The first step in this research is to study the possibilities for using biogas as part of a renewable energy system. This primarily includes investigating which fuels can be produced from biogas and in what ways these biogas-based fuels can be used. It further includes a shallow investigation of whether there is actually any potential in using them in these ways based on the fuels' characteristics and technological developments, both directly compared to the requirements of the usage areas and their users and in comparison with other alternatives. This step will support the aim by finding out which possible usage areas exist for biogas.

\section{RQ2. How can we assess whether biogas is suitable in a specific context?}

The second step continues by studying how the suitability of biogas in a specific context can be evaluated. How do we assess the contexts in which biogas is better suited than other alternatives? Here, suitability focuses on two different aspects: 2) suitability according to the user, and 3) suitability considering environmental, economic and social aspects. This step will support the aim by finding out how to determine where biogas should be used within a more sustainable energy system.

RQ3. What determines whether it is easy or difficult for a user to start using biogas? The third step in this research proceeds from RQ2, focusing on what limits the use of biogas in a certain application. The focus is thus on determining significant obstacles or driving forces, which is done by studying both the actors and their perceptions of biogas, as well as the maturity and recent developments of biogas in that application. The focus will primarily be on potential users who do not already use biogas, but also to a lesser degree on increased use by users who already use biogas. This step will support the aim by finding out whether it is actually likely that biogas can be used in a certain part of the renewable energy system.

\subsection{Scope of the research}

The research questions are addressed in the thesis based on the results of the four appended papers, which in turn are connected to two different research projects. The first project, the Environmental Bus project, was a collaborative project carried out together with a regional public transport company, a local municipality and a local utility company. My focus in the project was on different usage areas for biogas, such as heavy transport, shipping and manufacturing, as well as the development and analysis of different scenarios for biogas use. The second project, which was carried out within a national competence center for biogas (the Biogas Research Center), focused on establishing and applying a multi-criteria assessment tool for alternative bus technologies, including biogas, and involved collaboration and workshops with a number of relevant actors. Only the first part of the project, i.e. establishing the assessment tool, is part of this research. The research has been influenced by ideas about integrated research, and transdisciplinary research in particular (Stock and Burton, 2011). 


\subsubsection{Geographical framing}

The study is focused on biogas use in Sweden. Sweden was chosen as the study area for several reasons. Besides practical reasons, such as having access to and collaboration with important stakeholders and experts through Swedish-based research projects, Sweden is in many ways a very interesting case, and is of relevance for other countries, but also has its own particularities.

Sweden is an exception in that the majority of the biogas is used for transportation rather than heat and electricity. In 2017, over $60 \%$ of the $2 \mathrm{TWh}$ of biogas produced was upgraded and used as vehicle fuel for cars and buses (Swedish Energy Agency, 2018a). Many other countries are moving towards upgrading more biogas (as seen by combining data from e.g. Association Technique Energie Environnement, 2018; Bachmann, 2013; Baier et al., 2018; Danish Energy Agency, 2018; Huttunen et al., 2017; Theobald, 2015), which makes Sweden interesting since it has already come a long way in this regard and can thus be used to show the potential of using biogas in other ways than simply heat and electricity. There is also a current trend in Sweden towards liquefied biogas and an interest in this from sectors that have not traditionally used much biogas, which may show how the global development of biogas could evolve in the future into other applications.

In contrast to some other countries, the biogas in Sweden is also primarily produced by substrates that are not easily used for energy production in other ways, such as wastewater, manure and organic household waste. Every country in the world has some kind of organic waste that is not used to its fullest potential (International Energy Agency, 2016; combined with data from the World Bioenergy Association, 2013), and by studying the solutions in Sweden it can be shown that there is the potential to use this organic waste. Being able to use waste streams is one of the important benefits of biogas, and should be encouraged.

\subsection{Thesis disposition}

The aim is that this thesis should be written so that large parts of it can be understood by people with a general technical background, but some further knowledge of scientific research is required to understand the thesis in its entirety. Previous knowledge of biogas is not required from the reader, but will likely make it more interesting to read. The thesis consists of seven chapters, with this chapter (Chapter 1) introducing what is being researched, why it is interesting to study, and - in brief - how it was done. Chapter 2 is mainly written for readers who do not work in the biogas field, to introduce and give an overview of biogas so that the reader can understand the biogas context. The theoretical background in Chapter 3 introduces the theoretical context in which the study is carried out, followed by methodology in Chapter 4 that goes into more detail about how the research was conducted and why. Chapter 5 summarizes the four appended articles, which are listed before the table of contents. The appended articles are included in their entirety after the conclusions and the references. Chapter 6 discusses the results with respect to the research questions. The thesis then concludes in Chapter 7 with the conclusions of the study, an outlook for future research and what this thesis has contributed. 


\section{Technical background}

This chapter introduces biogas and provides an overview of the biogas context, in order to ensure that readers who do not work in the biogas field still have background knowledge about biogas and its current production and use, both globally and in Sweden.

\subsection{Biogas production}

Biogas is a gaseous mixture consisting mainly of methane and carbon dioxide, which is created by the anaerobic digestion of organic material (Scarlat et al., 2018). Apart from methane and carbon dioxide, there can also be smaller amounts of contaminants like nitrogen, hydrogen sulfide, ammonia and siloxanes (Angelidaki et al., 2018).

In 2016, the world production of biogas was 360 TWh (World Bioenergy Association, 2018). Europe accounted for half of the world's production (Figure 2) and within Europe, Germany was the largest producer with half of the European biogas production (Scarlat et al., 2018). Approximately $25 \%$ of all biogas in the world is thus produced in Germany. Apart from Europe, Asia is also a large producer of biogas, and several countries have important programs for biogas production (Scarlat et al., 2018). In the Americas, it is mainly the US that produces biogas, although there have been significant increases in biogas production in parts of Latin America (Scarlat et al., 2018). Africa still has very limited biogas production (Scarlat et al., 2018; World Bioenergy Association, 2018).

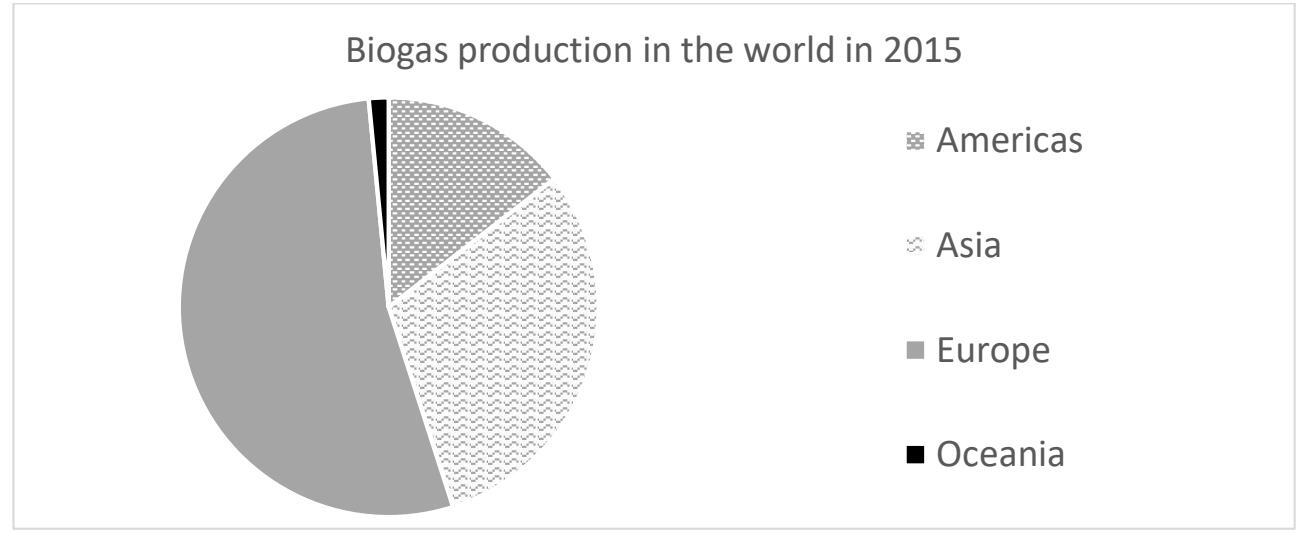

Figure 2. The biogas production in the world in 2015. Africa did not have enough biogas production to make a comparison. The data used to create the figure is from the World Bioenergy Association, 2018.

Biogas can be produced in different places, such as landfills, municipal wastewater treatment plants, industrial plants and farms (Winquist et al., 2019). Generally speaking, biogas production in developing countries is mainly small-scale and primarily supplies heat for domestic use, such as cooking (Scarlat et al., 2018). In developed countries, biogas production is mainly carried out on a larger scale (Scarlat et al., 2018). This is the case with Sweden, where there has been an increase in larger-scale biogas production plants (Swedish Energy Agency, 2016). Much of the biogas production in Sweden is from what are classified as wastewater 
treatment plants and co-digestion plants (Swedish Energy Agency, 2019b). The entire Swedish biogas production is 2 TWh (Swedish Energy Agency, 2019b). In 2015, over $90 \%$ of the biogas production plants produced less than $20 \mathrm{GWh}$ annually (Figure 3), and in total these smaller plants produced around half of the biogas in Sweden (Swedish Energy Agency, 2016). At the same time, the two largest plants had annual production of more than $100 \mathrm{GWh}$ of biogas each (Figure 3). Over half of the biogas production in 2015 came from the 20 largest biogas plants, which were mostly a mix of co-digestion plants and wastewater treatment plants (Swedish Energy Agency, 2016).

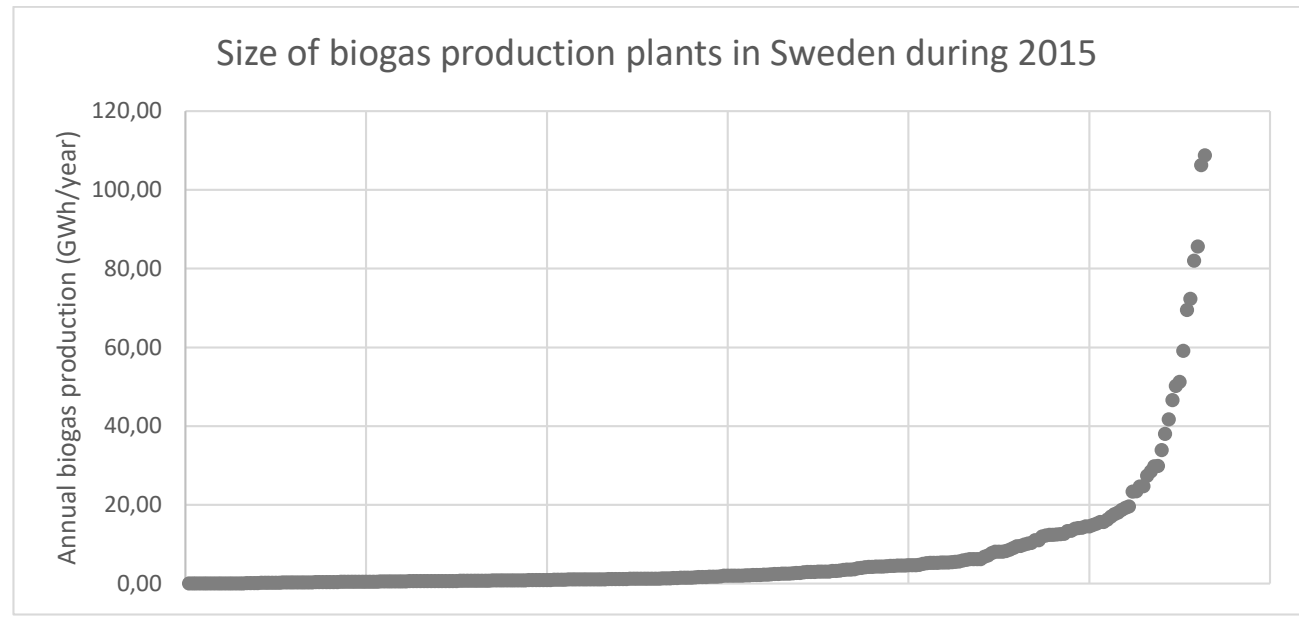

Figure 3. The size of the biogas production plants in Sweden in 2015. Each dot represents one biogas production plant. The data used to create the figure is from the Swedish Energy Agency (2016).

The main raw materials used in Europe for production are agricultural waste, manure, energy crops, organic materials that have been landfilled and sewage sludge (Scarlat et al., 2018). In Germany, the largest biogas producer in Europe, the use of energy crops has increased significantly during the last decade (Scarlat et al., 2018). By contrast, energy crops only accounted for $2 \%$ of Sweden's production in 2017 - the majority of the substrate used was sewage sludge and manure, followed by food waste and waste from the food industry (Figure 4). 


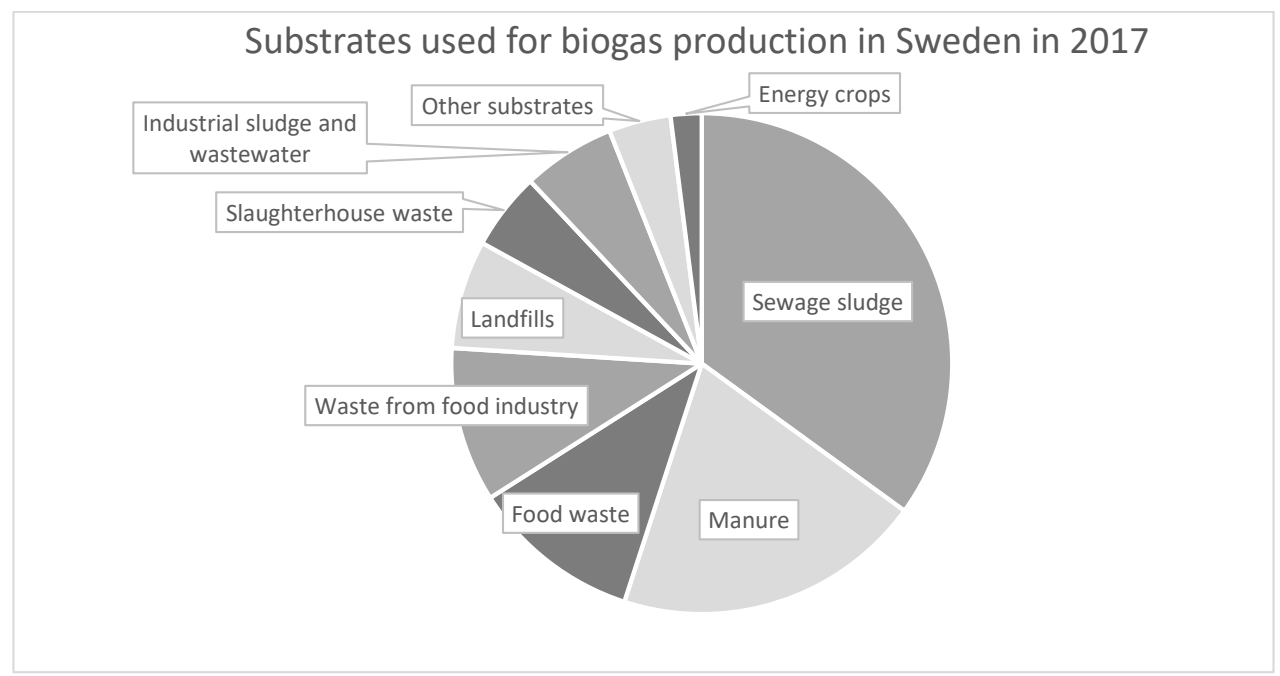

Figure 4. The substrates used for biogas production in Sweden during 2017. The data used to create the figure is from the Swedish Energy Agency (2018a) and is based on the total wet weight of incoming substrate.

\subsection{Use of biogas as energy}

Biogas as a form of renewable energy is currently mainly used in Sweden for three different purposes (Figure 5) (Swedish Energy Agency, 2019b):

- heat and/or power,

- transport fuel, or

- industrial use.

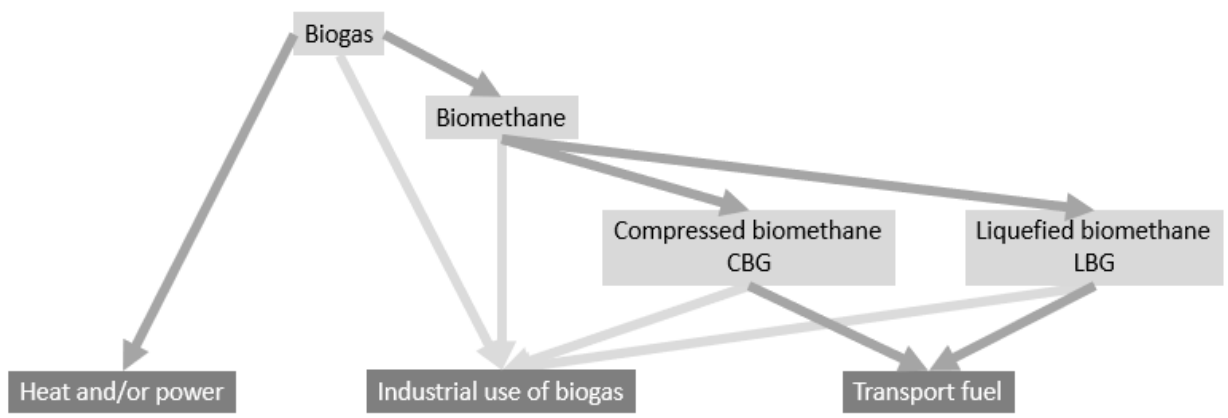

Figure 5. Biogas as a form of renewable energy is mainly used in three different ways: as heat and/or power, in manufacturing industries and as transport fuel.

The most common use of biogas in the world is the first alternative: burning biogas and producing heat and/or power (Scarlat et al., 2018). Power production from biogas mostly uses gas engines (Scarlat et al., 2018). In contrast to many other sources of renewable electricity (like wind or solar power), biogas-based electricity can have smaller production fluctuations (Häring et al., 2017). It is also possible to store biogas, although not as easily as liquid or solid 
fuels, and biogas can thus, via stable production and the potential to store it, be used to achieve more flexibility in the energy system (Häring et al., 2017). Another positive aspect of using biogas, particular for the production of electricity and heat together, is that it can have a higher energy efficiency than when biogas is used for transport (Hakawati et al., 2017).

The second alternative, using biogas as a transport fuel in gas vehicles, requires a higher methane concentration than raw biogas. Here, carbon dioxide and other impurities are removed from the biogas until it has a methane content corresponding to that of natural gas (Angelidaki et al., 2018). However, simply cleaning it does not create a high enough energy concentration to make it efficient to transport due to the gas being very voluminous, and additional measures to increase the energy concentration must be taken (Paper 1). This is currently achieved in two different ways: compressing or liquefying (Figure 5). The most common way is to compress the biomethane to a pressure of 200-250 bar, thus creating compressed biomethane (CBG) (Ullah Khan et al., 2017). The other method, liquefying the biogas by cooling it down to $-162^{\circ} \mathrm{C}$, is still a new development for biogas, although it has been used for decades for natural gas which requires the same technology (Paper 1). LBG is, however, growing in use and has the potential to enable biogas use in heavier transport since it is has an even higher energy concentration than CBG (Paper 1).

The third alternative, using it for industrial purposes as fuel for heat or as a raw material for chemicals, depends to a large extent on the user. Manufacturing industries that produce biogas themselves have the possibility to use it directly (Paper 2). For other industries, biogas has to be transported to where it will be used. If a gas grid exists, it can be used to transport gas to manufacturing industries (Paper 2). However, the Swedish natural gas grid is extremely limited. The national gas grid, which is connected to Denmark and the European gas grid, only supplies a portion of the southwestern part of the country, from Malmö to Gnosjö and Gothenburg (Swedegas, 2018). There is also a local gas grid in Stockholm, as well as some small local grids in other cities. If there is no gas grid, gas can be transported via trucks either as liquefied biomethane (Paper 2) or as compressed biomethane.

In contrast to most other countries, the majority of the biogas in Sweden is not used for heat or electricity (Scarlat et al., 2018). Instead, over $60 \%$ is upgraded to biomethane and used as transportation fuel (Figure 6). There are several countries which have increased their use of biogas in transport during the last few years, but in 2015 Sweden still accounted for $70 \%$ of the biogas used as transport fuel in Europe (Scarlat et al., 2018). 
Biogas usage in Sweden during 2018

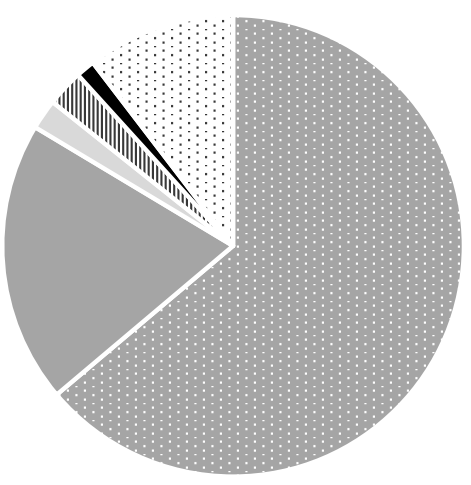

- Transport fuel

- Heat

Electricity

IIIII Industrial use

- Other use

$\therefore$ Flaring

Figure 6. How biogas was used in Sweden in 2018. Flaring means that the biogas was burnt without using it for anything. The data used to create the figure is from the Swedish Energy Agency (2019b).

The majority of all gas vehicles in Sweden are cars, and there has been a large rise in the number of gas cars during the last decade (Figure 7). However, the number of gas cars is still small if the entire car fleet is considered. It is only within the bus fleet that gas vehicles have managed to occupy a larger share - over $16 \%$ of all buses have been gas buses since 2014 (Figure 7).

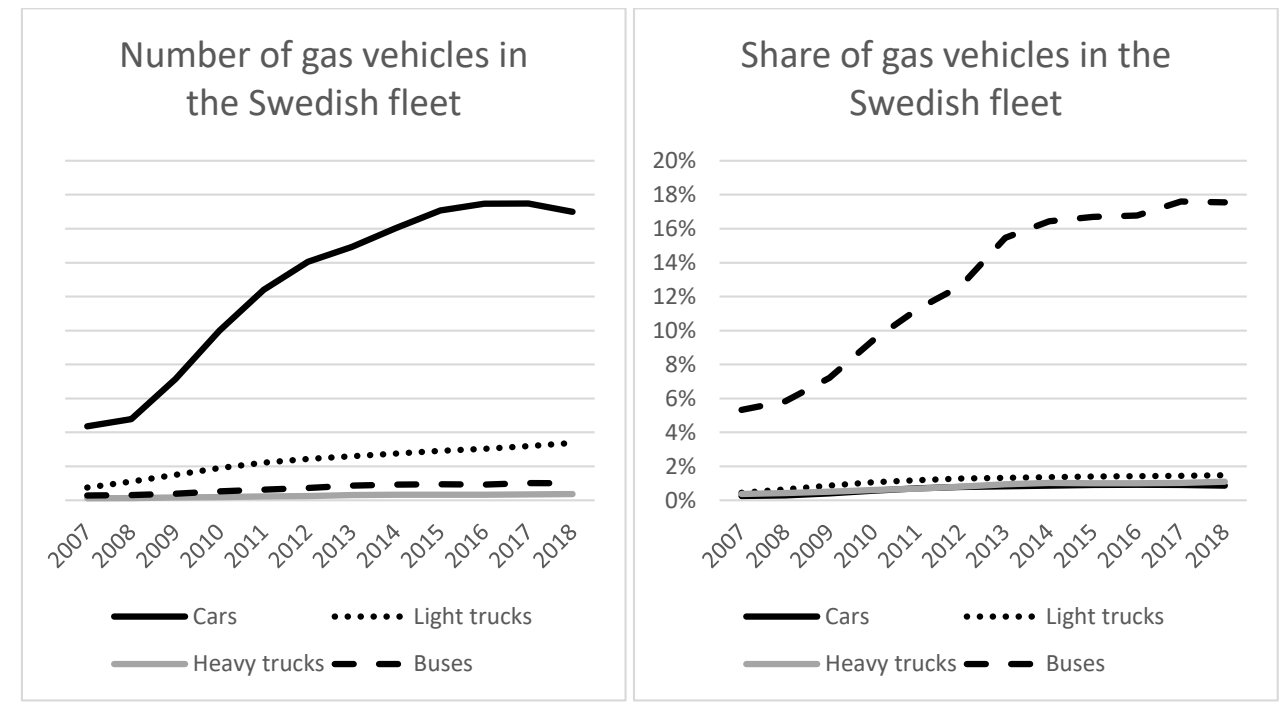

Figure 7. The number of gas vehicles and the share of gas vehicles in the Swedish fleet. The data used to create the figure is from Statistics Sweden (2019). 


\subsection{Biogas as something more than renewable energy}

Although the focus of this thesis is on biogas as a renewable energy source, biogas solutions can also offer much more. The first anaerobic digesters built in Sweden (during the 1930s), and the growing interest in anaerobic digesters at wastewater treatment plants starting in the 1960s, did not involve generating renewable energy (Svärd and la Cour Jansen, 2003). Instead, biogas was a by-product from sewage treatment plants, where the main purpose of the anaerobic digestion was to hygienize the sewage (Fallde and Eklund, 2015). It was not until the early 1990s that biogas started to be used as a transport fuel, driven largely by air pollution problems (Fallde and Eklund, 2015). Apart from wastewater treatment, anaerobic digestion can also be used in the treatment of other organic materials like food waste and manure, which can decrease methane emissions that might otherwise escape from normal degradation and can hygienize the waste for use as a fertilizer (Hagman and Eklund, 2016). Biogas solutions used in wastewater treatment also reduce the volumes of nutrients and other pollution from water, and can thus be used to clean wastewater in industries like the forest industries (Hagman et al., 2018).

Almost all the nutrients in the substrate remain after digestion, and in addition to biogas, anaerobic digestion thus also produces another product - digestate - which can be used as a fertilizer to circulate the nutrients and reduce the need for mineral fertilizers (Hagman and Eklund, 2016). Digestate is commonly used as a fertilizer within agriculture and can also enable more organic farming (Hagman et al., 2018). Additionally, digestate has several other benefits such as improving soil structure and reducing eutrophication (Table 1).

This thesis assumes that the use of the digestate/biofertilizers will not be affected by how the biogas is used.

\begin{tabular}{|l|l|}
\hline Treatment via anaerobic digestion & Digestate \\
\hline - Treating wastewater & - Balanced crop rotation \\
- Hygienizing waste & - Less pesticides used in agriculture \\
- Treating organic waste & - Improving soil structure \\
- Increasing resource efficiency & - Increasing yield for farmers \\
- Reducing methane from landfills & - High content of ammonium \\
- Reducing methane from manure & - Enabling organic farming \\
& - Less eutrophication \\
& - Circulating nutrients \\
& - Producing fertilizer \\
& - Reducing use of mineral fertilizer \\
\hline
\end{tabular}

Table 1. A summary of different benefits that biogas production can have in relation the anaerobic digestion treatment and the digestate, based based on Hagman and Eklund (2016). 


\section{Theoretical background}

This research is part of the broad movement of research in support of sustainable development that has emerged since the 1980s, sometimes referred to as sustainability science (Kates et al., 2001). It mainly connects to sustainability assessments, and to research on sustainability transitions and users' energy choices (in relation to biogas) (Figure 8). This chapter provides a brief introduction to these research areas, some of their central concepts, and previous research connected to those research areas that are relevant to this study.

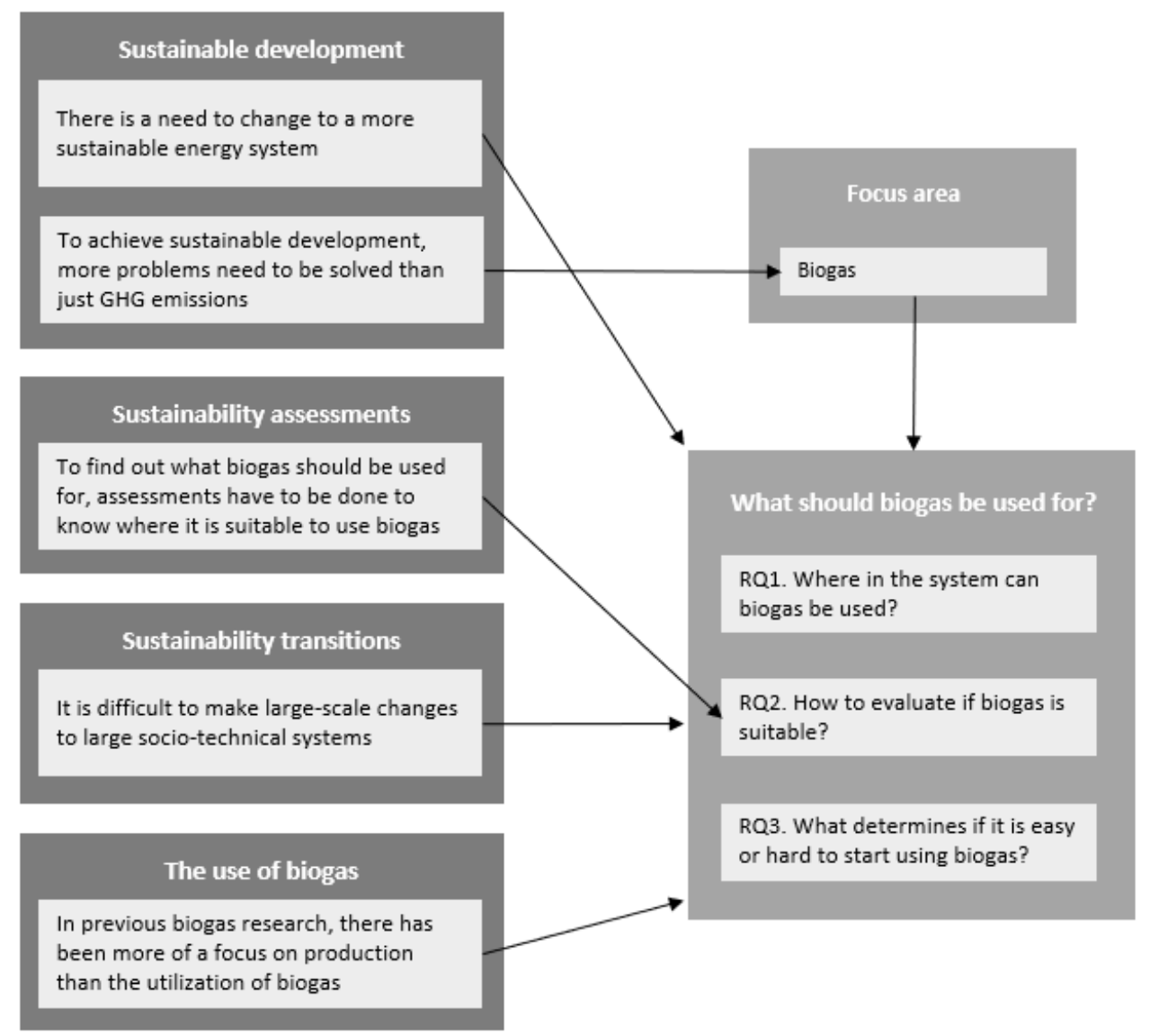

Figure 8. Illustration of how the different research areas and themes are connected to the research questions of the thesis. 


\subsection{Sustainable development and sustainability assessments}

Humans have always had an impact on the surrounding environment, but with the growing population and industrialization of the $19^{\text {th }}$ and $20^{\text {th }}$ centuries, this impact has increased immensely (Steffen et al., 2011). The first concerns about conserving nature and ideas about environmentalism date back further, beginning with the exploitation of colonized areas in the $17^{\text {th }}$ and $18^{\text {th }}$ centuries (Grove, 1992). However, it was not until the latter half of the $20^{\text {th }}$ century that environmental issues started to become more important in political contexts, and beginning in the 1960s there was a significant rise in number of environmental organizations in industrialized countries (Longhofer and Schofer, 2010). In 1987, the report 'Our Common Future' was published, introducing the term sustainable development (World Commission on Environment and Development, 1987) and the most commonly cited definition of what sustainable development means (Mensah, 2019): development that meets the needs of the current generation without compromising the ability of future generations to meet their own needs (World Commission on Environment and Development, 1987). There are many criticisms against sustainable development, for example that the environment should rather be considered a boundary of society (Rockström et al., 2009), or that sustainable development does not challenge the idea of continued economic growth (Martínez-Alier et al., 2010; Robinson, 2004). However, sustainable development has become highly influential and an increasingly important focus for national policies and companies, and related research has grown dramatically in recent decades. A bibliometric search of Scopus shows over 170,000 documents related to the term "sustainable development", and in 2016 the United Nations agreed on 17 Sustainable Development Goals as a "blueprint to achieve a better and more sustainable future for all" (United Nations, 2019a). One of these goals is "Ensure access to affordable, reliable, sustainable and modern energy", and this need to switch to more sustainable energy, together with sustainability involving much more than just climate change, was central in terms of deciding on the overall aim of the research - finding out how biogas can be part of this change and where it fits in a more sustainable energy system.

Research on sustainability is widespread, and has continuously increased and diversified during the course of several decades. Over the years, many different concepts and research fields have also evolved that link to and are motivated by sustainability, such as industrial ecology (Erkman, 1997), in which industrial systems are seen as an ecosystem with a certain distribution of materials, energy and information flow (Chertow, 2000), or sustainability assessments, which Devuyst et al. (2001) describe as “.... tool that can help decision-makers and policy-makers decide which actions they should or should not take in an attempt to make society more sustainable". Kates et al. (2001) raise seven different core questions for sustainability science that need to be researched further, for example which systems of incentive structures can most effectively improve social capacity to guide interactions between nature and society toward more sustainable trajectories. The aim of this research, to investigate what biogas should be used for in a future more sustainable energy system, assumes that some sort of evaluation should be carried out in order to see where biogas fits in the energy system, and this fits with the concept of sustainability assessments. However, it also connects to questions about incentive structures for realizing a transition of the energy system. 


\subsubsection{Assessment methods}

Related to the core questions established by Kates et al. (2001), Ness et al. (2007) suggest that the purpose of a sustainability assessment is to "provide decision makers with an evaluation of global to local integrated nature-society systems in short and long term perspectives in order to assist them to determine which actions should or should not be taken in an attempt to make society sustainable". Sustainability assessments have developed rapidly in recent decades, and there are a number of different methods that can be used to assess sustainability in different ways (Figure 9): for example, product-related assessments like Life Cycle Assessments or Life Cycle Cost Assessment; Material Flow Analyses, which study the physical metabolism of society; the Sustainable National Income index which takes sustainable resource utilization into account in addition to common national income accounting; and Environmental Impact Assessments (EIAs), in which the potential environmental impacts of development projects are evaluated (Ness et al., 2007).

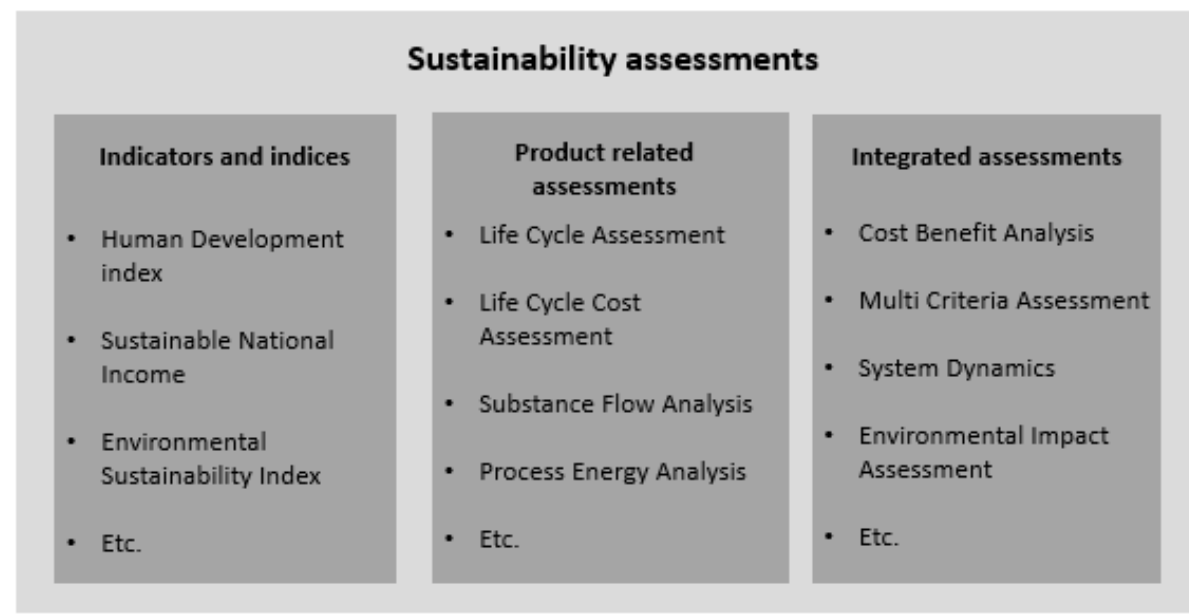

Figure 9. Different kinds of sustainability assessment methods, based on Ness et al. (2007).

\section{Cost-Benefit Analysis}

Different options can be used to assess the sustainability of biogas. Cost Benefit Analysis (CBA) is a method that weighs the costs of a project against the expected benefits - including costs associated with e.g. environmental impact - and is used to evaluate public or private investment proposals (Ness et al., 2007). According to Ness et al. (2007), this can be effective in connection with e.g. energy and transport, and several recent studies have evaluated fuel alternatives - for example Lajunen (2014) and Noel and McCormack (2014), who studied electric and diesel buses, or Shirazi, Carr and Knapp (2015), who in addition to electric and diesel also studied CNG buses. However, CBA has some weaknesses. For example, many impacts are difficult to express in quantitative monetary terms, and in many cases the cost estimates are highly uncertain (Browne and Ryan, 2011). 
Another method that can be used to rank different investment alternatives is Life Cycle Costing (LCC), which adds up the "total costs of a product, process or activity discounted over its lifetime" (Gluch and Baumann, 2004). LCC is not generally associated with environmental costs (Ness et al., 2007). Instead, a traditional LCC is an investment calculation focused on both investment and operating costs (Gluch and Baumann, 2004). The tool can still include environmental aspects in the decision, although there are difficulties with e.g. oversimplifications, uncertainties and underrating future costs (Gluch and Baumann, 2004). As Gluch and Baumann (2004) explain: "LCC-oriented tools may still be useful in practice if the decision maker is aware of the tool's inherent limitations".

\section{Multi Criteria Analysis}

A third commonly used sustainability assessment tool is Multi-Criteria Analysis (MCA), which as Ness et al. (2007) explain is used to identify the optimal choice when there are trade-offs between different evaluation criteria. An MCA involves identifying which indicators are relevant to use to assess the investment options and scaling them to evaluate the various options (based on e.g. Feiz and Ammenberg, 2017). There is also the possibility to weight the result and end up with a single answer to which option is most suitable (Beria et al., 2012). A strength of MCA is that it can quite easily incorporate qualitative aspects, and not only quantitative aspects (e.g. Beria et al., 2012; Ness et al., 2007). According to Browne and Ryan (2011), MCA is increasingly used for environmental and transport decision-making, since it is better at dealing with the complexity of the issues involved, the need for a holistic view of environmental, economic and social impacts, and the fact that tools like CBA or EIA are inadequate for capturing the full range of impacts. Previous MCA studies on transportation have focused on aspects such as high-speed rail (Janic, 2003), electric city delivery vehicles (Wątróbski et al., 2017), alternative fuels for light vehicles (Sehatpour et al., 2017) and alternative fuels for long-haul freight transport (Osorio-Tejada et al., 2017).

\section{Socio-technical scenarios}

Scenarios that can look at society as a whole rather than just a particular user are often used in connection with more integrated or regional sustainability assessments (Ness et al., 2007). During the last half century, it has become increasingly common to use scenarios to outline and analyze potential futures (Bunn and Salo, 1993), with a particular focus on climate change scenarios in recent years, such as those performed by the Intergovernmental Panel on Climate Change. The purpose of such scenarios is often to strategically evaluate different options and to try to understand how the future will change depending on which decisions are made. They can reveal opportunities and threats, and can improve communication (Bunn and Salo, 1993). Scenarios are often divided into two categories: exploratory scenarios, which start with the current situation and project different alternative futures based on previous developments, and anticipatory scenarios, which start by presenting an alternative future and then studying how to get there or avoid getting there (Mahmoud et al., 2009). "Backcasting" - a more concrete study of how exactly the desired future can be reached - is often mentioned in connection with anticipatory scenarios. 
However, one weakness of scenarios is that they are often quantitative and technology focused (Hofman et al., 2004). To manage and assist with the complex, transition-oriented decisionmaking that often takes place when working with sustainability, a more informal scenario discipline was launched in the early the 2000s: socio-technical scenarios (Geels et al., 2018). Socio-technical scenarios were initially used together with the multilevel perspective (Geels, 2002) and focused on niche/regime developments. This has evolved into a form of scenario that offers a more qualitative approach and considers both technology and society (Hillman and Sandén, 2008), and can combine quantitative and qualitative analysis (Auvinen et al., 2015). It also has the potential to include storylines to describe the scenarios and relate them to the context (Weimer-Jehle et al., 2016), as well as explaining development processes rather than just final outcomes (Hillman and Sandén, 2008).

Many studies have examined different scenarios for transitions towards a more sustainable energy systems. For example, Azar et al. (2003) carried out a scenario study focusing on century-long scenarios for transitions towards low greenhouse gas emissions in the global energy and transportation system. There have also been scenario studies focusing on biogas, such as Cherubini et al. (2009), who studied different scenarios for waste management in Italy where biogas production was part of two of the scenarios, or Rehl and Müller (2011), who studied different scenarios for processing digestate from biogas production. There have also been scenario studies focusing on biogas as energy. Lauer et al. (2017) is one such example, studying power generation from biogas plants in Germany with different scenarios regarding plant configurations, operation modes and schedules. Another scenario study that focused on biogas as energy was carried out by Kanase-Patil et al. (2010), who looked at biogas within the possibilities for off-grid rural electrification. In relation to biogas as a transport fuel, Murphy et al. (2004) developed and analyzed different scenarios including a focus on production and the use of biomethane.

\subsection{Sustainability transitions}

Sustainability transitions have evolved in connection with sustainability research, based on the difficulties of making large-scale changes in large socio-technical systems (Markard et al., 2012). Large socio-technical systems feature interacting components, such as physical features, actors or institutions, that work together to provide specific services for society (Markard et al., 2012). The energy system is one such large socio-technical system (Markard et al., 2012) and consists of different components that work together to produce and distribute energy to different users, which can be part of other large socio-technical systems such as the transport system or the industrial systems (see Figure 1). To reduce the environmental impacts from the energy system, the components using fossil fuels should be exchanged for components that use energy with lesser negative impacts on sustainability aspects.

A key feature of such systems is that the components are interrelated and interdependent, meaning that if a component in the system changes, the other components will change accordingly (Hughes, 1987). This interdependency may hinder changes in the system. It is not enough to simply substitute one component with a component with less impact, since the other components must change accordingly if a component in the system changes. For example, it is not enough to customize an engine to run on biogas instead of gasoline - there must also be corresponding changes in production, distribution, markets, regulations, etc. This makes it 
more difficult and slower to substitute components with less negative impact. Fundamentally, implementing large-scale shifts in the system tends to be a slow and complicated process. This difficulty in inducing the desired change has led to an increased interest in better understanding these complex large-scale changes and how to promote them, which is a major challenge of transition studies.

Sustainability transitions are, according to Markard et al. (2012), "long-term multidimensional, and fundamental transformation processes through which established sociotechnical systems shift to more sustainable modes of production and consumption". This framework has also led to other concepts being developed - transition management (e.g. Kemp et al., 2007; Loorbach, 2010), strategic niche management (e.g. Kemp et al., 1998; Schot and Geels, 2008), technological innovation systems (e.g. Bergek et al., 2008; Hekkert et al., 2007) and the multi-level perspective (e.g. Geels, 2011, 2002).

\subsubsection{Biogas in sustainability transitions}

Regarding biogas and energy transitions, many studies in recent years (e.g. Boston, 2013; Connolly et al., 2011; Foxon, 2013; Jacobson and Delucchi, 2011; Kowalski et al., 2009; Krajačić et al., 2009; Lund and Mathiesen, 2009) have focused on how to switch to more renewables in different parts of the world. However, these studies seldom mention biogas as an option. When biogas is addressed, it is most often in the context of power and/or heat (e.g. Foxon, 2013; Kowalski et al., 2009). However, a few studies focus solely on the possibilities of using biogas instead of fossil fuels, usually for either heat or electricity (e.g. Häring et al., 2017; Huopana et al., 2013) or as CBG in cars, buses or light trucks (e.g. Kalinichenko et al., 2016). Biogas can also be used to produce fuels other than CBG, as shown by e.g. Yang et al. (2014), Zinoviev et al. (2010) and Ahmadi Moghaddam et al. (2015), and for purposes other than heat and electricity and relatively light road vehicles, as shown by e.g. Brynolf et al. (2014). Another study that looked at biogas more directly from a sustainability transition perspective is that carried out by Magnusson and Berggren (2018), who studied the competition between electrified and biogas vehicles, using the concepts of technological innovation systems and strategic niche management to understand this competition and its implications.

However, an added difficulty with biogas is that, in contrast to many other fuels, it is connected to many different parts of society. Depending on the substrate, it can be connected to wastewater management, waste management, agriculture, fishing, forestry, food industries or manufacturing industries. It is frequently based on local, small-scale production which contributes to local employment. Substrate, digestate and biogas are often transported between different facilities, and in Sweden this is often done by trucks. The digestate is commonly used as a fertilizer and is thus connected to the agriculture sector, and can enable ecological farming which is connected to the food industry. Fallde and Eklund (2015) carried out a socio-technical transitions study of the development of biogas in a local context during the last 40 years, focusing on aspects such as how the biogas system developed over the years from almost nothing to become a major public transport fuel, what drove this change and which actors were involved. Ammenberg et al. (2018) also had a larger systems focus in their study of policies and actors, focusing not only on users and distributors but also on different kinds of production 
(e.g. waste collection, industrial production and agricultural production) as well as other areas connected to the use of biogas in transport, such as procurement and vehicle sales.

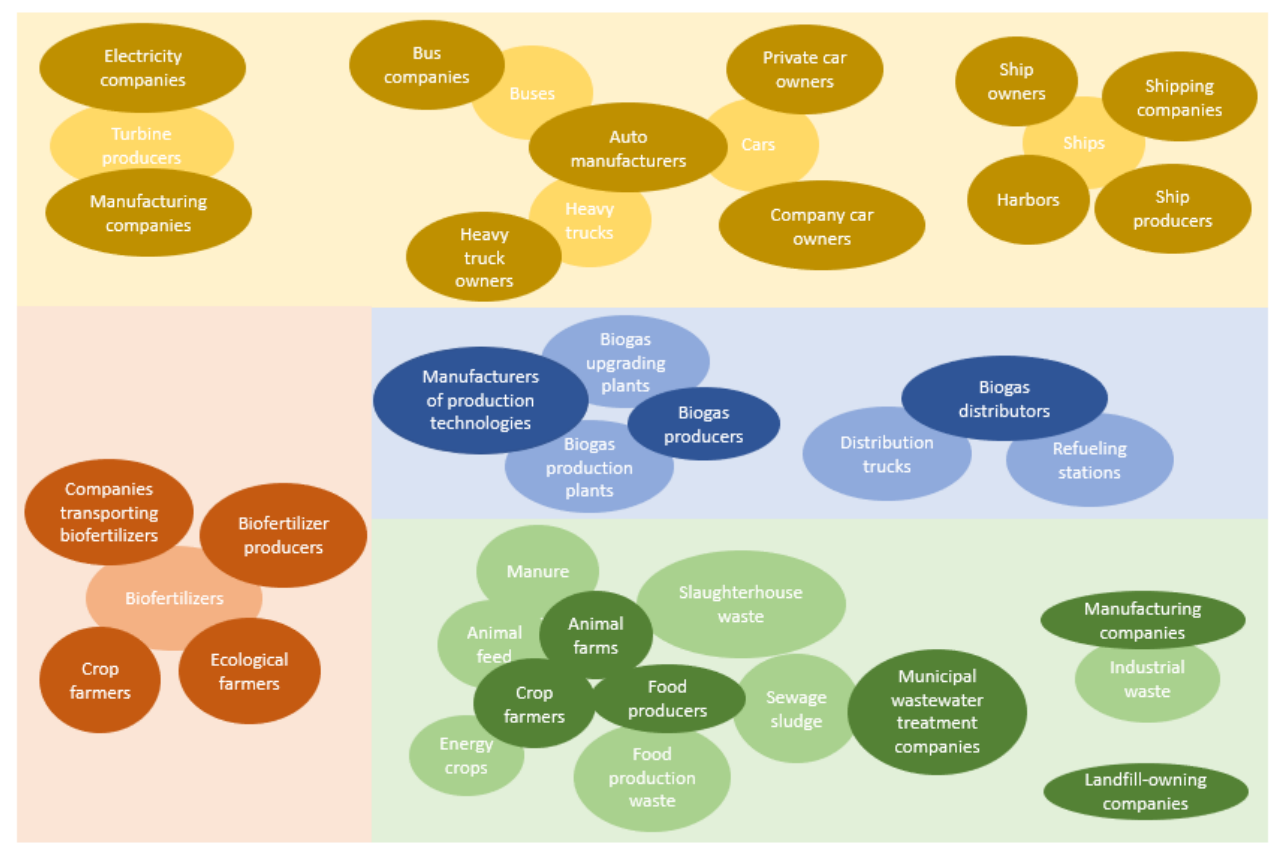

Figure 10. A simplified overview of actors involved in the biogas system. The green area represents substrates for biogas production, the blue area represents biogas production, the red area represents the digestate/biofertilizer part of the biogas system and the yellow area represents biogas users. Darker circles represent actors, while lighter circles represent biogas-related artefacts related to the actor. There will also be more actors involved, such as companies transporting things between different parts of the system, repair and maintenance companies, car sales businesses and so forth.

This added connectivity of biogas (Figure 10) can make it more difficult to involve biogas in a transition, since more connected pieces means that for each change, many phenomena need to change accordingly.

\subsection{The use of biogas}

Although some studies focus on the possibilities of using biogas instead of fossil fuels, the majority of the research on biogas has a different focus. Mao et al. (2015) review a large number of studies on anaerobic digestion for biogas production, and earlier similar reviews include Weiland (2010), Mata-Alvarez et al. (2000) and Gunaseelan (1997). There are also several studies focusing on how biogas can be upgraded for use as fuel, which have been reviewed in papers like Angelidaki et al. (2018), Sun et al. (2015), Yang et al. (2014), Bauer et al. (2013) and Abatzoglou and Boivin (2009). Many of these studies focus mostly on the production or upgrading of biogas, and less on its actual use. However, some studies have focused on its use in various ways. For example, Ammenberg et al. (2018) focused on actors and policies on the demand side of biogas in the transport sector. Larsson et al. (2016) studied policy instruments regarding upgraded biogas for transport. Bengtsson et al. (2014, 2012) 
focused on whether biogas or one of the other alternatives is the better option for the shipping industry, while Lantz et al. (2007) discussed incentives for biogas utilization.

However, studies that focus on utilization are still rather scarce in comparison to those that focus on production. There are ambitions in Sweden to increase production, but at the same time a previously large use area - biogas in city buses - is moving towards electricity; an investigation commissioned by the Swedish Government presented scenarios for city buses in Sweden with a rapid pace of electrification (Swedish Government Official Reports, 2013), studies have noted significant interest in electric buses (Ammenberg et al., 2018; Mutter, 2019), and many cities in Sweden have started to electrify their city buses (e.g. Bussmagasinet, 2017, 2016; Hedlund, 2017; Lärka, 2016; Nohrstedt, 2017; Norrtälje Municipality, 2017; Scania Group, 2017; Umeå Municipality, 2017). However, starting to use electricity instead of biogas in city buses is only beneficial if the biogas is also used in other ways, i.e. increasing the total amount of renewable energy use rather than simply moving from one renewable fuel to another. There is thus a potential amount of biogas that is available for use in other areas where it is more suitable. These potential users are the focus of this research, and are connected to the first research question of the potential users of biogas. The user focus is also paramount to research question 2, which focuses on whether biogas is suitable and involves the user perspective in the definition of suitability, and to research question 3, where the focus on what makes it easy or hard to use biogas is largely focused on users and their perspectives on biogas. 


\section{Methodology}

This research focuses on investigating which role biogas should play in a more sustainable energy system. Much of the research carried out for this thesis was inspired by ideas of integrated research, especially in connection with focusing on problems, going beyond disciplines and involving non-academic actors. The research took place within two research projects: the Environmental Bus project, with its focus on alternative uses of biogas, and a project within the Biogas Research Center, focusing on creating and applying a multi-criteria assessment tool for alternative bus technologies. This chapter presents a more detailed description of the research performed, focusing on integrated research and how it has influenced the research, the approaches of the research projects, and how the research was carried out regarding methods for data collection and analysis. Specific details and descriptions of the methods used can be found in the respective appended papers.

\subsection{Integrated research}

Research on sustainability issues often stems from a societal need to deal with problems. Ultimately, the point of carrying out such research is often to find ways of dealing with these problems. According to Mauser et al. (2013), basing research on problems rather than disciplines requires less traditional methods of doing research, combining several different research areas into more integrated research. Integrated research looks further than just one single, limited discipline, and goes beyond the usual framework of a field. There are several levels of integrated research, depending on the degree of integration and cooperation (Stock and Burton, 2011):

- Different scientists can contribute perspectives from their own disciplines, or

- Scientists may have shared questions and goals, where the research leads to the creation of new frameworks for knowledge, or

- There can be a broader transcendence of multiple disciplinary perspectives while focusing on a specific real world problem, including advanced collaboration with multiple actors from outside academia.

This last level of integrated research, transdisciplinary research, is usually both the most desirable and the hardest to obtain of these three kinds of integrated research (Holm et al., 2013). It might even be impossible to achieve according to some, due to the amount of collaboration and integration needed (Stock and Burton, 2011).

For environmental and sustainability research in particular, many sources advocate the use of integrated research. For example, Stock and Burton (2011) argue that "sustainability almost inherently requires transdisciplinary attempts" - the focus on the problem rather than the discipline makes it better able to deal with real, complex problems like sustainability than if the research stayed within the disciplinary boundaries. The results should be able to help stakeholders make informed decisions (Mauser et al., 2013). It is thus important to include stakeholders to some extent in research on sustainability. Good collaboration between researchers and non-academic stakeholders can increase both legitimacy and accountability for the problem and the potential solutions (Mauser et al., 2013). If the research is in any way 
connected with policies or other public processes, collaboration between researchers and nonacademic stakeholders can also improve public acceptance and the fit of the solutions to the actual needs of society (Moser, 2016).

This study was inspired by these thoughts about focusing on problems rather than disciplines, and about collaboration. Of the four appended articles, Papers 3 and 4 are based on close collaboration with non-academic stakeholders and Paper 2 is based on the opinions of relevant non-academic stakeholders. None of the papers follow any strict disciplinary ideas, but are rather focused on different aspects of achieving a more sustainable society.

\subsection{Research projects and appended papers}

The research for this thesis took place within two research projects, the Environmental Bus project and the Biogas Research Center project, resulting in the four papers appended to this thesis.

\subsubsection{The Environmental Bus project}

The Environmental Bus research project was a collaborative project involving the regional public transport company, the local municipality and the local utility company. The project consisted of three sub-studies: one focusing on cities that had tested electric buses, one focusing on the potential of electric buses in Linköping, and one focusing on alternative uses for biogas. Regular meetings were held as part of the project, and were attended by the project partners and other actors, including a national energy company and an international heavy transport manufacturer. The research from all the sub-studies was presented and discussed during the meetings, to obtain input from various relevant actors.

My part in this project was the third sub-study, focusing on alternative uses for biogas. The research involved literature studies focusing on how biogas is used today and theoretical potential uses, as well as an interview study among different sectors that could use biogas but are not large users, in order to find out what they conceived to be the drivers and barriers for biogas use. This part of the project resulted in two papers, namely the appended Papers 1 and 2 .

Once all the sub-studies had been finalized, they were used together with the input from a workshop to create scenarios for implementing electric buses while shifting the use of biogas to other purposes. The workshop was carried out with 24 participants from twelve different organizations. The organizations represented at the workshop were the project partners, the region, two gas producers/distributors, two international heavy transport manufacturers, a manufacturer that had recently decided to switch to biogas and a trade organization for distribution trucks. The scenarios produced via this final part of the research project are the basis for the appended Paper 4. 


\subsubsection{The Biogas Research Center: A sustainability evaluation of bus technologies using multi-criteria analysis}

The Biogas Research Center is a national competence center for biogas with more than 20 different partners, ranging from biogas producers, regions, municipalities and biogas distributors to companies working with digestate and international auto manufacturers. All partners meet at biannual meetings where they can present and discuss current research and their knowledge about biogas. Within the competence center, research is carried out by smaller working groups, which are then further divided into individual projects.

One such project, focusing on creating and applying a multi-criteria assessment tool for alternative bus technologies, made up part of the research for this thesis. The project was a continuous collaboration with two of the partners within the competence center - the regional public transport company and a large biogas producer/distributor. Further input was obtained from other relevant stakeholders through discussions during poster presentations at the internal Biogas Research Center meetings. Input was also gathered at workshops held with partners from the Biogas Research Center, as well as during presentation and discussion sessions at Biogas Research Center and Environmental Bus Project meetings. During all these sessions, the project was discussed with a particular focus on which indicators and scales were relevant for evaluating different bus technologies, as well as evaluations of relevant bus technologies according to these scales.

This project resulted in two papers: a part I paper in which the assessment method is established and a part II paper in which the assessment is applied to relevant alternative bus technologies. However, only part I is included in this thesis, and is appended as Paper 3.

\subsubsection{Research projects, appended papers and their relationship to the research questions}

This thesis includes four appended papers (Table 2). The Environmental Bus Project resulted in three papers: one focusing on which fuels can be created from biogas (Paper 1), one focusing on the drivers and barriers for biogas use in heavy road transport, manufacturing and shipping (Paper 2), and one focusing on a socio-technical scenario analysis of a local case of energy transition (Paper 4). The Biogas Research Center project resulted in one paper, focusing on developing a Multi-Criteria Assessment method for bus technologies (Paper 3).

The open setting for the Environmental Bus Project allowed for a general focus on all possible biogas-based fuels and usage areas, and to study certain alternatives in greater depth. However, it was based on specific regional biogas production, which gave the project a regional and national setting. This regional production is also one of the largest biogas production sites in Sweden, which may have biased the project's research in favor of solutions for large-scale biogas production. 


\begin{tabular}{|c|c|c|c|c|}
\hline & Paper 1 & Paper 2 & Paper 3 & Paper 4 \\
\hline 쿻 & $\begin{array}{l}\text { Biogas-based fuels as } \\
\text { renewable energy in } \\
\text { the transport sector }\end{array}$ & $\begin{array}{l}\text { Drivers and barriers } \\
\text { for increased biogas } \\
\text { usage: a demand side } \\
\text { perspective focusing } \\
\text { on manufacturing, } \\
\text { road transport and } \\
\text { shipping }\end{array}$ & $\begin{array}{c}\text { Sustainability } \\
\text { assessment of } \\
\text { public transport- } \\
\text { a multi-criteria } \\
\text { approach to } \\
\text { compare different } \\
\text { bus technologies }\end{array}$ & $\begin{array}{c}\text { Sociotechnical } \\
\text { scenarios and local } \\
\text { practice - Assessing } \\
\text { the future role of } \\
\text { biogas in a regional } \\
\text { energy and } \\
\text { transport system }\end{array}$ \\
\hline $\begin{array}{l}\frac{7}{0} \\
\frac{0}{0} \\
\frac{7}{7}\end{array}$ & $\begin{array}{c}\text { The Environmental Bus } \\
\text { project }\end{array}$ & $\begin{array}{c}\text { The Environmental } \\
\text { Bus project }\end{array}$ & $\begin{array}{c}\text { The Biogas } \\
\text { Research Center } \\
\text { project }\end{array}$ & $\begin{array}{c}\text { The Environmental } \\
\text { Bus project }\end{array}$ \\
\hline 高 & Draft & Published in 'Biofuels' & Draft & $\begin{array}{l}\text { To be submitted to } \\
\text { Transportation } \\
\text { Research Part A: } \\
\text { Policy and Practice }\end{array}$ \\
\hline 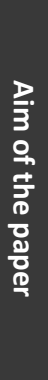 & $\begin{array}{l}\text { To contribute an } \\
\text { overview and an } \\
\text { increased } \\
\text { understanding of } \\
\text { different biogas-based } \\
\text { fuels and their } \\
\text { potential to be used as } \\
\text { a substitute for fossil } \\
\text { fuels in the transport } \\
\text { sector }\end{array}$ & $\begin{array}{l}\text { To contribute to the } \\
\text { current discourse on } \\
\text { increasing the share } \\
\text { of energy from } \\
\text { renewable energy } \\
\text { sources in different } \\
\text { sectors }\end{array}$ & $\begin{array}{l}\text { To develop a } \\
\text { Multi-Criteria } \\
\text { Assessment (MCA) } \\
\text { method for } \\
\text { assessing the } \\
\text { sustainability of } \\
\text { public bus } \\
\text { technologies }\end{array}$ & $\begin{array}{l}\text { To show how energy } \\
\text { transition research } \\
\text { can interact with } \\
\text { local practice by } \\
\text { means of socio- } \\
\text { technical scenario } \\
\text { analysis }\end{array}$ \\
\hline 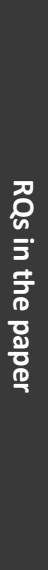 & $\begin{array}{l}\text { - For what purpose } \\
\text { have they been } \\
\text { developed? } \\
\text { - What strengths and } \\
\text { weaknesses do the } \\
\text { fuels have? } \\
\text { - How far have the } \\
\text { fuels come in their } \\
\text { development and how } \\
\text { are they produced and } \\
\text { used today? }\end{array}$ & $\begin{array}{l}\text { - What are the major } \\
\text { drivers and barriers } \\
\text { for increased biogas } \\
\text { usage in road } \\
\text { transport, } \\
\text { manufacturing and } \\
\text { shipping? } \\
\text { - In which settings } \\
\text { can biogas already be } \\
\text { a feasible option and } \\
\text { what is needed for } \\
\text { wider introduction } \\
\text { and use in other } \\
\text { settings? }\end{array}$ & & \\
\hline
\end{tabular}

Table 2. An overview of the appended papers. 
The Biogas Research Center project focused sharply on buses, which is relevant in the Swedish biogas context since this is a major use of biogas $-20 \%$ of public buses in Sweden were biogas buses in 2018 (Fridas användarförening, 2019). However, the energy used by public buses, at just 2 TWh in 2018 (Fridas användarförening, 2019), is very low compared to the total energy use of 378 TWh in 2017 (Swedish Energy Agency, 2019a, excluding energy losses and energy used for non-energy purposes). The research within the project is thus focused on a very limited energy user. However, even though the assessment in Paper 3 is developed for public buses in Sweden, the method of developing it may also be useful for other areas. Several of the indicators are likely to be relevant for types of transport other than buses, and could thus be used as a basis for assessments focusing on other transportation types. It is also possible to use the same method to create other assessments for areas that are further away from public transport - the participatory method can be used to understand what is actually important for stakeholders to consider.

In relation to this thesis, the appended papers helped to answer the research questions in different ways (Table 3).

\begin{tabular}{|c|c|c|c|c|}
\hline & Paper 1 & Paper 2 & Paper 3 & Paper 4 \\
\hline קֶ, & $\begin{array}{l}\text { Overview of } \\
\text { alternative biogas- } \\
\text { based fuels and their } \\
\text { potential usage areas } \\
\text { and developments }\end{array}$ & $\begin{array}{l}\text { Basic preconditions for } \\
\text { using biogas for } \\
\text { manufacturing, shipping } \\
\text { and heavy transport }\end{array}$ & & \\
\hline 귱 & & & $\begin{array}{l}\text { Establishing a } \\
\text { possible } \\
\text { assessment } \\
\text { method (MCA) } \\
\text { Overview of } \\
\text { aspects of } \\
\text { importance to } \\
\text { potential users }\end{array}$ & $\begin{array}{c}\text { Application of a } \\
\text { possible } \\
\text { assessment } \\
\text { method (scenario } \\
\text { analysis) } \\
\text { Identifying } \\
\text { factors that are } \\
\text { important from a } \\
\text { societal point of } \\
\text { view }\end{array}$ \\
\hline :ొర్జ & $\begin{array}{c}\text { Identifying factors that } \\
\text { influence how easy or } \\
\text { difficult it is to use } \\
\text { biogas }\end{array}$ & $\begin{array}{l}\text { Overview of drivers and } \\
\text { barriers experienced by } \\
\text { potential biogas users } \\
\text { within manufacturing and } \\
\text { heavy transport }\end{array}$ & $\begin{array}{l}\text { Identifying factors } \\
\text { that influence } \\
\text { how easy or } \\
\text { difficult it is to use } \\
\text { biogas }\end{array}$ & $\begin{array}{l}\text { Identifying } \\
\text { factors that } \\
\text { influence how } \\
\text { easy or difficult it } \\
\text { is to use biogas }\end{array}$ \\
\hline
\end{tabular}

Table 3. An overview of the appended papers' relationships to the research questions. Darker boxes indicate that the paper was more important for answering the research question. Lighter boxes indicate that the paper was used to answer the research question, but to a lesser degree. 


\subsection{Data collection}

Three main methods were used to collect data during the research: workshops with stakeholders, document and literature reviews, and interviews (Table 4). More detailed descriptions of the methods used can be found in each paper.

\begin{tabular}{|c|c|c|c|}
\hline & $\begin{array}{l}\text { Workshops with } \\
\text { stakeholders }\end{array}$ & $\begin{array}{c}\text { Document and literature } \\
\text { review }\end{array}$ & Interviews \\
\hline 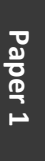 & & $\begin{array}{c}\text { Review of journal articles, gray } \\
\text { literature and mass media for an } \\
\text { overview of alternative biogas- } \\
\text { based fuels }\end{array}$ & \\
\hline 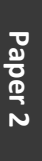 & & $\begin{array}{l}\text { Review of journal articles on } \\
\text { drivers and barriers for } \\
\text { technological choice in industry }\end{array}$ & $\begin{array}{l}\text { Interviews with company } \\
\text { representatives connected to } \\
\text { heavy transport, } \\
\text { manufacturing and shipping }\end{array}$ \\
\hline 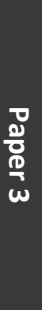 & $\begin{array}{l}\text { Several different kinds } \\
\text { of workshops with a } \\
\text { diversity of actors }\end{array}$ & $\begin{array}{l}\text { Review of journal articles on } \\
\text { sustainable public procurements } \\
\text { and sustainability assessments } \\
\text { Review of journal articles and } \\
\text { gray literature on indicators and } \\
\text { scales that could be relevant for } \\
\text { assessing bus technologies }\end{array}$ & \\
\hline & $\begin{array}{l}\text { Several meetings with } \\
\text { representatives from } \\
\text { local partners }\end{array}$ & $\begin{array}{c}\text { Review of journal articles on } \\
\text { scenario construction and } \\
\text { evaluation }\end{array}$ & \\
\hline$\stackrel{5}{1}$ & $\begin{array}{l}\text { A workshop involving } \\
\text { participants from twelve } \\
\text { different organizations }\end{array}$ & $\begin{array}{c}\text { Review of gray literature on the } \\
\text { current regional transport } \\
\text { demand }\end{array}$ & \\
\hline
\end{tabular}

Table 4. An overview of the data collection methods for the papers.

\subsubsection{Workshops with stakeholders}

The aim of this research is to investigate which role biogas may play in a more sustainable energy system, a question that has been arisen from the complex sustainability problems that we are now experiencing and the need to work to minimize these problems. As such, the concept of transdisciplinary research became important - especially advanced collaboration with actors outside academia, in order to better suit the research to the actual needs of society.

The Environmental Bus project was a collaborative project involving three local actors as partners, who were represented at several meetings regarding the project and were also part of the framing of the project. A workshop was also held with 24 participants from twelve different organizations in order to establish the scenarios for implementing electric buses. The participants were sent background material to read beforehand, and at the workshop they were divided into three groups: one for a baseline scenario, one for a small-scale implementation of 
electric buses and one for a large-scale implementation of electric buses. The groups then discussed issue such as how these scenarios could be managed and what the results would be.

The Biogas Research Center project featured regular workshops involving the local public transport authority and a large biogas producer and distributor, at which the various criteria were developed iteratively. Potential indicators and scales were also presented and discussed during several poster presentations, presentation/discussion sessions and additional workshops, mainly in connection with the Biogas Research Center.

Each participant can be considered to be subjective and to think mainly from the perspective of the organization they represented. Having more participants might have reduced the risk of subjectivity due to the participants' responses, and might have included more knowledge and other viewpoints that could have improved the work. However, all work with stakeholders is time-consuming and it is difficult to schedule meetings so that participants will attend, especially with a large number of participants. It was thus important to achieve a balance between having enough participants to get sufficient value out of the meetings and ensuring that there were not so many participants that this would place excessive demands on scheduling.

\subsubsection{Document and literature reviews}

Document and literature reviews were carried out within both projects in relation to all the articles by the author of this thesis, the other authors of the papers and the project participants. For Papers 2-4, literature reviews were conducted for journal articles within the research field in order to better understand what had already been done and what knowledge existed. These reviews focused on previous studies on drivers and barriers in Paper 2, sustainable public procurement and sustainability assessments in Paper 3 and scenario construction and evaluation in Paper 4.

A document and literature review was also carried out for Paper 1, focusing on journal articles, gray literature and mass media output in order to provide an overview of which fuels can be produced from biogas and how they can be used. The main sources used were statistical reports from various organizations, as well as mass-media output for those fuels that are still unusual enough not to be included in statistical data. For Paper 3, journal articles and gray literature were reviewed to determine which indicators and scales could be relevant for assessing bus technologies, and for Paper 4 gray literature was used to understand the current regional transport demand.

To assess the quality of documents, Bryman (2015) proposes four criteria: whether the evidence is genuine and of unquestionable origin, whether the evidence is free from error and distortion, whether the evidence is typical of its kind, and whether the evidence is clear and comprehensible. In the case of the review for Paper 1, national statistical reports were preferred as source material since they have been carefully reviewed by governmental organizations before publication and since the data they use is likely based on all the available statistical data there is. National statistics and reports, and especially regional statistics and reports, were also paramount to the review for Paper 4 in order to understand the current regional transport demand, since these was considered to have the most authentic sources. Mass media output 
was used in Paper 1 for technologies that were too unusual to be part of national statistics, in order to show that these technologies are technically feasible but are not yet used to any large degree. In most cases, the mass media outputs were of the type that "company $\mathrm{X}$ has changed/are going to change to technology $\mathrm{Y}$ that is better", i.e. promotional media that positively portrays the companies involved. However, although the media outputs could thus be considered biased, they do show that it is actually possible to use technology $\mathrm{Y}$ in the sector of company $\mathrm{X}$ - and that it is not the most common thing, since it would otherwise not have been in the news. In the literature review for Paper 3, it was important to find quality data regarding possible indicators and scales that could contribute to the input given by the participants in the study. Regarding creating the scales, direct sources such as EU or Swedish legislations were preferred as they have direct impact on the users.

\subsubsection{Interviews}

Interviews were conducted within the Environmental Bus project on drivers and barriers for biogas use within three different sectors: manufacturing, shipping and freight road transport. The interviews were flexible and focused on the interviewee's point of view, but with an interview guide that made the interviews semi-structured. The majority of the interviews took place either by telephone or by video chat, which according to Bryman (2015) has little difference to in-person interviews regarding the response the researcher gets. All interviews were recorded and fully transcribed in order to allow for a more thorough and repeated examination and to bring the author of this thesis closer to each participant's response, in accordance with Bryman's (2015) suggestions regarding interviews. As with the workshops, having a higher number of participants in the interviews could have changed the results as more viewpoints would have been included. However, it is a time-consuming task and finding relevant companies that agreed to be interviewed was not without difficulties. A more detailed description of the interviews can be found in Paper 2.

\subsection{Analysis}

Two different methods were used in the papers to analyze the data: thematic analysis and scenario analysis (Table 5). More detailed descriptions of the analyses can be found in the respective papers. 


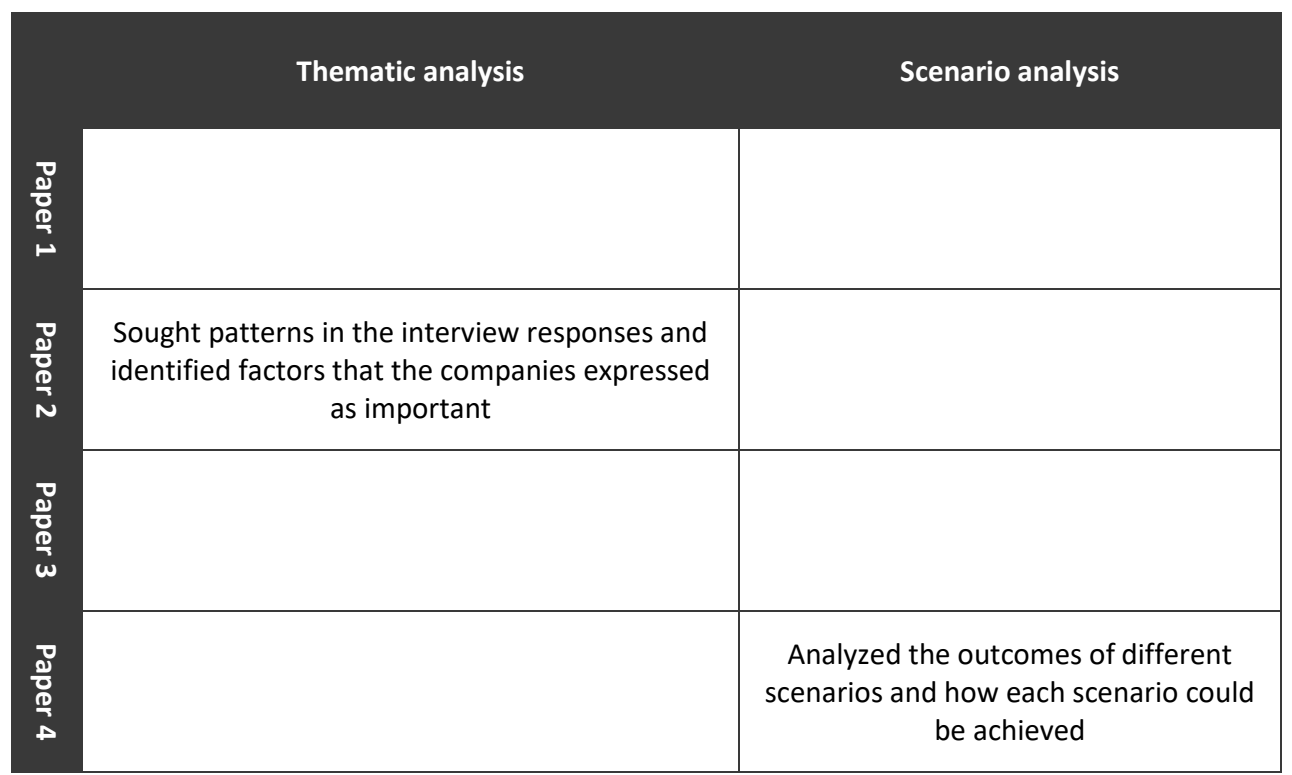

Table 5. An overview of the analysis methods used in the papers.

\subsubsection{Thematic analysis}

According to Bryman (2015), thematic analysis can involve activities searching for themes by finding recurring motives through a thorough reading of transcripts and producing themes from these motives. Accordingly, a thematic analysis was carried out the interviews related to Paper 2 , to study the drivers and barriers for potential biogas users. The interview transcripts were analyzed by looking for factors that the companies expressed as being important. These factors were then compared against each other by looking for patterns, and were also compared against previous literature. The identified similar or unique themes found in the interviews were then compiled into a list of drivers and barriers, divided up into the three studied sectors (heavy road transport, manufacturing and shipping). The results of this thematic analysis became the results in Paper 2.

\subsubsection{Scenario analysis}

A scenario analysis was carried out within the Environmental Bus project, assessing the effects of city bus electrification and the subsequent use of biogas in three alternative usage areas. The scenario analysis also assessed what is needed to realize the different scenarios in terms of the actors involved and the policies needed. The scenarios were then compared to see which would be most beneficial and likely. The results of this scenario analysis became the results in Paper 4 . 


\section{Appended papers}

\section{Paper 1: Biogas-based fuels as renewable energy in the transport sector}

The majority of the energy used in the world comes from fossil sources, and changing to more renewables is needed in order to avoid more global warming. There is no single renewable source that can currently be used as a substitute for all fossil fuels, a system of different renewable alternatives working together will be needed. Biogas, which has several societal benefits, can be part of such a system. However, biogas can be used as a substitute for fossil fuels in many different ways and may be suitable for different parts of the renewable energy system that needs to be developed.

The purpose of Paper 1 was to contribute an overview and an increased understanding of different biogas-based fuels and their potential to be used as a substitute for fossil fuels in the energy system, with a particular focus on the transport sector. This was done by addressing three questions: 1) For what purpose have they been developed? 2) What strengths and weaknesses do the fuels have? and 3) How far have the fuels come in their development, and how are they produced and used today globally?

To answer these questions, a literature and internet-based inventory was produced which resulted in a combination of journal articles, gray literature and newspaper articles These were reviewed in order to obtain a historical context and a good overview of the research, as well as an overview of the most recent developments in connection with the fuels.

The results show that the production of transportation fuels from biogas mainly follows two different tracks (Figure 11) - either upgrading biogas to a higher methane content and then compressing it or liquefying it (CBG and LBG), or gasifying it to produce syngas for further fuel synthesis (hydrogen, methanol, dimethyl ether (DME) and Fischer-Tropsch fuels (FT fuels)). 


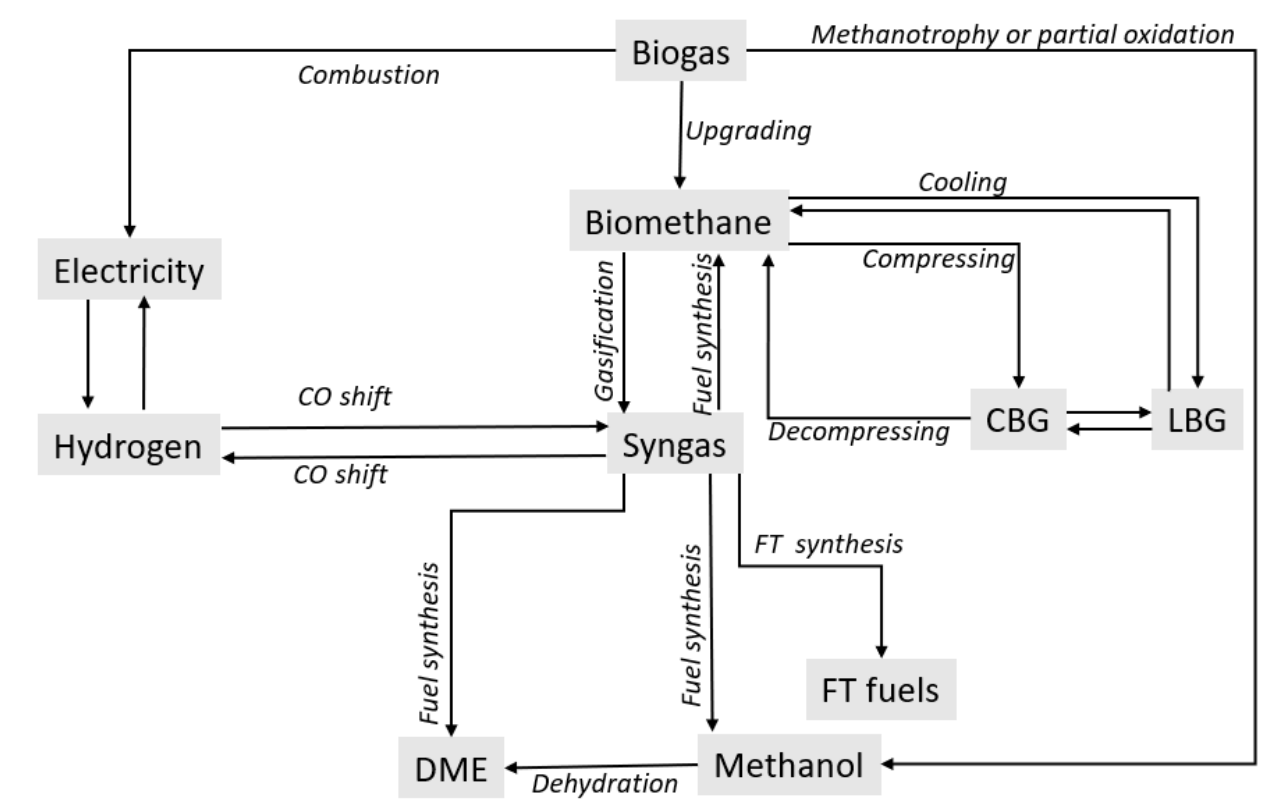

Figure 11. The different ways in which biogas can be used to produce fuels.

CBG is the fuel alternative that has come furthest in its technological development, with millions of compatible vehicles worldwide. CBG and LBG are the only alternatives currently being commercially produced from biogas. $\mathrm{CBG}$ can be economically viable in smaller scales than the other alternatives and has a high fuel yield, but it is a gaseous fuel with a large volume which makes transportation less efficient. The use of CBG further risks counteracting the climate benefits through accidental leaks. LBG, which is produced from biogas to a much more limited extent, is liquefied and has much lower volume requirements. However, it has to be kept cool continuously and needs a larger production scale to be economically viable.

For all fuels produced from gasification, the production scale needed in order to be economically efficient will probably be too large for most biogas production processes. Hydrogen vehicles exist commercially, but are still rare and expensive with little refueling infrastructure in place, and there is a similar problem to CBG of being a gaseous fuel and thus requiring large volumes. However, hydrogen is often considered a fuel that will be used in the future due to the fact that it is relatively easy to produce from excess electricity and can be used in fuel cell vehicles without any tailpipe air pollution. Methanol can also be used in fuel cells, but is most often instead used in combustion vehicles and especially as a low blend in gasoline. Interest in methanol is very local, and is limited to a few countries and a few shipping companies. There is currently no production of methanol from biogas, but in contrast to CBG and hydrogen it is a liquid at room temperature. Like methanol, there is currently no commercial production of DME or FT fuels based on biogas. There are no compatible infrastructure or vehicles for DME, which also places greater demands on the engine due to factors such as low viscosity. By contrast, FT fuels include synthetic diesel, which is compatible with all diesel infrastructure and vehicles, and thus with a very large part of the world's current road vehicle fleet. 
The short-term potential for using biogas as a vehicle fuel thus lies mainly in the expanded use of CBG and LBG. However, hydrogen, methanol, DME and FT fuels all have strengths that CBG and LBG lack and that might make them interesting alternatives in the future. Hydrogen in particular is likely to be a part of the future energy system.

\section{Paper 2: Drivers and barriers for biogas use in manufacturing, road transport and shipping: a demand side perspective}

Biogas has been suggested as a potentially important future fuel for manufacturing, heavy road transport and shipping, although the use of biogas in these sectors so far has been marginal. The purpose of Paper 2 was to contribute to the current discourse on increasing the share of energy from renewable energy sources in different sectors. The article manuscript did so by addressing two questions: 1) What are the major drivers and barriers for increased biogas usage in road transport, manufacturing and shipping? and 2) In which settings can biogas already be a feasible option and what is needed for its wider introduction and use in other settings?

Biogas was introduced in Sweden in the $20^{\text {th }}$ century to decrease sewage sludge amounts, since which production has expanded into other areas. Since the 1990s, biogas has been used as a vehicle fuel and more than $60 \%$ of the biogas produced in Sweden was upgraded to vehicle fuel in 2017. However, the sales of new gas vehicles has stagnated since 2014, and this together with various other changes within the market - has led to increased interest in examining for alternative uses. Manufacturing, heavy road transport and shipping are three sectors where the use of biogas is currently very limited but where there is the potential to increase its use and to replace fossil fuels. Recent changes might also generate additional interest in such a substitution - for example, tax exemption for fossil fuels in manufacturing has gradually been phased out and emission regulations for the shipping industry have been introduced.

The study was based on insights from previous scientific studies that addressed the adoption of renewable energy technologies. It was particularly inspired by the works of Ingrid Mignon and Anna Bergek, and was based on semi-structured interviews with eleven selected companies. Three of four companies represented each sector, and some of the interviewed companies had already switched or decided to switch to biogas, while other companies did not express any direct interest in switching to biogas. A thematic analysis was then carried out on the interview data to find patterns.

In previous scientific studies, several drivers and barriers for the diffusion of renewable energy technologies have been identified. At the system level, drivers include existing infrastructure and institutional requirements and expectations, while at the actor level the drivers relate more to individual adopters, for example price advantages and strengthening companies' environmental profiles. Barriers at the system level concerned areas such as market structures favoring existing technologies, high costs and unstable policies, while barriers at the actor level concerned areas including a lack of financial resources and social capital.

The interviews identified five drivers and nine barrier which the companies experienced with regard to biogas (Table 6). Several companies in each sectors state that drivers for biogas 
included the importance of environmental actions for the company and the fact that companies can win market shares by being "the environmental alternative". Common barriers were related to either cost (too expensive, or unfavorable policies) or biogas itself (too little production, not suitable/compatible, or a lack of infrastructure).

\begin{tabular}{|c|c|c|c|}
\hline & Manufacturing & $\begin{array}{l}\text { Heavy road } \\
\text { transport }\end{array}$ & Shipping \\
\hline & $\begin{array}{l}\text { Four } \\
\text { companies } \\
(A, B, C, D)\end{array}$ & $\begin{array}{l}\text { Three } \\
\text { companies } \\
(E, F, G)\end{array}$ & $\begin{array}{l}\text { Four } \\
\text { companies } \\
(\mathrm{H}, \mathrm{I}, \mathrm{J}, \mathrm{K})\end{array}$ \\
\hline \multicolumn{4}{|l|}{ Drivers } \\
\hline $\begin{array}{l}\text { Environmental actions are important to the } \\
\text { company }\end{array}$ & $A, B, C, D$ & $E, F, G$ & $\mathrm{H}, \mathrm{K}$ \\
\hline $\begin{array}{l}\text { Winning market shares by being "the } \\
\text { environmental alternative" }\end{array}$ & $A, B, C$ & $E, F, G$ & $\mathrm{H}, \mathrm{J}$ \\
\hline Family business & $B, C$ & - & K \\
\hline Contract requirements & - & - & 1 \\
\hline Internal biogas production & A & - & - \\
\hline \multicolumn{4}{|l|}{ Barriers } \\
\hline $\begin{array}{l}\text { The unreliability and short-sightedness of } \\
\text { current policies }\end{array}$ & B & $\mathrm{E}, \mathrm{G}$ & - \\
\hline Policies favor other fuels more & D & - & $\mathrm{H}, \mathrm{K}$ \\
\hline Biogas is expensive & $\mathrm{C}-a$ & - & $\mathrm{H}, \mathrm{J}, \mathrm{K}$ \\
\hline Lack of suitable biogas & D (liquefied) & $E, F$ & $\mathrm{H}, \mathrm{J}, \mathrm{K}$ \\
\hline Lack of infrastructure & $B, C$ & - & - \\
\hline Not compatible with current system & A, D & $E, G$ & $\mathrm{H}, \mathrm{K}$ \\
\hline Existing biogas technology is not suitable & - & G & $\mathrm{I}, \mathrm{J}$ \\
\hline Contract requirements & - & - & 1 \\
\hline Previous bad experience with methane gas & - & $\mathrm{E}$ & - \\
\hline
\end{tabular}

Table 6. The drivers and barriers experienced by the companies in the studied sectors.

The results from the interviews confirmed some of the drivers and barriers found in the empirical studies, but the literature also included additional drivers and barriers which the companies did not express in their interviews (Table 7). The opposite also applies - one driver raised in the interviews that is rarely mentioned in the renewable energy adoption literature is that of family-owned businesses and their more long-term, intergenerational perspectives in connection with strategic decisions. The issue of drivers and barriers can also be complex, and an aspect can be both a driver and a barrier for the same actor. 


\begin{tabular}{|c|c|}
\hline Level of analysis & Sub-categories \\
\hline System level & 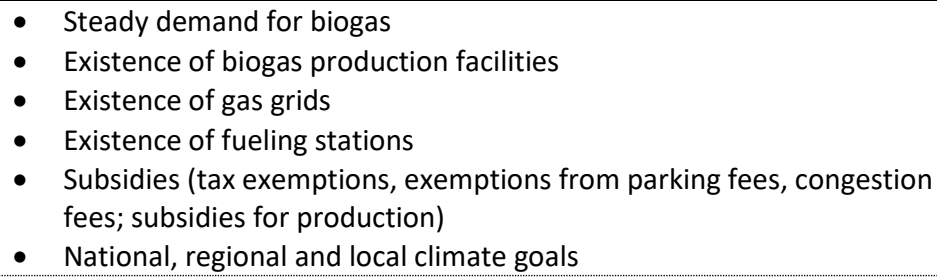 \\
\hline Actor level & 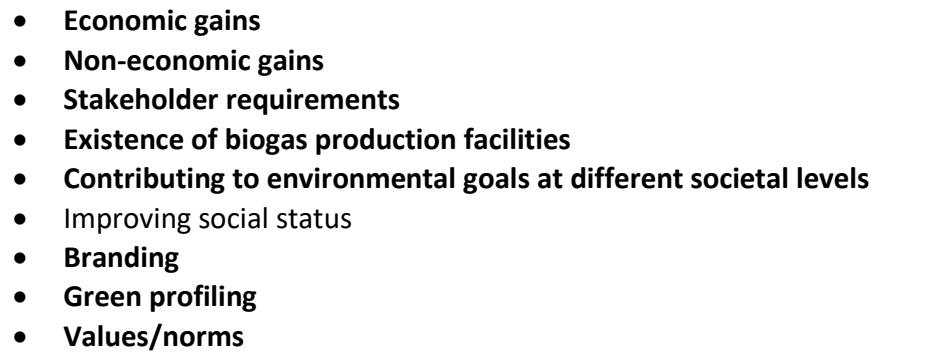 \\
\hline
\end{tabular}

Barriers

\begin{tabular}{|c|c|}
\hline Level of analysis & Sub-categories \\
\hline System level & 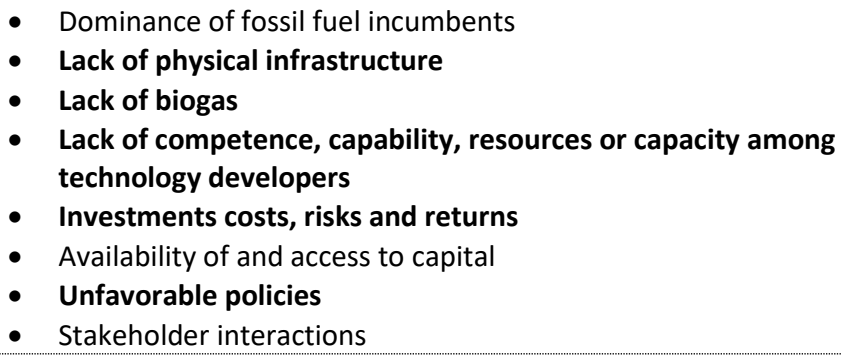 \\
\hline Actor level & $\begin{array}{ll}\text { - } & \text { Lack of knowledge } \\
\text { - } & \text { Dissatisfactory experience } \\
\text { - } & \text { Limited financial resources } \\
\text { - } & \text { Incompatibility with physical resources } \\
\text { - } & \text { Lack of social capital } \\
\text { - } & \text { Values/norms } \\
\text { - } & \text { Characteristics of potential adopter } \\
\text { - } & \text { Strategies of potential adopter }\end{array}$ \\
\hline
\end{tabular}

Table 7. Summary of identified drivers and barriers to the diffusion of biogas in the manufacturing, shipping, and road transport sectors. The drivers and barriers confirmed by the results of Paper 2 are shown in bold.

The study in Paper 2 suggests that there is a need for more ambitious policy strategies guided by long-term trajectories, to provide a stable basis for adopters to make investments, as well as experimentation to prevent lock-in in sub-optimal energy solutions. 


\section{Paper 3: Sustainability assessment of public transport, part I - a multi- criteria assessment method to compare different bus technologies}

Transport systems are linked to many essential challenges, related to issues such as the environment or health, and there is a need for a transition towards more sustainable alternatives. Many organizations take actions to improve their sustainability performance, and this includes Swedish regions. Swedish regions are responsible for public transport in Sweden and the public bus fleet has undergone a major transition during the last two decades, from mainly using fossil fuels to more than $60 \%$ of buses using renewables in 2017. The regional public transport authorities, which are controlled by the Swedish regions, have been key actors in this transition via the public procurement process. However, several different alternative bus technologies exist, which raises questions from the regions regarding the most suitable alternative. There seems to be a significant need for improved knowledge and supporting methods when it comes to how sustainability assessments can and should be included in public procurement, which is also relevant for transportation. The purpose of Paper 3 was to establish such a method - a multi-criteria assessment method - to be used when assessing the sustainability of public bus technologies. The companion paper, Part II, applies the method to the alternative bus technologies that are currently relevant in Sweden.

In previous research, it has been shown that key actors such as authorities struggle to implement and maintain sustainable public procurement, especially at local level. This can be due to factors including budget constraints, a lack of sufficient knowledge or a lack of simple methods and guidance. There are two main groups of methods, based on a single criterion and multiple criteria. The advantage of single criterion methods is that they are simple to communicate, but it is difficult to include all relevant effects and to correctly estimate the values of the included effects. Multi-criteria methods, on the other hand, allow several different types of indicators to be included and can provide more holistic evaluations, while also facilitating communication and obtaining an overview.

Assessing the sustainability of different bus technologies is a broad and multi-faceted task, which makes a multi-criteria approach suitable. This MCA process, involving developing a tool to support regional public procurement processes, was participatory and iterative in nature and involved several stakeholders and experts.

In this process, four key areas were developed (technical performance, economic performance, environmental and energy performance, and societal performance) along with key questions to define the purposes of the key areas. Twelve indicators were then developed to answer the questions for the key areas (Table 8). 


\begin{tabular}{|c|c|}
\hline Key areas and key questions & Indicators \\
\hline $\begin{array}{l}\text { Technical performance } \\
\text { Is the technology robust and convenient to } \\
\text { use? }\end{array}$ & $\begin{array}{l}\text { - Technical maturity } \\
\text { - Daily operational availability }\end{array}$ \\
\hline $\begin{array}{l}\text { Economic performance } \\
\text { Is the technology cost-efficient with a } \\
\text { stable cost development? }\end{array}$ & $\begin{array}{l}\text { - Total cost of ownership } \\
\text { - Need for investments in infrastructure } \\
\text { - Cost stability }\end{array}$ \\
\hline $\begin{array}{l}\text { Environmental and energy performance } \\
\text { Is the technology favorable concerning } \\
\text { energy efficiency, environmental impacts } \\
\text { and management of natural resources? }\end{array}$ & $\begin{array}{l}\text { - Energy efficiency } \\
\text { - Greenhouse gas emission savings } \\
\text { - Local/regional impact on land and aquatic } \\
\text { environments } \\
\text { - Air pollution } \\
\text { - Noise }\end{array}$ \\
\hline $\begin{array}{l}\text { Social performance } \\
\text { Is the technology favorable in concerning } \\
\text { societal and social issues? }\end{array}$ & $\begin{array}{l}\text { - Energy security and employment } \\
\text { - Sociotechnical system services }\end{array}$ \\
\hline
\end{tabular}

Table 8. The key areas, key questions and indicators established in Paper 3 for assessing public bus technologies.

Each indicator was assigned a 5- or 3-point scale, ranging from very poor to very good - via either a quantitative scale or a qualitative scale. For example, the indicator "technical maturity" is a qualitative indicator with a scale ranging from "Possible technology, but not developed enough to be seen as a reasonable alternative from a technical perspective" to "Well established technology on the Swedish and international market. No relevant doubts regarding the technical performance. High operational availability is expected.".

Finally, the process and the indicators were discussed based on advice for effective and efficient sustainability assessments.

\section{Paper 4: Socio-technical scenario construction and local practice - Assessing the future use of biogas, biodiesel and electricity in a regional transport system}

To assist with complex transition-oriented decision-making, substituting fossil fuels for renewables is often analyzed and outlined using scenarios which frequently focus on certain contexts to discuss the viability of different options. Socio-technical scenario analyses that combine quantitative indicators with qualitative techniques can help address such complexities. The purpose of Paper 4 was to show how transition research can interact with local practice by presenting a socio-technical scenario analysis that involves different renewable energy technologies, and by describing a process that entails substituting fossil fuels as well as redeploying renewable fuels into new application contexts.

The focus is on a delimited region, the Swedish county of Östergötland, highlighting the critical role of local actors in the realization of energy transitions. Östergötland is a frontrunner within biogas production in Sweden and started to substitute diesel buses with biogas buses in the early 1990s. However, an investigation commissioned by the Swedish Government presented scenarios for city buses in Sweden involving a rapid pace of electrification and where the current biofuels used for buses would be redeployed for other uses. Sweden has come a long 
way in its transition from fossil fuels, with more than $60 \%$ of energy consumption originating from renewable sources, but there is still large-scale use of fossil fuels and emissions of greenhouse gases within the manufacturing industry and the transport sector.

This scenario study presents four regional sociotechnical scenarios developed based on current development trends and in collaboration with representatives from actors such as the local energy utility, the municipality and the regional public transport authority. The baseline scenario assumes large, sudden changes and is based on development trends, which show that the region is growing and that traveling and transportation are assumed to increase by 2030 . In the second scenario, a limited implementation of electric city buses in Linköping by 2030 is assumed, with the excess biogas replacing diesel for regional express bus routes. In the third and fourth scenarios, $90 \%$ of all Linköping's city buses are assumed to be electrified by 2030, with the excess biogas being liquefied into LBG and then being used instead of diesel in heavyduty trucks or instead of LPG in manufacturing industries.

\begin{tabular}{|l|l|l|}
\hline Scenario 1 & Baseline & $\begin{array}{l}\text { Continuous transport growth up until 2030 based on } \\
\text { development trends since 2005. Traveling by public transport } \\
\text { increases its share of traveling in the region. The share of biogas } \\
\text { remains unchanged in public transport. No electrification of city } \\
\text { buses, and no important biogas introduction in industry or heavy } \\
\text { freight transport. }\end{array}$ \\
\hline Scenario 2 & $\begin{array}{l}\text { Electricity and } \\
\text { biogas in public } \\
\text { transport }\end{array}$ & $\begin{array}{l}\text { Limited implementation of electric city buses in Linköping by } \\
\text { 2030, biogas replacing HVO for inter-city bus routes. HVO } \\
\text { replacing fossil diesel in heavy-duty trucks. }\end{array}$ \\
\hline Scenario 3 & $\begin{array}{l}\text { Electricity in city } \\
\text { buses and biogas } \\
\text { in trucks }\end{array}$ & $\begin{array}{l}90 \% \text { of all city bus lines in Linköping electrified. Biogas in heavy- } \\
\text { duty trucks replacing fossil diesel. }\end{array}$ \\
\hline Scenario 4 & $\begin{array}{l}\text { Electricity in city } \\
\text { buses and biogas } \\
\text { in manufacturing } \\
\text { industry }\end{array}$ & $\begin{array}{l}90 \% \text { of all city bus lines in Linköping electrified. Biogas in } \\
\text { industrial processes replacing fossil gas. }\end{array}$ \\
\hline
\end{tabular}

Table 9. Summary of the scenarios.

Depending on what the excess biogas is used for, different actors need to be involved to realize the scenario and doing so depends on different government policies. The scale of electric bus implementation will affect the environmental impact of the change, with scenarios 3 and 4 having larger reductions in the amount of non-renewable primary energy needed and in emissions of greenhouse gases and air pollutants in the cities (Figure 12). However, scenario 2 offers a larger degree of substitution in its area (regional bus traffic), while the amount of excess biogas would have less impact on the larger sectors of heavy-duty trucks or manufacturing industries. 


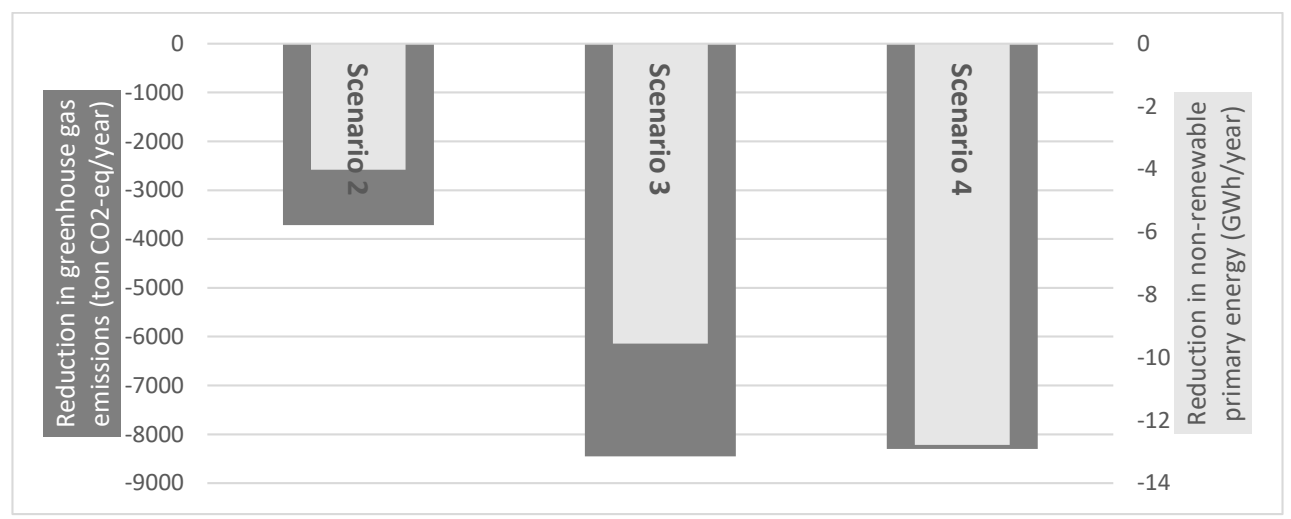

Figure 12. The resulting reductions in greenhouse gases and primary energy use for the scenarios, compared to the baseline scenario.

At the start of the project, a decision to implement electric city buses appeared unlikely and distant for the actors involved, but after the end of the project it was announced that the regional public authority would start implementing electric buses during the 2020-2030 contract period. A key factor in making the implementation of electric buses politically feasible in the local context was engaging stakeholders in dialogue on alternative ways to use biogas, and the project partners acknowledged that the project had resulted in a broadened understanding that strengthened their ability to evaluate different technology options. Participation was more important than prediction, and acceptability was more important than accuracy in the scenario construction. 


\section{Results and discussion}

There is a need for a large-scale sustainability transition in the energy system, and biogas can be part of a more sustainable energy system. However, it is not certain which usage areas are most suitable for biogas, and this needs to be assessed. Such an assessment requires methods to assess different alternatives, with relevant aspects being taken into consideration, as well as an investigation into what determines whether it is more or less difficult to introduce new uses for biogas. This chapter will summarize, synthetize and discuss findings in relation to the research questions.

\subsection{In what ways can biogas be used in a more sustainable energy system?}

It is difficult to bring about a transition of a socio-technical system such as the energy system. Several studies, such as McKendry (2002), Demirbas (2007) and Armaroli and Balzani (2007), have shown that many different renewable alternatives can contribute importantly to such a change. In the case of the energy system in Sweden, there have been some changes and more renewable energy than fossil energy was used in 2017. However, there are major differences between individual sectors. While fossil fuels are barely used for electricity production and district heating, large amounts of fossil fuels are still used within the transport and manufacturing sectors.

\subsubsection{Heat and electricity}

Even if the use of fossil fuels for heat and electricity is small compared to its use in manufacturing and transportation, 3-10 GWh of fossil fuels are used for electricity, district heating and housing/services each year (Swedish Energy Agency, 2019a). Thus, each of these sectors still uses more fossil fuels than Sweden's annual biogas production. Instead of using biogas in one of the fossil fuel intense sectors, it could be used to further reduce use in sectors that might have difficulties substituting remaining fossil fuels.

\section{Biogas for heat}

In Sweden, biogas is more often used to generate heat than electricity. One benefit of producing heat from biogas is that it is the easiest way to use biogas (Lantz, 2012). Börjesson and Ahlgren (2012) showed the investment costs per $\mathrm{kW}$ are lower for heat plants only producing heat tham if the plant were also to produce electricity. As such, it may be interesting to generate heat using smaller biogas production plants. This can also be seen in the statistics for biogas production plants in Sweden - almost all the largest plants are upgrading much of their biogas to biomethane, while smaller plants, especially plants that have a lower annual production than $3 \mathrm{GWh}$, almost never upgrade biogas to biomethane but instead nearly always use it for heat (or electricity to a lesser extent) (Swedish Energy Agency, 2016). However, using biogas for heat in Sweden is not necessarily the most economical option since there are other renewable fuels that can be burned and that cost less (Lantz, 2012). There are also large seasonal changes in heat demand, with little demand during the summer (Lantz, 2012). 


\section{Biogas for electricity}

Using biogas to generate electricity is, like heat production, simpler than using it for transport in that it does not require the biogas to be upgraded and the technology is less advanced. In a study on biogas options in Italy, the upgrading options required a capital cost that was more than ten times as high as the capital cost for the CHP option (Patrizio et al., 2015). However, like biogas for heat production, CHP from biogas might not be the most economical option either - Lantz (2012) found that CHP from manure-based biogas was not profitable in Sweden under the existing market conditions.

In addition to the lower investment costs, another benefit of biogas-based electricity production is that it could be used as balancing power, which might become more important in the future. During the last two decades, electricity production in Sweden has mainly been based on water power and nuclear energy, but has also used some smaller amounts of electricity from combined heat and power plants (Swedish Energy Agency, 2019a). The main change is that, during the last dozen years, wind power has gone from almost no production to $10 \%$ of the country's entire electricity production (Swedish Energy Agency, 2019a). Apart from wind power, there has also been a rapid increase in solar power in Sweden, but the amounts produced are still too small to be visible in the energy production statistics (Swedish Energy Agency, 2018 b). One problem with such a shift towards more wind and solar power is that they are very intermittent power sources, and that it can be difficult to balance the load - especially considering the planned nuclear phase-out in Sweden (Fischer et al., 2018). In recent years, several studies have focused on biogas and the possibility of using it for more flexible power production, such as Mauky et al. (2017) who found that flexible feeding can result in more variable gas production and thus also greater flexibility in power production. Other examples of recent studies in the area include Lauer and Thrän (2017), who found that more flexible biogas plants in the future could be used to improve the system integration of intermittent renewable energy, and both Lauven et al. (2019) and Lauer et al. (2020) carried out economic assessments of flexible power generation from biogas.

\subsubsection{Transportation}

Much of the biogas produced in Sweden is already being used in the transport sector in the form of CBG for cars, buses and light trucks. Considering the anticipated rapid growth in electric cars and buses, biogas might instead be used as a fuel for other kinds of transportation, such as heavy trucks and ships. Compressed biomethane is too voluminous for these options, but biogas can be used to produce many other fuels. There are two main alternatives for producing transportation fuels from biogas (Paper 1). The biogas can either be upgraded and made more energy dense via compression or liquefaction, or can be reformed into syngas via gasification and further reformed into hydrogen, methanol, DME or Fischer-Tropsch fuel (Figure 13). However, in view of the amount of fossil fuel used in transportation, current biogas production levels and the still relatively small (albeit growing) number of electric cars in Sweden ${ }^{1}$, compressed biomethane could play an important role as fuel for cars.

\footnotetext{
${ }^{1} 0.3 \%$ and $1 \%$ of the cars in Sweden were electric and plug-in hybrids respectively in 2018 . The numbers of both electric cars and plug-in hybrids have, however, increased since 2012 at an increasingly rapid pace (Statistics Sweden, 2019).
} 


\section{Biogas}

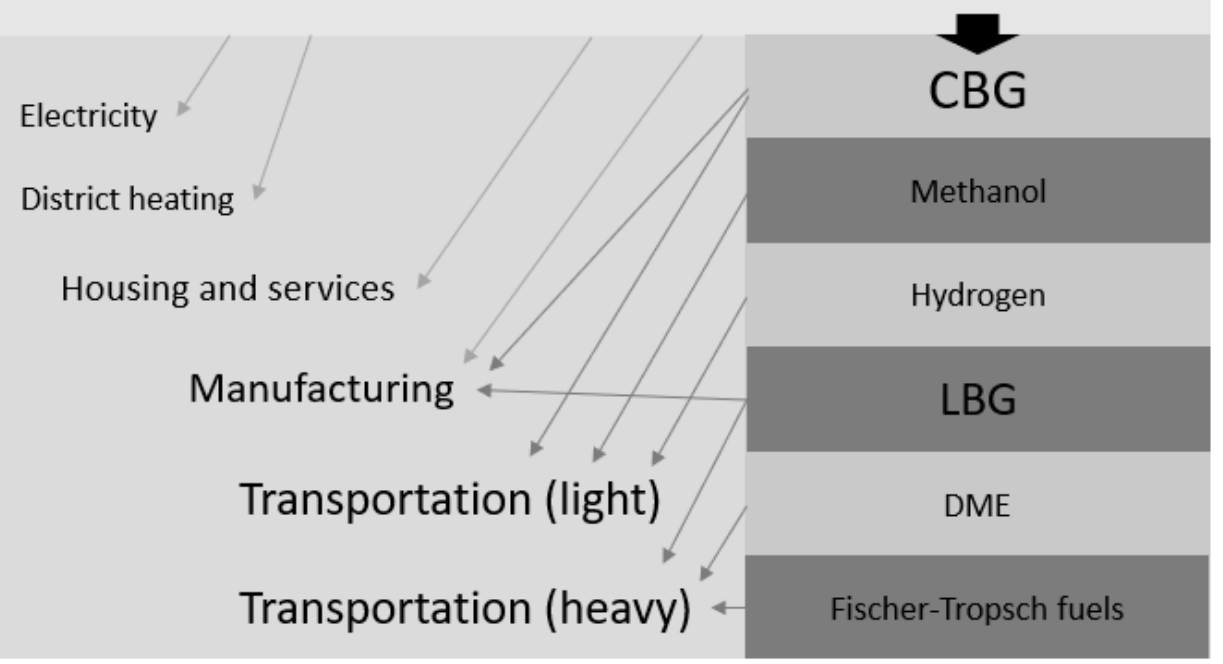

Figure 13. An overview of what biogas can be used for, either as raw biogas or via reformation to other fuels like CBG or LBG (cf. Paper 1). The size of the text indicates the amount of fossil fuel usage in Sweden, where the electric sector uses the smallest amount of fossil fuels and the transportation sector uses the largest amount.

\section{Biomethane and fuels via gasification into syngas}

Today, biogas is mainly used as a transport fuel in the form of upgraded biogas that has been compressed into CBG. To a lesser but increasing degree, upgraded biogas is instead liquefied into an even higher energy concentration $(\mathrm{LBG})$ in order to be used in heavier transport such as long-distance trucks or ships (Paper 1).

The fuels produced via syngas, methanol, DME and FT fuels have certain qualities that could make them interesting in some transport contexts (Paper 1). Methanol and FT fuels are liquid and are thus easier to transport, existing vehicles can be retrofitted for use with both DME and methanol, and FT diesel can be used directly in the current fleet and infrastructure (Paper 1). However, although these fuels have some qualities that CBG and LBG lack and although some of them are currently used on commercial scales, there has not yet been a movement towards large-scale production based on biogas and it is therefore not likely that they will be viewed as potential alternatives to biogas in the foreseeable future (Paper 1). The other fuel that can be produced via syngas, hydrogen, has more obvious development potential since it is expected to be part of a future energy system due to its ability to be used in fuel cells without any tailpipe emissions as well as its ability to be produced from excess electricity (Paper 1).

However, CBG will most likely continue to dominate as the most common biogas-based fuel, together with increased use of LBG. Paper 1 shows that CBG is the only fuel alternative used on a large scale today, and therefore has advantages in terms of technical maturity. The rising interest in LBG in Sweden, with increasing numbers of refueling stations (e.g. 
Bioenergitidningen, 2018; Fordonsgas, 2018), vehicles (e.g. Daimler, 2018; DNV GL, 2016; Scania Global, 2017) and production sites (e.g. Tekniska Verken, 2018), may pave the way for increased use of biogas. Since CBG is too voluminous to transport over large distances effectively, the introduction of LBG opens up the possibility of a less regional and more national biogas market, since biogas then can be distributed over longer distances. Areas where biogas production is limited can thus, with LBG, use biogas, which was not previously possible since the ineffective transportation of CBG forced biogas to be used close to the production site. LBG also brings opportunities for new usage areas where biogas has not previously been used due to CBG being too voluminous, such as heavy road vehicles and shipping. In both of these areas, liquefied methane use is developing with larger numbers of vehicles and refueling options (Paper 1), thus expanding the possible market for biogas to more areas and more energy sources that could be substituted.

The current rising interest in LBG is, however, largely based on LNG. While many refueling stations are being built in Sweden, there are still only two production plants for LBG. Several shipping companies have stated that an advantage of LNG ships is that LBG could be used instead (interview transcripts related to Paper 2), but none of them had any plans to do so in the near future (Paper 2). Sanches-Pereira et al. carried out a study in 2015 on the relationship between natural gas and biogas, and found that the biogas agenda might result in an increase in natural gas imports in Sweden, and this seems to be a risk with the current trend towards vehicles and infrastructure that can use liquefied methane but with very limited LBG production. However, they also found that the future development of upgraded biogas could be hampered by natural gas being phased out, so even though LBG can enable more LNG use in some ways, the opposite may also be true.

\subsubsection{Manufacturing industries}

Biogas as a fuel for manufacturing industries depends to a large extent on the user, and can thus use raw biogas and biomethane from pipelines, CBG and LBG. If the manufacturer produces biogas itself, as in the case of Agroetanol, it can use the biogas directly (Paper 2). If the manufacturer is connected or close to a gas pipeline, like Arvid Nordquist, it can use biomethane from the pipeline (Paper 2). If the manufacturer is further away, like Toyota Material Handling, it can use LBG transported using trucks (Paper 2). However, the use of biogas in manufacturing industries is still quite limited (Figure 6). Recent policy changes might however change this, since the previous tax exemptions on fossil fuel use within manufacturing industries have now been removed (Swedish Tax Agency, 2018). The rising interest in LBG in Sweden today may also offer opportunities for more users, as it did for Toyota Material Handling. Manufacturers that are far away from both biogas production and gas pipelines have previously not had the chance to use biogas (Paper 2).

Among the manufacturing industries that use fossil fuels, 14.1 TWh, 9.9 TWh and 4.2 TWh of coal, oil products and natural gas respectively were used in 2017 (Swedish Energy Agency, 2019a). The steel and metal industry was responsible for half of this fossil fuel use (Swedish Energy Agency, 2019a), mainly due to its dependency on coal-fired furnaces to produce steel (Swedish Environmental Protection Agency, n.d.). A previous study by Johansson and Söderström (2011) found that some steel manufacturing could use methane instead, and at least one steel company has tried using biogas in its production (Energigas Sverige, 2017a). 
However, for substitution to biogas, it is mainly the industries using oil or natural gas that are most relevant. Of these, natural gas users could directly substitute natural gas for biogas, as Svenska Brasserier did for its stoves (Paper 2). Much of the natural gas used in manufacturing industries in Sweden is not used for direct energy purposes, but rather as a raw material for chemical production. However, some industries see the potential for biogas use (Energigas Sverige, 2017a). For oil products such as fuel oil or liquefied petroleum gas, the manufacturing facility would require parts of the current system to be rebuilt, since methane requires different equipment for components such as injectors and pipes (Paper 2). Due to this additional cost when starting to use biogas in manufacturing, biogas may be more relevant for industries with older facilities that need to be upgraded. LPG is cleaner than fuel oil, has a lower environmental impact and is cheaper, and several manufacturing plants have changed from fuel oil to LPG (Energigas Sverige, 2017b). There is thus a possibility that industries using oil will have older facilities than those using LPG, and that biogas may be of more interest as a replacement for oil in these older facilities. However, the manufacturing plants that have already switched to biogas in Sweden used either LPG or natural gas before switching (see the examples in Paper 2, Energigas Sverige, 2017a; Isberg, 2017).

\subsection{How can we assess whether biogas is suitable in a specific context?}

To find out whether something is suitable in a specific context, a systematic assessment is needed. Such an assessment can be carried out by applying a sustainability assessment tool that assesses relevant aspects.

\subsubsection{Assessment tools}

There are a number of different assessment tools that can be used to assess whether or not biogas is suitable in a specific case. For biogas, some sort of product-related assessment or integrated assessment is probably better, since suitability depends on the specific technology and usage area, but exactly which tool is best for biogas assessments will vary from case to case.

Paper 3 establishes a multi-criteria assessment method for alternative technologies for public buses. This method is intended as an aid in the early stages of public procurement processes, where users would be able to identify the optimal option for them, which is what Ness et al. (2007) explained that MCAs are used for. The goal was primarily to help make the issue more transparent so that decision-makers could decide for themselves how to balance the various important aspects. The participatory nature of this kind of MCA, where decision-makers can be involved in deciding on trade-offs, can be positive. According to Moser (2016), collaboration with stakeholders can increase the fit of the solutions to the actual needs of society, and Strantzali and Aravossis (2016) explain that objectives often differ between users, with the best fitting solution thus being highly dependent on the preferences of the decisionmaker. However, this can also be a significant risk with MCAs. According to Browne and Ryan (2011), value-laden weightings may be used and may lead to subjective, non-transparent bias.

As an integrated assessment tool, Multi-Criteria Assessment is primarily suitable for supporting decisions related to a policy or a project in a specific region (Ness et al., 2007). For 
smaller companies, it is possible that this will be too complex. Adding environmental considerations to a life cycle costing assessment, which is usually a common investment calculation, might be a better option.

Paper 4 uses another assessment option: socio-technical scenarios. Instead of focusing on a certain user, it focused on which fuel is suitable from a broader societal viewpoint, where the entire region was included. The study found that the environmental impact differed depending on what the biogas was used for - mainly due to which fuel biogas was substituted for. Although the manufacturing industry could substitute more of its current fuel than long-haul truck transportation due to differences in engine energy efficiency, long-haul trucks still represented a greater reduction in greenhouse gas emissions due to biogas having been substituted for diesel rather than LPG as in the manufacturing industry. This corresponds to the findings of other studies, such as Ammenberg et al. (2018) who identified a risk of replacing one renewable fuel with another without an alternative usage area for the substituted fuel. A scenario study similar to that in Paper 4 could thus, like Bunn and Salo (1993), be used for a strategic evaluation of different options to understand how a society will change in future depending on which choices are made.

\subsubsection{Which aspects should be part of an assessment?}

Which aspects should be included in an assessment depends on the usage area. For example, vehicles for city traffic will have more impact on noise and local air pollution than a manufacturer that uses biogas as a raw material for chemical production. There are many previous sustainability assessment studies that have based their assessments on the three pillars of sustainable development (i.e. environmental, social and economic aspects), such as Maoh and Kanaroglu (2009). However, there are also studies that have included other aspects, especially in relation to the fact that the alternative should function well - such as system effectiveness (e.g. system performance for transportation systems) in a study by Jeon et al. (2013), or Mitropoulos and Prevedouros (2014) who also considered technology performance and users. Since the user perspective is an important part of this research, this assessment includes two perspectives: 1) whether it is suitable according to the user, and 2) whether it is suitable considering more general social, environmental and economic aspects.

\section{User perspective}

The user perspective is based on what each specific user would find relevant to evaluate in order to see whether or not it suits them. The user is here defined as the user of the biogas, for example a bus operator.

In Paper 3, the MCA method was used together with relevant stakeholders of the alternatives studied, and identified a number of aspects that they considered important for assessing different fuels for buses - for example biogas. Some of these were technical issues related to the use of the technology - whether the technology could be used as needed by the user. In the case of buses, this was expressed as technical maturity, to ensure that the buses would function as they should and not experience problems, as well daily operational availability, to ensure that the buses would not need any additional stops during the day that would cost the user 
money. Economic issues were also found to be important. In the case of buses, this related to the cost of owning the bus, the cost of investments in infrastructure and cost stability.

Mitropoulos and Prevedouros (2014) included a user focus as part of their essential factors in their sustainability assessment for urban transportation vehicles. Similar to Paper 3, they considered day-time availability to be an important indicator for users, but they also included other indicators such as mobility, demand, delay, safety, leg room/cargo space, access time and fueling opportunities. The safety indicator could be of particular importance for biogas. Some stakeholders involved in one of the workshop sessions connected to Paper 3, held shortly after a biogas bus exploded in Stockholm after driving into a tunnel that was too low for the bus, were concerned about safety issues. Fueling opportunities, i.e. available locations for fueling, can also be important for biogas. Paper 1 shows that there are still areas of Sweden where there are long distances between biogas refueling stations - especially for liquefied biogas. However, for public buses, addressed by Paper 3, the issue of fueling opportunities is less relevant since there are often refueling possibilities at Swedish bus depots.

\section{The sustainability perspective}

Since public buses in Sweden are operated on behalf of the region, who have regional development as part of their work, Paper 3 also identified several aspects connected to general problems in the region rather than being specifically focused on buses and bus use - noise, air pollution, energy security, employment and local/regional impact on land and aquatic environments.

Since Paper 3 was based on regional viewpoints, with regional development and sustainability in mind, it included several aspects that are connected more to general sustainability issues than to the user's direct use of the technology. In terms of environmental aspects, it focused on e.g. GHG emissions - which the participants agreed upon was of central importance for the region. GHG emissions have also been used to compare different alternatives in many previous studies, such as Maoh and Kanaroglou (2009), who studied urban sustainability and where greenhouse gases from transport were one of the considerations, or Ahmadi Moghaddam et al. (2015), who studied different possible biogas-based fuels that could be used in buses and their respective greenhouse gas emissions. Another important aspect identified for public buses in Paper 3 was energy efficiency from a life cycle perspective, which is more important due to the fact that only engine efficiencies are considered. This was also considered an important area for Paper 4 - since the scenario study focused on the region rather than an individual actor, a life cycle perspective on energy efficiency was much more appropriate for the study. One example is the way Swedish public buses were previously assessed only on the basis of engine efficiency. According to Gustafsson et al. (2018), it would be beneficial to have a longer well-to-wheel perspective. Other studies, such as Mitropoulos and Prevedouros (2014), also focused on a broader perspective for energy efficiency than simply engine efficiency.

Other important environmental aspects identified through the collaborative process in connection with Paper 3 were air pollution, noise and local/regional impact on land and aquatic environments. These issues have also been included in other assessment studies. Maoh and Kanaroglou (2009) considered PM and NOx air pollution and noise to be social indicators rather than environmental indicators, since they affect the health of individuals. However, there 
are also studies that, like Paper 3, count air pollution and noise as environmental impact, for example Mitropoulos and Prevedouros (2014). In their studies evaluating urban sustainability, Maoh and Kanaroglou (2009) also separated out several issues that could be considered for the local/regional impact on land and aquatic environment, such as acidifying gases, land coverage, volatile organic compounds and fragmentation of open space.

In terms of social aspects, Paper 3 only included an indicator for energy security and employment, although other indicators were also discussed, such as synergies between sociotechnical synergies. Maoh and Kanaroglou (2009) did not focus on these aspects, instead considering several other social aspects such as opportunities for the vitality of the city center and the surrounding region and the fair distribution of economic benefits. The vitality of the surrounding region in particular could be impacted to a large degree by whether or not biogas is used, since biogas often has strong regional ties via substrates, production and digestate.

Since the study in Paper 3 was more focused on what was important for users and the regions that procure bus services, economic considerations were also more focused on this. Other studies have had a more societal focus, such as Maoh and Kanaroglou (2009) who studied the urban sustainability of transport and who took a societal perspective, emphasizing the benefits from the transport option particularly considering issues such as investment and operational costs, user benefits and external costs for accidents and other health issues.

\subsection{What determines whether it is easy or difficult for a user to start using biogas?}

According to the findings in the appended papers, six main areas affect how easy or difficult it is for a user to start using biogas: technological maturity, tank volume, distance between the producer and the user, scale of energy use, policies and costs, and strategies of individual organizations.

\subsubsection{Technical maturity}

One requirement for any kind of introduction is that the technology is sufficiently developed to be an interesting alternative. The participatory study in Paper 3 found that the potential users of buses, where biogas was one alternative, thought of technical maturity as an important aspect to consider since newer technologies are more prone to failure. Kemp et al. (1998) also add that new technologies can face different difficulties compared to more mature technologies. In addition to small scales of production leading to more expensive production, they often have to confront suboptimal policies, skepticism regarding "strange" solutions, competition with the companies' current solutions and lack of infrastructure. A lack of infrastructure was also noted as a barrier in Paper 2, where the interviewed potential biogas users pointed out that they experienced this as a barrier to biogas implementation. Some companies also mentioned the fact that the existing technologies were not yet sufficiently developed to be suitable for their purposes. This difficulty with gas infrastructure is corroborated by Börjesson and Ahlgren (2012), who explain that gas distribution is a central problem in terms of enabling the best use of the available biogas potential. 


\subsubsection{Tank volume}

An important aspect to consider for biogas is that it is a gaseous fuel, and thus requires a large volume (Paper 1). All different fuels that can be produced from biogas depart from the edict of increasing the concentration of energy in the fuel, by concentrating it, compressing it, liquefying it or converting it into a more manageable energy carrier (Paper 1). The concentration of energy in the fuel will have a large effect on the possible uses for biogas, since more fuel-intense users require more energy, and if a higher energy demand requires larger volumes than what is possible for the vehicle, biogas cannot be introduced. It is thus paramount for the possibility of introducing biogas-based fuels that the fuel requires an acceptable amount of volume for storage, and this differs depending on the circumstances. Light vehicles are less energy intense and can thus use a fuel with a lower energy concentration, while heavy freight road vehicles or ships require very large volumes to store enough compressed biomethane, for example. This aspect has also been identified as important in other studies. Toyota Material Handling did not introduce biogas until there was a version with a higher energy concentration - LBG (Paper 3). Biogas has not been considered an option for double-decker buses due to the bulky nature of the fuel tanks (Paper 4).

\subsubsection{Distance between the producer and the user}

A related issue is the distance between the producer and the user. Since the gas grid in Sweden is very limited, biogas has been limited in the rest of the country to being transported via trucks. It is possible to extend the gas grid, and this was done for Arvid Nordquist when the company planned to start using biogas (Paper 2). However, the extension was only extremely short and Arvid Nordquist explained that moving production to a new site with no nearby grid or production would result in the company being unable to use biogas. Being restricted to trucks carrying CBG - the only option until the recent rise in LBG production - has limited the geographical area in which biogas can be used, since CBG is very voluminous and takes up too much space in trucks for long-distance transportation to be efficient. Ahmadi Moghaddam et al. (2015) showed this difficulty in their study of different biogas-based fuels: while CBG was the most energy efficient option over smaller distribution distances, it became the worst option when the distribution distances increased. However, the rise in LBG production brings new opportunities to increase the market from a local/regional scale to a more national scale. With its higher energy concentration and subsequently more efficient distribution via trucks, LBG has the potential to be used further away from its production -thus achieving a function similar to that of a fully developed gas pipeline system, where the market for gas becomes more national.

\subsubsection{Scale of energy use}

The scale of the energy use for potential users is another area that can make matters more or less difficult for a potential user.

Almost half of the interviewed companies in Paper 2, especially the shipping companies, explained that the scale of biogas production was currently too small to be a relevant option for them. Ships often require large amounts of fuel. According to Stena Line, a single ferry has an average yearly fuel use on the same scale as the annual production of the largest biogas production plant in Sweden. It would be very difficult to manage any large-scale high-blend 
substitution to LBG in the near future when each ship requires all the fuel produced by a facility, or more. Hansson et al. (2019) identified a similar difficulty, and noted that LBG is currently only of interest for minor applications in short-distance sea shipping or as low-blends in LNG. The manufacturing sector may experience similar difficulties. In the region studied in Paper 4, there were three identified major concentrations with annual LPG use of 80-130 GWh - roughly the same scale as the largest biogas production plants in Sweden. However, manufacturing plants exist in many different sizes, and there are also a number of plants that currently use smaller amounts of fossil fuels that could easily be covered by the scale of biogas production. It is mainly such smaller plants where biogas could be a relevant alternative.

In contrast to shipping, the heavy road vehicle sector consists of many small, moving units that need to be able to refuel in different places (Paper 1). However, each moving unit has been too fuel-consuming for biogas to be relevant before the introduction of LBG. Although each moving unit is small, the sector as a whole is large (Swedish Government Official Reports, 2013), which means that switching to biogas will not have any large effect on the entire sector due to the lack of scale of biogas production, only on limited parts of it.

\subsubsection{Policies and costs}

Users will incur investment costs when starting to use biogas, as experienced by Toyota Material Handling, Agroetanol and Arvid Nordquist in Paper 2. The fuel price of biogas will in turn be affected by the investment costs for starting to produce biogas. The price of biogas can also be affected by the plant's operating costs and the distribution costs for biogas, as well as by potential costs for the substrate and potential gains from digestate sales. Policies affect the development of biogas solutions through changes in conditions for the production and use of biogas, which in turn affect the price of the fuel - such as investments grants, environmental permits for production, tax reductions on using the fuel and subsidies for certain substrates.

\section{Policies as drivers}

Policies are often seen as enablers, for example in the case of CNG vehicles in New Zealand in the 1980s, when CNG vehicles rose to $10 \%$ of the national fleet over the course of seven years with various grants, loans etc. (Paper 1). The current gradual phasing out of fossil fuel tax exemptions in Sweden has made manufacturing companies more interested in renewable alternatives (Swedish Tax Agency, 2018). The tax exemption of renewable fuels within the road transport sector has encouraged the growth of biogas use within transportation, and emission controls has resulted in greater interest in LNG for shipping (Paper 2).

\section{Policies as barriers}

However, policies can also make it more difficult to introduce biogas, depending on how the policy instruments are shaped. The policy structures for shipping differ from other transportation options since much of shipping is international and thus hard to regulate via national policies; furthermore, those policies that do exist are not always positive for biogas (Paper 2). For three of the four interviewed shipping companies, policies acted as barriers since fossil fuels were tax exempt but not necessarily renewable fuels (Paper 2). As a result, they stated that biogas was simply too expensive (Paper 2). Hansson et al. (2019) studied both LNG and LBG as alternative fuels for shipping in an MCA study, finding that fuel price was 
considered the most important criterion by ship owners. They also found that LNG was often seen as preferable to the other studied fuels due to its low fuel price, but according to their literature-based study, the price of LBG was estimated to be more than double that of LNG (Hansson et al., 2019).

Other companies described difficulties relating to the unreliability of the current policies, which made it difficult to make investments in biogas. The road transport sector is especially affected by unreliable policies, since the tax exemption there (Swedish Tax Agency, 2019) is based on a dispensation from EU that only covers the next few years (Energigas Sverige, 2018). The road transport sector has also previously experienced rapid changes in the policy landscape regarding RME (Paper 2).

Policies were also found to be a consideration when deciding between different bus technologies, according to some stakeholders related to Paper 3. The indicator "price stability" was established to consider current policies and their stability, as well as potential effects on prices if they were changed.

\subsubsection{Strategies of organizations}

Ultimately, how influential different factors are in connection with biogas introduction depends on the ambitions and strategies of different organizations to actually take the step and introduce biogas - either as users themselves or as buyers of services where they have a strong influence over which fuel is used. When it comes to new technologies, not everyone starts to use them at the same time - some adopt new technologies earlier, while others do so later (Schilling, 2017). The strategies of individual organizations may depend on values and attitudes, i.e. how important environmental actions and profiling are for various companies. Family businesses seem prioritize environmental actions in their values and attitudes due to intergenerational thinking, which is not often mentioned in the renewable energy adoption literature. Of three interviewed family businesses, two had already switched to biogas and they both emphasized that being a family-owned business gave them an intergenerational perspective. The other family business, a shipping company, also emphasized that its sustainability work was steered by its owners, but that they were mainly looking at other renewable fuel options. Family businesses and intergenerational thinking are, however, connected to long-term thinking, and were identified by Afshar Jahanshahi et al. (2017) as one of three groups of entrepreneurs who care more about sustainability, and who feel more commitment towards future generations. 


\section{Conclusions}

The aim of this research was to investigate what biogas should be used for in a future more sustainable energy system, focusing on Sweden, by answering three research questions:

- In what ways can biogas be used in a more sustainable energy system?

- How can we assess whether biogas is suitable in a specific context?

- What determines whether it is easy or difficult for a user to start using biogas?

Biogas can be used to generate heat or electricity, or as fuel for manufacturing or transport. Heat and electricity are mainly of interest on smaller production scales since biogas can be used directly and with smaller investments. For transport, a higher energy content is required and biogas thus has to be reformed into other fuels - most commonly CBG and LBG. There are, however, also possibilities of producing methanol, hydrogen, DME and Fischer-Tropsch fuels, even though these alternatives are not likely to play an important role in biogas use in the near future. CBG and LBG can be used for different parts of the transport system, such as cars or buses for $\mathrm{CBG}$ or long-distance trucks or shipping for LBG.

Several different methods can be used to evaluate whether biogas is suitable in a specific context. This study has particularly focused on Multi-Criteria Assessment and scenario analysis, which can be appropriate in different contexts. Several aspects should be considered in an assessment relating to biogas. From a user perspective, technical issues to ensure that the technology functions as it should and does not experience any problems are important, as are economic issues relating to investment and operating costs. From a sustainability perspective, several different environmental aspects - such as GHG emissions - should be considered. Regarding economics, it may be beneficial to take a broader perspective and include aspects such as user benefits and external costs rather than investment and operating costs. There are also several social aspects that could be of importance when assessing biogas, especially the vitality of the surrounding region.

Six main factors were identified that can make it easier or more difficult to introduce biogas:

- technical maturity,

- tank volume,

- distance between the producer and the user,

- scale of energy use,

- policies and costs, and

- strategies of individual organizations.

Challenges relating to new innovations make it more difficult to introduce biogas technologies that lack technological maturity, and the voluminous CBG makes it difficult to use biogas for more energy-intense purposes or to distribute it using trucks. However, this gap is being bridged by the introduction of LBG. The scale of production of biogas is often limited, making it more difficult to use biogas for single users that need large amounts of energy such as large ships or manufacturing plants. Policies can both enable and hinder the introduction of biogas, depending on how the policy instruments are shaped. Ultimately, however, it is individual 
organizations that decide whether or not to introduce biogas, and this is often affected by their respective strategies.

Overall, the rise in LBG production creates new opportunities for biogas use. In Sweden, biogas has previously been restricted to the limited gas grid that exists in the southwestern part of the country, or to regional contexts due to the low energy concentration of CBG that results in inefficient distribution. LBG, with its higher energy concentration and subsequently more efficient distribution, will make it possible to use this fuel further away from its production, thus achieving a function that is similar to that of a fully developed gas grid, where the market for gas becomes more national. LBG also enables the use of biogas in new areas such as heavy transport and shipping. Since LNG is becoming increasingly important as a fuel for shipping, this presents opportunities for an almost unlimited usage area for biogas considering the large amount of energy used in the shipping sector. However, these large energy demands also makes it unlikely that biogas will ever play a major role as a fuel for shipping. It was also found to be difficult to make such a change towards LBG due to increased fuel costs in comparison to LNG, and since much of the market is international, national policies favoring biogas are not able to counter this discrepancy easily.

There is no simple answer to the question of what biogas should be used for in a more sustainable future energy system - rather, it depends on the circumstances. The results suggest that small-scale biogas production should be used mainly for heat and/or electricity generation, since this requires less investment, but this seems unlikely at present since it is hard to make these processes profitable in Sweden. There are, however, opportunities to use biogas for balancing power, which might make it more relevant in a future with more intermittent power sources and volatile electricity prices. For larger scale biogas production, biogas is likely to be dominated by the production of $\mathrm{CBG}$ and $\mathrm{LBG}$, for use in vehicles or manufacturing industries. CBG is already used on a large scale in Sweden, and recent changes indicate that LBG is on the rise. That is, however, considering a short timeframe - in 50 years, biogas may be more interesting for other uses. Hydrogen and fuel cells are seen by many as applications that will play a major role in the future, and if this development occurs on a large scale it may be more relevant in the future to use biogas to produce hydrogen. Biogas does not necessarily have to be used in the same way now as it will be used in a couple of decades - if it is used as CBG or LBG now, there will be time to switch to hydrogen use in the future if society moves in that direction instead.

\subsection{Future research}

Interesting areas for future research including addressing specific possible usage areas for biogas in greater depth. Three areas are particularly interesting to study in relation to increased LBG development: heavy road transport, shipping and manufacturing industries. Some manufacturing industries have already switched to biogas, or plan to do so in the near future, and a more in-depth study of these cases to establish what drove the change, and how this was achieved, could be relevant. It could also be relevant to look at the manufacturing industries and biogas from a larger, more systems-focused perspective. Within shipping, it would be worth digging deeper into the potential of biogas as LBG, and within heavy road transport it could be of great value to look at the possibilities of using biogas - where it is suitable, and where is it currently hardest to find other renewable fuels. 
Other areas of interest include continue to work on the development of the MCA assessment tool - not only by applying the established assessment method for buses, but also by looking into how it can be adapted for other usage areas such as long-distance freight trucks. It could also be interesting to combine multi-criteria assessment with scenario analysis for an assessment of biogas. 


\section{References}

Abatzoglou, N., Boivin, S., 2009. A review of biogas purification processes. Biofuels Bioprod. Biorefining 3, 42-71. https://doi.org/10.1002/bbb.117

Afshar Jahanshahi, A., Brem, A., Bhattacharjee, A., 2017. Who Takes More Sustainability-Oriented Entrepreneurial Actions? The Role of Entrepreneurs' Values, Beliefs and Orientations. Sustainability 9, 1636. https://doi.org/10.3390/su9101636

Ahmadi Moghaddam, E., Ahlgren, S., Hulteberg, C., Nordberg, Å., 2015. Energy balance and global warming potential of biogas-based fuels from a life cycle perspective. Fuel Process. Technol. 74-82.

Alburquerque, J.A., de la Fuente, C., Ferrer-Costa, A., Carrasco, L., Cegarra, J., Abad, M., Bernal, M.P., 2012. Assessment of the fertiliser potential of digestates from farm and agroindustrial residues. Biomass Bioenergy 40, 181-189. https://doi.org/10.1016/j.biombioe.2012.02.018

Ammenberg, J., Anderberg, S., Lönnqvist, T., Grönkvist, S., Sandberg, T., 2018. Biogas in the transport sector-actor and policy analysis focusing on the demand side in the Stockholm region. Resour. Conserv. Recycl. 129, 70-80. https://doi.org/10.1016/j.resconrec.2017.10.010

Angelidaki, I., Treu, L., Tsapekos, P., Luo, G., Campanaro, S., Wenzel, H., Kougias, P.G., 2018. Biogas upgrading and utilization: Current status and perspectives. Biotechnol. Adv. 36, 452-466. https://doi.org/10.1016/j.biotechadv.2018.01.011

Armaroli, N., Balzani, V., 2007. The Future of Energy Supply: Challenges and Opportunities. Angew. Chem. Int. Ed. 46, 52-66. https://doi.org/10.1002/anie.200602373

Association Technique Energie Environment, 2018. Statistiques filière biogaz - Juillet 2018 [Statistics biogas sector - July 2018].

Auvinen, H., Ruutu, S., Tuominen, A., Ahlqvist, T., Oksanen, J., 2015. Process supporting strategic decision-making in systemic transitions. Technol. Forecast. Soc. Change 94, 97-114. https://doi.org/10.1016/j.techfore.2014.07.011

Azar, C., Lindgren, K., 2003. Global energy scenarios meeting stringent $\mathrm{CO} 2$ constraints - costeffective fuel choices in the transportation sector. Energy Policy 16.

Bachmann, N., 2013. Swiss Country Report. IEA Bioenergy.

Baier, U., Buchs, M., Hermle, S., 2018. Switzerland - 2018 update. Bioenergy policies and status of implementation. IEA Bioenergy.

Bauer, F., Persson, T., Hulteberg, C., Tamm, D., 2013. Biogas upgrading - technology overview, comparison and perspectives for the future. Biofuels Bioprod. Biorefining 7, 499-511. https://doi.org/10.1002/bbb.1423

Bengtsson, S., Fridell, E., Andersson, K., 2014. Fuels for short sea shipping: A comparative assessment with focus on environmental impact. J. Eng. Marit. Environ. 228, 44-54. https://doi.org/10.1177/1475090213480349

Bengtsson, S., Fridell, E., Andersson, K., 2012. Environmental assessment of two pathways towards the use of biofuels in shipping. Energy Policy 44, 451-463. https://doi.org/10.1016/j.enpol.2012.02.030

Bergek, A., Jacobsson, S., Carlsson, B., Lindmark, S., Rickne, A., 2008. Analyzing the functional dynamics of technological innovation systems: A scheme of analysis. Res. Policy 37, 407429. https://doi.org/10.1016/j.respol.2007.12.003

Beria, P., Maltese, I., Mariotti, I., 2012. Multicriteria versus Cost Benefit Analysis: a comparative perspective in the assessment of sustainable mobility. Eur. Transp. Res. Rev. 4, 137-152. https://doi.org/10.1007/s12544-012-0074-9

Bioenergitidningen, 2018. Klimatklivet beviljar Gasum stöd för etablering av biogas- och LNGstationer för tunga transporter [Klimatklivet grants Gasum support for establishing biogas 
and LNG stations for heavy vehicles] [WWW Document]. 2018-10-01. URL

https://bioenergitidningen.se/biodrivmedel-transport/klimatklivet-beviljar-gasum-stod-foretablering-av-biogas-och-Ing-stationer-for-tunga-transporter (accessed 10.5.18).

Blumenstein, B., Siegmeier, T., Möller, D., 2016. Economics of anaerobic digestion in organic agriculture: Between system constraints and policy regulations. Biomass Bioenergy $86,105-$ 119. https://doi.org/10.1016/j.biombioe.2016.01.015

Börjesson, M., Ahlgren, E.O., 2012. Cost-effective biogas utilisation - A modelling assessment of gas infrastructural options in a regional energy system. Energy 48, 212-226.

Boston, A., 2013. Delivering a secure electricity supply on a low carbon pathway. Energy Policy 52, 55-59. https://doi.org/10.1016/j.enpol.2012.02.004

Browne, D., Ryan, L., 2011. Comparative analysis of evaluation techniques for transport policies. Environ. Impact Assess. Rev. 31, 226-233. https://doi.org/10.1016/j.eiar.2010.11.001

Bryman, A., 2015. Social research methods, 5th edition. ed. Oxford university press.

Brynolf, S., Fridell, E., Andersson, K., 2014. Environmental assessment of marine fuels: liquefied natural gas, liquefied biogas and bio-methanol. J. Clean. Prod. 74, 86-95. https://doi.org/10.1016/j.jclepro.2014.03.052

Bunn, D.W., Salo, A.A., 1993. Forecasting with scenarios. Eur. J. Oper. Res. 68, 291-303. https://doi.org/10.1016/0377-2217(93)90186-Q

Bussmagasinet, 2017. 32 elbussar till Malmö.

Bussmagasinet, 2016. Värnamo första elektriska stad i Sverige.

Chertow, M.R., 2000. Industrial Symbiosis: Literature and Taxonomy. Annu. Rev. Energy Environ. 25, 313-337. https://doi.org/10.1146/annurev.energy.25.1.313

Cherubini, F., Bargigli, S., Ulgiati, S., 2009. Life cycle assessment (LCA) of waste management strategies: Landfilling, sorting plant and incineration. Energy 34, 2116-2123. https://doi.org/10.1016/j.energy.2008.08.023

Connolly, D., Lund, H., Mathiesen, B.V., Leahy, M., 2011. The first step towards a $100 \%$ renewable energy-system for Ireland. Appl. Energy 88, 502-507. https://doi.org/10.1016/j.apenergy.2010.03.006

Cuéllar, A.D., Webber, M.E., 2008. Cow power: the energy and emissions benefits of converting manure to biogas. Environ. Res. Lett. 3, 034002. https://doi.org/10.1088/17489326/3/3/034002

Daimler, 2018. Daimler Trucks at a Glance Edition 2018.

Danish Energy Agency, 2018. Perspektiver for produktion og anvendelse af biogas i Danmark [Perspectives for the production and use of biogas in Denmark].

Demirbas, A., 2007. Progress and recent trends in biofuels. Prog. Energy Combust. Sci. 33, 1-18. https://doi.org/10.1016/j.pecs.2006.06.001

DNV GL, 2016. Full list of LNG vessels in operation and on order (as of March 2016).

Energigas Sverige, 2018. Biogas fortsatt skattefri [WWW Document]. Energigas Sver. URL https://www.energigas.se/om-oss/nyheter-och-press/nyheter/biogas-fortsatt-skattefri/ (accessed 10.9.19).

Energigas Sverige, 2017a. "Sverige behöver en strategi för att maximera nyttan av biogas" [WWW Document]. Energigas Sver. URL https://www.energigas.se/om-oss/nyheter-ochpress/debattartiklar/sverige-behoever-en-strategi-foer-att-maximera-nyttan-av-biogas/ (accessed 10.26.19).

Energigas Sverige, 2017b. Olja mot gasol gav renare stålverk [WWW Document]. URL http://www.energigas.se/publikationer/tidningen-energigas/olja-mot-gasol-gav-renarestaalverk/ (accessed 11.27.18).

Erkman, S., 1997. Industrial ecology: An historical view. J. Clean. Prod. 5, 1-10. https://doi.org/10.1016/S0959-6526(97)00003-6 
Fallde, M., Eklund, M., 2015. Towards a sustainable socio-technical system of biogas for transport: the case of the city of Linköping in Sweden. J. Clean. Prod. 98, 17-28. https://doi.org/10.1016/j.jclepro.2014.05.089

Feiz, R., Ammenberg, J., 2017. Assessment of feedstocks for biogas production, part I-A multicriteria approach. Resour. Conserv. Recycl. 122, 373-387. https://doi.org/10.1016/j.resconrec.2017.01.019

Fierro, J., Gómez, X., Murphy, J.D., 2014. What is the resource of second generation gaseous transport biofuels based on pig slurries in Spain? Appl. Energy 114, 783-789. https://doi.org/10.1016/j.apenergy.2013.08.024

Fischer, R., Elfgren, E., Toffolo, A., 2018. Energy Supply Potentials in the Northern Counties of Finland, Norway and Sweden towards Sustainable Nordic Electricity and Heating Sectors: A Review. Energies 11, 751. https://doi.org/10.3390/en11040751

Fordonsgas, 2018. Kommande etableringar | Snart öppnar vi flera nya tankstationer för flytande gasenergi. FordonsGas. URL https://fordonsgas.se/kommande-etableringar/ (accessed 10.9.19).

Foxon, T.J., 2013. Transition pathways for a UK low carbon electricity future. Energy Policy 52, 10 24. https://doi.org/10.1016/j.enpol.2012.04.001

Fridas användarförening, 2019. FRIDA miljö- och fordonsdatabas [WWW Document]. URL http://www.frida.port.se/hemsidan/default.cfm

Geels, F.W., 2011. The multi-level perspective on sustainability transitions: Responses to seven criticisms. Environ. Innov. Soc. Transit. 1, 24-40. https://doi.org/10.1016/j.eist.2011.02.002

Geels, F.W., 2002. Technological transitions as evolutionary reconfiguration processes: a multi-level perspective and a case-study. Res. Policy 31, 1257-1274.

Geels, F.W., McMeekin, A., Pfluger, B., 2018. Socio-technical scenarios as a methodological tool to explore social and political feasibility in low-carbon transitions: Bridging computer models and the multi-level perspective in UK electricity generation (2010-2050). Technol. Forecast. Soc. Change. https://doi.org/10.1016/j.techfore.2018.04.001

Gluch, P., Baumann, H., 2004. The life cycle costing (LCC) approach: a conceptual discussion of its usefulness for environmental decision-making. Build. Environ. 39, 571-580. https://doi.org/10.1016/j.buildenv.2003.10.008

Grove, R.H., 1992. Origins of Western Environmentalism. Sci. Am. 267, 42-47. https://doi.org/10.1038/scientificamerican0792-42

Gunaseelan, V.N., 1997. Anaerobic Digestion of Biomass for Methane Production. Biomass Bioenergy 13.

Gustafsson, M., Svensson, N., Anderberg, S., 2018. Energy performance indicators as policy support for public bus transport - The case of Sweden. Transp. Res. Part Transp. Environ. 65, 697709. https://doi.org/10.1016/j.trd.2018.10.008

Hagman, L., Blumenthal, A., Eklund, M., Svensson, N., 2018. The role of biogas solutions in sustainable biorefineries. J. Clean. Prod. 172, 3982-3989. https://doi.org/10.1016/j.jclepro.2017.03.180

Hagman, L., Eklund, M., 2016. The role of biogas solutions in the circular and bio-based economy, Biogas Research Center Report. Biogas Research Center, Linköping University.

Hakawati, R., Smyth, B.M., McCullough, G., De Rosa, F., Rooney, D., 2017. What is the most energy efficient route for biogas utilization: Heat, electricity or transport? Appl. Energy 206, 10761087. https://doi.org/10.1016/j.apenergy.2017.08.068

Hansson, J., Månsson, S., Brynolf, S., Grahn, M., 2019. Alternative marine fuels: Prospects based on multi-criteria decision analysis involving Swedish stakeholders. Biomass Bioenergy 126, 159173. https://doi.org/10.1016/j.biombioe.2019.05.008

Häring, G., Sonnleitner, M., Bär, K., Brown, N., Zörner, W., 2017. Demonstration of Controllable Electricity Production via Biogas Plants. Chem. Eng. Technol. 40, 298-305. https://doi.org/10.1002/ceat.201600195 
Hedlund, C., 2017. Efter beställningen - nu har Eskilstuna flest elbussar i trafik. SVT Nyheter.

Hekkert, M.P., Suurs, R.A.A., Negro, S.O., Kuhlmann, S., Smits, R.E.H.M., 2007. Functions of innovation systems: A new approach for analysing technological change. Technol. Forecast. Soc. Change 74, 413-432. https://doi.org/10.1016/j.techfore.2006.03.002

Hillman, K.M., Sandén, B.A., 2008. Exploring technology paths: The development of alternative transport fuels in Sweden 2007-2020. Technol. Forecast. Soc. Change 75, 1279-1302. https://doi.org/10.1016/j.techfore.2008.01.003

Hofman, P.S., Elzen, B.E., Geels, F.W., 2004. Sociotechnical scenarios as a new policy tool to explore system innovations: Co-evolution of technology and society in The Netherland's electricity domain. Innovation 6, 344-360. https://doi.org/10.5172/impp.2004.6.2.344

Holm, P., Goodsite, M.E., Cloething, S., Agnoletti, M., Moldan, B., Lang, D.J., Leemans, R., Moeller, J.O., Buendía, M.P., Pohl, W., Scholz, R.W., Sors, A., Vanheusden, B., Yusoff, K., Zondervan, R., 2013. Collaboration between the natural, social and human sciences in Global Change Research. Environ. Sci. Policy 28, 25-35. https://doi.org/10.1916/j.envsci.2012.11.010

Hughes, T.P., 1987. The Evolution of Large Technological Systems, in: The Social Construction of Technological Systems.

Huopana, T., Song, H., Kolehmainen, M., Niska, H., 2013. A regional model for sustainable biogas electricity production: A case study from a Finnish province. Appl. Energy 102, 676-686. https://doi.org/10.1016/j.apenergy.2012.08.018

Huttunen, M.J., Kuittinen, V., Lampinen, A., 2017. Suomen biokaasulaitosrekisteri N:O 21 [Finish Biogas Register No. 21]. University of Eastern Finland.

Intergovernmental Panel on Climate Change, 2018. Global warming of $1.5^{\circ} \mathrm{C}$.

Intergovernmental Panel on Climate Change (Ed.), 2007. Climate change 2007 - Mitigation of climate change: contribution of Working Group III to the fourth assessment report of the Intergovernmental Panel on Climate Change. Cambridge Univ. Pr, Cambridge, Mass.

International Energy Agency, 2018. Key World Energy Statistics 2018.

International Energy Agency, 2016. Key world energy statistics.

Isberg, C., 2017. HK Scan satsar miljoner på biogas. Kristianstadsbladet.

Jacobson, M.Z., Delucchi, M.A., 2011. Providing all global energy with wind, water, and solar power, Part I: Technologies, energy resources, quantities and areas of infrastructure, and materials. Energy Policy 39, 1154-1169. https://doi.org/10.1016/j.enpol.2010.11.040

Janic, M., 2003. Multicriteria Evaluation of High-speed Rail, Transrapid Maglev and Air Passenger Transport in Europe. Transp. Plan. Technol. 26, 491-512. https://doi.org/10.1080/0308106032000167373

Jeon, C.M., Amekudzi, A.A., Guensler, R.L., 2013. Sustainability assessment at the transportation planning level: Performance measures and indexes. Transp. Policy 25, 10-21. https://doi.org/10.1016/j.tranpol.2012.10.004

Johansson, M.T., Söderström, M., 2011. Options for the Swedish steel industry - Energy efficiency measures and fuel conversion. Energy 26, 191-198. https://doi.org/10.1016/j.energy.2010.10.053

Kalinichenko, A., Havrysh, V., Perebyynis, V., 2016. Evaluation of Biogas Production and Usage Potential. Ecol. Chem. Eng. S 23. https://doi.org/10.1515/eces-2016-0027

Kanase-Patil, A.B., Saini, R.P., Sharma, M.P., 2010. Integrated renewable energy systems for off grid rural electrification of remote area. Renew. Energy 35, 1342-1349. https://doi.org/10.1016/j.renene.2009.10.005

Kates, R.W., Clark, W.C., Corell, R., Hall, J.M., Jaeger, C.C., Lowe, I., McCarthy, J.J., Schellnhuber, H.J., Bolin, B., Dickson, N.M., Faucheux, S., Gallopin, G.C., Grübler, A., Huntley, B., Jäger, J., Jodha, N.S., Kasperson, R.E., Mabogunje, A., Matson, P., Mooney, H., Moore, B.I., O'Riordan, T., Svedin, U., 2001. Sustainability Science. Science 292, 641-642. 
Kemp, R., Loorbach, D., Rotmans, J., 2007. Transition management as a model for managing processes of co-evolution towards sustainable development. Int. J. Sustain. Dev. World Ecol. 14, 78-91. https://doi.org/10.1080/13504500709469709

Kemp, R., Schot, J., Hoogma, R., 1998. Regime shifts to sustainability through processes of niche formation: The approach of strategic niche management. Technol. Anal. Strateg. Manag. 10, 175-198. https://doi.org/10.1080/09537329808524310

Kowalski, K., Stagl, S., Madlener, R., Omann, I., 2009. Sustainable energy futures: Methodological challenges in combining scenarios and participatory multi-criteria analysis. Eur. J. Oper. Res. 197, 1063-1074. https://doi.org/10.1016/j.ejor.2007.12.049

Krajačić, G., Duić, N., Carvalho, M. da G., 2009. H2RES, Energy planning tool for island energy

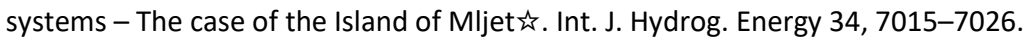
https://doi.org/10.1016/j.ijhydene.2008.12.054

Kummamuru, B., 2017. WBA Global Bioenergy Statistics 2017. World Bioenergy Association. Ladanai, S., Vinterbäck, J., 2009. Global Potential of Sustainable Biomass for Energy (No. Report 013). Swedish University of Agricultural Sciences, Uppsala.

Lajunen, A., 2014. Energy consumption and cost-benefit analysis of hybrid and electric city buses. Transp. Res. Part C Emerg. Technol. 38, 1-15. https://doi.org/10.1016/j.trc.2013.10.008

Lantz, M., 2012. The economic performance of combined heat and power from biogas produced from manure in Sweden - A comparison of different CHP technologies. Appl. Energy 98, 502511.

Lantz, M., Svensson, M., Björnsson, L., Börjesson, P., 2007. The prospects for an expansion of biogas systems in Sweden-Incentives, barriers and potentials. Energy Policy 35, 1830-1843. https://doi.org/10.1016/j.enpol.2006.05.017

Lärka, P., 2016. Här är Ängelholms nya elbuss. SVT Nyheter.

Larsson, M., Grönkvist, S., Alvfors, P., 2016. Upgraded biogas for transport in Sweden - effects of policy instruments on production, infrastructure deployment and vehicle sales. J. Clean. Prod. 112, 3774-3784. https://doi.org/10.1016/j.jclepro.2015.08.056

Lauer, M., Dotzauer, M., Hennig, C., Lehmann, M., Nebel, E., Postel, J., Szarka, N., Thrän, D., 2017. Flexible power generation scenarios for biogas plants operated in Germany: impacts on economic viability and GHG emissions: Flexible power generation scenarios for biogas plants. Int. J. Energy Res. 41, 63-80. https://doi.org/10.1002/er.3592

Lauer, M., Leprich, U., Thrän, D., 2020. Economic assessment of flexible power generation from biogas plants in Germany's future electricity system. Renew. Energy 146, 1471-1485. https://doi.org/10.1016/j.renene.2019.06.163

Lauer, M., Thrän, D., 2017. Biogas plants and surplus generation: Cost driver or reducer in the future German electricity system? Energy Policy 109, 324-336. https://doi.org/10.1016/j.enpol.2017.07.016

Laurent, A., Olsen, S.I., Hauschild, M.Z., 2012. Limitations of Carbon Footprint as Indicator of Environmental Sustainability. Environ. Sci. Technol. 46, 4100-4108. https://doi.org/10.1021/es204163f

Lauven, L.-P., Geldermann, J., Desideri, U., 2019. Estimating the revenue potential of flexible biogas plants in the power sector. Energy Policy 128, 402-410. https://doi.org/10.1016/j.enpol.2019.01.007

Longhofer, W., Schofer, E., 2010. National and Global Origins of Environmental Association. Am. Sociol. Rev. 75, 505-533. https://doi.org/10.1177/0003122410374084

Loorbach, D., 2010. Transition management for sustainable development: a prescriptive, complexitybased governance framework. Governance 23, 161-183.

Lund, H., Mathiesen, B.V., 2009. Energy system analysis of $100 \%$ renewable energy systems-The case of Denmark in years 2030 and 2050. Energy 34, 524-531. https://doi.org/10.1016/j.energy.2008.04.003 
Magnusson, T., Berggren, C., 2018. Competing innovation systems and the need for redeployment in sustainability transitions. Technol. Forecast. Soc. Change 126, 217-230.

https://doi.org/10.1016/j.techfore.2017.08.014

Mahmoud, M., Liu, Y., Hartmann, H., Stewart, S., Wagener, T., Semmens, D., Stewart, R., Gupta, H., Dominguez, D., Dominguez, F., Hulse, D., Letcher, R., Rashleigh, B., Smith, C., Street, R., Ticehurst, J., Twery, M., van Delden, H., Waldick, R., White, D., Winter, L., 2009. A formal framework for scenario development in support of environmental decision-making. Environ. Model. Softw. 24, 798-808. https://doi.org/10.1016/j.envsoft.2008.11.010

Mao, C., Feng, Y., Wang, X., Ren, G., 2015. Review on research achievements of biogas from anaerobic digestion. Renew. Sustain. Energy Rev. 45, 540-555. https://doi.org/10.1016/j.rser.2015.02.032

Maoh, H., Kanaroglou, P., 2009. A tool for evaluating urban sustainability via integrated transportation and land use simulation models. Environ. Urbain 3, 28-46. https://doi.org/10.7202/037599ar

Markard, J., Raven, R., Truffer, B., 2012. Sustainability transitions: An emerging field of research and its prospects. Res. Policy 41, 955-967. https://doi.org/10.1016/j.respol.2012.02.013

Martínez-Alier, J., Pascual, U., Vivien, F.-D., Zaccai, E., 2010. Sustainable de-growth: Mapping the context, criticisms and future prospects of an emergent paradigm. Ecol. Econ. 69, 17411747. https://doi.org/10.1016/j.ecolecon.2010.04.017

Mata-Alvarez, J., Macé, S., Llabrés, P., 2000. Anaerobic digestion of organic solid wastes. An overview of research achievements and perspectives. Bioresour. Technol. 74, 3-16. https://doi.org/10.1016/S0960-8524(00)00023-7

Mauky, E., Weinrich, S., Jacobi, H.-F., Nägele, H.-J., Liebetrau, J., Nelles, M., 2017. Demand-driven biogas production by flexible feeding in full-scale - Process stability and flexibility potentials. Anaerobe 46, 86-95. https://doi.org/10.1016/j.anaerobe.2017.03.010

Mauser, W., Klepper, G., Rice, M., Schmalzbauer, B.S., Hackmann, H., Leemans, R., Moore, H., 2013. Transdisciplinary global change research: the co-creation of knowledge for sustainability. Curr. Opin. Environ. Sustain. 5, 420-431. https://doi.org/10.1016/j.cosust.2013.07.001

McKendry, P., 2002. Energy production from biomass (part 1): overview of biomass. Bioresour. Technol. 83, 37-46. https://doi.org/10.1016/S0960-8524(01)00118-3

Mensah, J., 2019. Sustainable development: Meaning, history, principles, pillars, and implications for human action: Literature review. Cogent Soc. Sci. 5. https://doi.org/10.1080/23311886.2019.1653531

Mitropoulos, L.K., Prevedouros, P.D., 2014. Multicriterion Sustainability Assessment in Transportation: Private Cars, Carsharing, and Transit Buses. Transp. Res. Rec. J. Transp. Res. Board 2403, 52-61. https://doi.org/10.3141/2403-07

Möller, K., Müller, T., 2012. Effects of anaerobic digestion on digestate nutrient availability and crop growth: A review: Digestate nutrient availability. Eng. Life Sci. 12, 242-257. https://doi.org/10.1002/elsc.201100085

Moser, S.C., 2016. Can science on transformation transform science? Lessons from co-design. Curr. Opin. Environ. Sustain. 20, 106-115. https://doi.org/10.1016/j.cosust.2016.10.007

Murphy, J.D., McKeogh, E., Kiely, G., 2004. Technical/economic/environmental analysis of biogas utilisation. Appl. Energy 77, 407-427. https://doi.org/10.1016/j.apenergy.2003.07.005

Mutter, A., 2019. Mobilizing sociotechnical imaginaries of fossil-free futures - Electricity and biogas in public transport in Linköping, Sweden. Energy Res. Soc. Sci. 49, 1-9. https://doi.org/10.1016/j.erss.2018.10.025

Ness, B., Urbel-Piirsalu, E., Anderberg, S., Olsson, L., 2007. Categorising tools for sustainability assessment. Ecol. Econ. 60, 498-508. https://doi.org/10.1016/j.ecolecon.2006.07.023

Noel, L., McCormack, R., 2014. A cost benefit analysis of a V2G-capable electric school bus compared to a traditional diesel school bus. Appl. Energy 126, 246-255.

https://doi.org/10.1016/j.apenergy.2014.04.009 
Nohrstedt, L., 2017. Snart rullar fler elbussar i Göteborg. Ny Tek.

Norrtälje kommun, 2017. Norrtälje först i landet med elbussar i hela stadsnätet [WWW Document]. URL http://www.norrtalje.se/nyheterna/2017-06/norrtalje-forst-i-landet-med-elbussar-ihela-stadsnatet/ (accessed 10.17.17).

Osorio-Tejada, J.L., Llera-Sastresa, E., Scarpellini, S., 2017. A multi-criteria sustainability assessment for biodiesel and liquefied natural gas as alternative fuels in transport systems. J. Nat. Gas Sci. Eng. 42, 169-186. https://doi.org/10.1016/j.jngse.2017.02.046

Patrizio, P., Leduc, S., Chinese, D., Dotzauer, E., Kraxner, F., 2015. Biomethane as transport fuel - A comparison with other biogas utilization pathways in northern Italy. Appl. Energy 157, 2534. https://doi.org/10.1016/j.apenergy.2015.07.074

Rehl, T., Müller, J., 2011. Life cycle assessment of biogas digestate processing technologies. Resour. Conserv. Recycl. 56, 92-104. https://doi.org/10.1016/j.resconrec.2011.08.007

Robinson, J., 2004. Squaring the circle? Some thoughts on the idea of sustainable development. Ecol. Econ. 48, 369-384. https://doi.org/10.1016/j.ecolecon.2003.10.017

Rockström, J., Steffen, W., Noone, K., Persson, Å., Chapin, F.S.I., Lambin, E., Lenton, T.M., Scheffer, M., Folke, C., Schellnhuber, H.J., Nykvist, B., de Wit, C.A., Hughes, T., van der Leeuw, S., Rodhe, H., Sörlin, S., Snyder, P.K., Costanza, R., Svedin, U., Falkenmark, M., Karlberg, L., Corell, R.W., Fabry, V.J., Hansen, J., Walker, B., Liverman, D., Richardson, K., Crutzen, P., Foley, J., 2009. Planetary Boundaries: Exploring the Safe Operating Space for Humanity. Ecol. Soc. 14. https://doi.org/10.5751/ES-03180-140232

Scania Global, 2017. Scania extends its gas offering with powerful 13-litre gas trucks for sustainable solutions [WWW Document]. Scania Glob. URL

https://www.scania.com/global/en/home/experience-scania/news-and-

events/news/scania-launches-a-new-range-of-solutions-for-sustainable-city-

transport/scania-extends-its-gas-offering-with-powerful-13-litre-gas-truck.html (accessed 10.9.19).

Scania Group, 2017. Scania startar provtrafik med elbussar i Östersund [WWW Document]. URL https://www.scania.com/se/sv/home/experience-scania/news-andevents/News/archive/2017/02/scania-startar-provtrafik-med-elbussar.html (accessed 10.17.17).

Scarlat, N., Dallemand, J.-F., Fahl, F., 2018. Biogas: Developments and perspectives in Europe. Renew. Energy 129, 457-472. https://doi.org/10.1016/j.renene.2018.03.006

Schilling, M.A., 2017. Strategic Management of Technological Innovation, 5th edition. ed.

Schot, J., Geels, F.W., 2008. Strategic niche management and sustainable innovation journeys: theory, findings, research agenda, and policy. Technol. Anal. Strateg. Manag. 20, 537-554. https://doi.org/10.1080/09537320802292651

Sehatpour, M.-H., Kazemi, A., Sehatpour, H., 2017. Evaluation of alternative fuels for light-duty vehicles in Iran using a multi-criteria approach. Renew. Sustain. Energy Rev. 72, 295-310. https://doi.org/10.1016/j.rser.2017.01.067

Shirazi, Y., Carr, E., Knapp, L., 2015. A cost-benefit analysis of alternatively fueled buses with special considerations for V2G technology. Energy Policy 87, 591-603. https://doi.org/10.1016/j.enpol.2015.09.038

State of the Environment Norway, 2019. Norway's Environmental Targets [WWW Document]. URL https://www.miljostatus.no/goals/ (accessed 9.9.19).

Statistics Sweden, 2019. Fordonsbestånd 2018 [Vehicle stock 2018].

Steffen, W., Grinevald, J., Crutzen, P., McNeill, J., 2011. The Anthropocene: conceptual and historical perspectives. Philos. Trans. R. Soc. Math. Phys. Eng. Sci. 369, 842-867. https://doi.org/10.1098/rsta.2010.0327

Stock, P., Burton, R.J.F., 2011. Defining terms for integrated (Multi-Inter-Trans-disciplinary) sustainability research.pdf. Sustainability 1090-1113. https://doi.org/10.3390/su3081090 
Strantzali, E., Aravossis, K., 2016. Decision making in renewable energy investments: A review. Renew. Sustain. Energy Rev. 55, 885-898. https://doi.org/10.1016/j.rser.2015.11.021

Sun, Q., Li, H., Yan, J., Liu, L., Yu, Z., Yu, X., 2015. Selection of appropriate biogas upgrading technology-a review of biogas cleaning, upgrading and utilisation. Renew. Sustain. Energy Rev. 51, 521-532. https://doi.org/10.1016/j.rser.2015.06.029

Svärd, Å., la Cour Jansen, J., 2003. Svenska biogasanläggningar - erfarenhetssammanställning och rapporteringssystem.

Sveriges miljömål, 2019. Sveriges miljömål [WWW Document]. URL http://www.sverigesmiljomal.se/ (accessed 9.9.19).

Swedegas, 2018. Svenska stamnätet [WWW Document]. URL https://www.swedegas.se/gasnatet/gasnatet (accessed 3.19.18).

Swedish Energy Agency, 2019a. Energiläget i siffror 2019.

Swedish Energy Agency, 2019b. Produktion och användning av biogas och rötrester år 2018 (No. ER 2019:23).

Swedish Energy Agency, 2018a. Produktion och användning av biogas och rötrester år 2017 [Production and use of biogas and digestate 2017] (No. ET 2018:01).

Swedish Energy Agency, 2018b. Nätanslutna solcellsanläggningar 2017 - Statistik, analys och prognos (No. ER 2018:22).

Swedish Energy Agency, 2016. Biogas statistics 2015 (dataset).

Swedish Environmental Protection Agency, n.d. Sektorsunderlag industri - Underlag till Färdplan 2050.

Swedish Government Official Reports, 2013. Fossilfrihet på väg [Freedom from fossils on roads] (No. SOU 2013:84).

Swedish Tax Agency, 2019. Ändrade bestämmelser om skattebefrielse för biodrivmedel [WWW Document]. URL

https://www.skatteverket.se/foretagochorganisationer/skatter/punktskatter/energiskatter/ energiskatterpabranslen/skattebefrielseforbiodrivmedel.4.2b543913a42158acf800021393.h $\mathrm{tml}$ (accessed 10.9.19).

Swedish Tax Agency, 2018. Lägre skatt för industriell verksamhet [Lower tax for manufacturing] [WWW Document]. URL

https://www.skatteverket.se/foretagochorganisationer/skatter/punktskatter/energiskatter/ verksamhetermedlagreskatt/industriellverksamhet.4.18e1b10334ebe8bc80002009.html (accessed 11.27.18).

Swedish Waste Management Association, 2008. Den svenska biogaspotentialen från inhemska råvaror.

Tekniska Verken, 2018. Världsunikt samarbete när Toyota tar ett stort kliv mot fossilfrihet med flytande biogas [Unique collaboration when Toyota takes a big step towards fossil freedom with liquefied biogas] [WWW Document]. 2018-04-19. URL http://www.mynewsdesk.com/se/tekniskaverken/pressreleases/toyota-tar-stort-kliv-motfossilfrihet-med-flytande-biogas-2414206 (accessed 1.15.19).

Theobald, O., 2015. Country Report France (IEA Bioenergy Task 37). French Agency for Environment and Energy Management.

Ullah Khan, I., Hafiz Dzarfan Othman, M., Hashim, H., Matsuura, T., Ismail, A.F., RezaeiDashtArzhandi, M., Wan Azelee, I., 2017. Biogas as a renewable energy fuel - A review of biogas upgrading, utilisation and storage. Energy Convers. Manag. 150, 277-294. https://doi.org/10.1016/j.enconman.2017.08.035

Umeå kommun, 2017. Fossilfri kollektivtrafik i Umeå [WWW Document]. URL http://www.umea.se/arkiv/nyheter/toppartiklar/fossilfrikollektivtrafikiumea.5.159c28515de d26ff4c2a36c.html (accessed 10.17.17). 
United Nations, 2019a. About the Sustainable Development Goals [WWW Document]. U. N. Sustain. Dev. URL https://www.un.org/sustainabledevelopment/sustainable-development-goals/ (accessed 3.15.19).

United Nations, 2019b. The Paris Agreement [WWW Document]. URL https://unfccc.int/processand-meetings/the-paris-agreement/the-paris-agreement (accessed 8.2.19).

Varel, V.H., Wells, J.E., Shelver, W.L., Rice, C.P., Armstrong, D.L., Parker, D.B., 2012. Effect of anaerobic digestion temperature on odour, coliforms and chlortetracycline in swine manure or monensin in cattle manure*: Effect of anaerobic digestion on chlortetracycline and monensin. J. Appl. Microbiol. 112, 705-715. https://doi.org/10.1111/j.13652672.2012.05250.x

Wątróbski, J., Małecki, K., Kijewska, K., Iwan, S., Karczmarczyk, A., Thompson, R., 2017. Multi-Criteria Analysis of Electric Vans for City Logistics. Sustainability 9, 1453. https://doi.org/10.3390/su9081453

Weiland, P., 2010. Biogas production: current state and perspectives. Appl. Microbiol. Biotechnol. 85, 849-860. https://doi.org/10.1007/s00253-009-2246-7

Weimer-Jehle, W., Buchgeister, J., Hauser, W., Kosow, H., Naegler, T., Poganietz, W.-R., Pregger, T., Prehofer, S., von Recklinghausen, A., Schippl, J., Vögele, S., 2016. Context scenarios and their usage for the construction of socio-technical energy scenarios. Energy 111, 956-970. https://doi.org/10.1016/j.energy.2016.05.073

Winquist, E., Rikkonen, P., Pyysiäinen, J., Varho, V., 2019. Is biogas an energy or a sustainability product? - Business opportunities in the Finnish biogas branch. J. Clean. Prod. 233, 13441354. https://doi.org/10.1016/j.jclepro.2019.06.181

World Bioenergy Association, 2018. WBA Global Bioenergy Statistics 2018.

World Bioenergy Association, 2013. Biogas - an important renewable energy source.

World Commission on Environment and Development, 1987. Our Common Future. Oxford University Press.

Yang, L., Ge, X., Wan, C., Yu, F., Li, Y., 2014. Progress and perspectives in converting biogas to transportation fuels. Renew. Sustain. Energy Rev. 40, 1133-1152. https://doi.org/10.1016/j.rser.2014.08.008

Zinoviev, S., Müller-Langer, F., Das, P., Bertero, N., Fornasiero, P., Kaltschmitt, M., Centi, G., Miertus, S., 2010. Next-Generation Biofuels: Survey of Emerging Technologies and Sustainability Issues. ChemSusChem 3, 1106-1133. https://doi.org/10.1002/cssc.201000052 
Appendix 


\section{Papers}

The papers associated with this thesis have been removed for copyright reasons. For more details about these see:

http://urn.kb.se/resolve?urn=urn:nbn:se:liu:diva-162033 


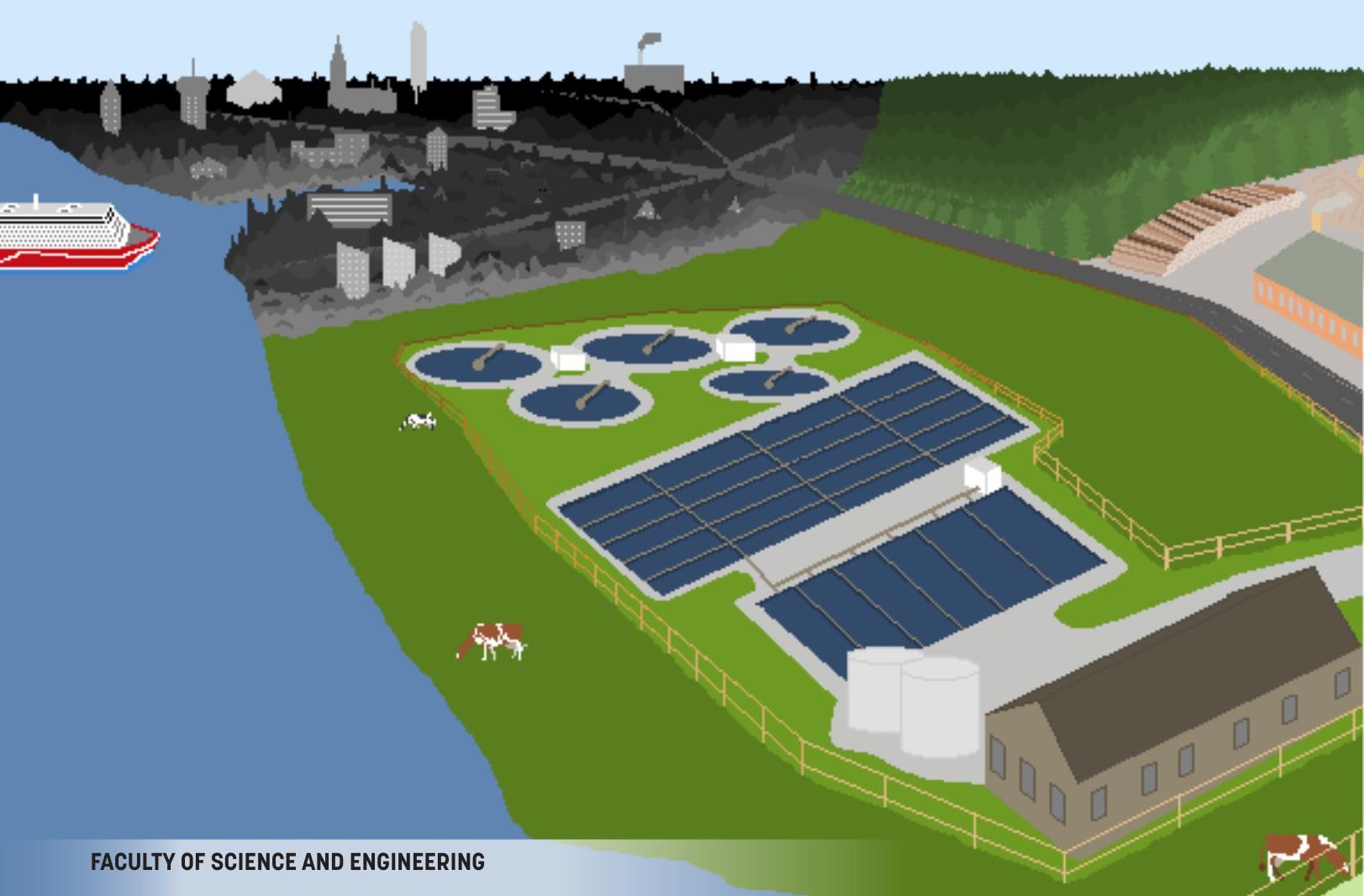

Linköping Studies in Science and Technology, Licentiate Thesis No. 1861, 2019 Department of Management and Engineering

\section{Linköping University}

SE-581 83 Linköping, Sweden

\section{www.liu.se}
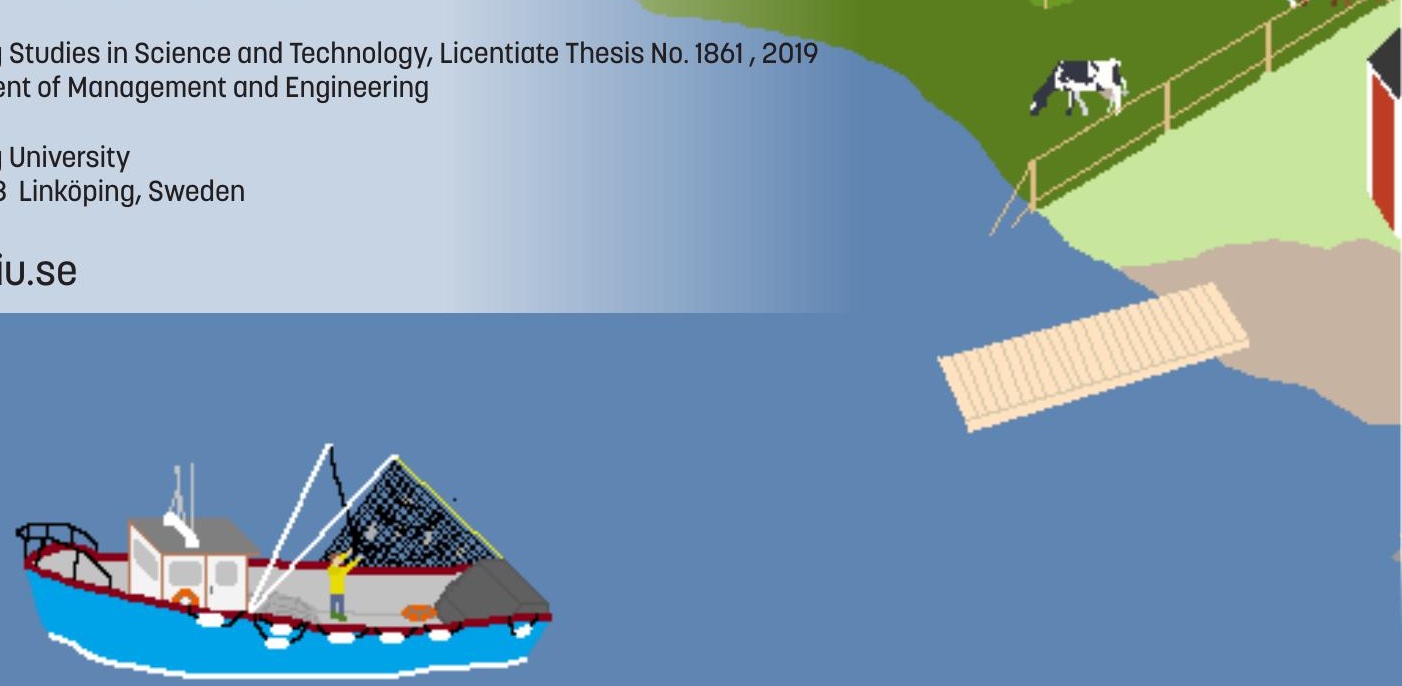

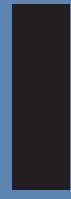

